UNIVERSIDADE DE SÃO PAULO

FACULDADE DE MEDICINA DE RIBEIRÃO PRETO

DEPARTAMENTO DE GENÉTICA

HEVERTON LUIS MOREIRA

Objetivos de Seleção e Valores Econômicos para Bovinos Nelore em Sistema de Ciclo Completo

RIBEIRÃO PRETO - SP

2015 
HEVERTON LUIS MOREIRA

\section{Objetivos de Seleção e Valores Econômicos para Bovinos Nelore em Sistema de Ciclo Completo}

Tese apresentada ao Departamento de Genética da Faculdade de Medicina de Ribeirão Preto da Universidade de São Paulo, como parte dos requisitos para a obtenção do título de Doutor em Ciências.

Área de concentração: Genética.

Orientador: Prof. Dra. Claudia Cristina Paro de Paz

RIBEIRÃO PRETO - SP

2015 


\section{AUTORIZO A DIVULGAÇÃO TOTAL OU PARCIAL DESTE TRABALHO, POR QUALQUER MEIO CONVENCIONAL OU ELETRÔNICO, PARA FINS DE ESTUDO E PESQUISA, DESDE QUE CITADA A FONTE.}

\section{FICHA CATALOGRÁFICA}

Preparada pela Biblioteca Central do Campus Administrativo de Ribeirão Preto/USP

Moreira, Heverton Luis.

Objetivos de seleção e valores econômicos para bovinos Nelore em sistema de ciclo completo/ Heverton Luis Moreira; orientadora: Profa. Dra. Claudia Cristina Paro de Paz. Ribeirão Preto, 2015.

100p. il., $30 \mathrm{~cm}$.

Tese de Doutorado, Programa de Pós-graduação em Genética, Faculdade de Medicina de Ribeirão Preto da Universidade São Paulo.

Orientadora: Paz, Claudia Cristina Paro

Título em inglês: Breeding Objectives and Economic Values for Nellore Cattle in a FullCycle System

1. Característica de Produtivas. 2. Modelo Bioeconômico. 3. Parâmetros Genéticos. 4. Ponderadores econômicos. 5. Seleção Genética. 


\section{FOLHA DE APROVAÇÃO}

Moreira, Heverton Luis

Utilização de Índices de Seleção no Melhoramento de Bovinos da Raça Nelore

Tese apresentada ao Departamento de Genética da Faculdade de Medicina de Ribeirão Preto da Universidade de São Paulo, como parte dos requisitos para a obtenção do título de Doutor em Ciências.

Aprovado em: 1

Banca Examinadora

Prof. Dr.

Instituição: Assinatura:

Prof. Dr.

Instituição:

Assinatura:

Prof. Dr.

Instituição: Assinatura:

Prof. Dr.

Instituição:

Assinatura:

Prof. Dr.

Instituição: Assinatura: 


\section{APOIO E SUPORTE FINANCEIRO}

CONSELHO NACIONAL DE DESENVOLVIMENTO DE PESQUISA (CNPq) FINANCIAMENTO DO PROJETO

Processos 472753/2010-0

CONSELHO NACIONAL DE DESENVOLVIMENTO DE PESQUISA (CNPq) BOLSA DE ESTUDO

Processos 140517/2011-1

ASSOCIAÇÃO NACIONAL DOS CRIADORES E PESQUISADORES (ANCP) CONCESSÃO DE DADOS 
Dedicatória 
Aos meus pais José Pedro Moreira e Nadir Costa Moreira; Minha noiva Érika Canova; Meus Irmãos Rodrigo e Silmari;

Meus sobrinhos Arthur e Luiza; 
Agradecimentos 


\section{AGRADECIMENTOS}

A Deus por sua infinita bondade de me guiar até aqui e a Nossa Senhora Aparecida por iluminar todo meu caminho;

A minha orientadora Prof. Dra. Claudia Cristina Paro de Paz pela oportunidade, auxílios e amizade que se iniciaram no mestrado e que levarei por toda a vida;

Aos professores e pesquisadores que encontrei ao longo desse período e que compartilharam seus ensinamentos promovendo meu crescimento humano e intelectual;

Ao departamento de genética em nome do $\operatorname{Prof}^{\mathrm{o}}$ Espencer e da secretária Susie Nalon que os representam com a máxima educação, profissionalismo e amizade com todos os pósgraduandos do departamento;

A todos os alunos, professores e funcionários do Bloco $\mathrm{C}$ da genética que tornaram cada dia de trabalho os mais agradáveis;

Aos meus pais, Zé Pedro e Nadir, pelo apoio e amor infinito, sem os quais eu não chegaria a lugar nenhum;

A minha noiva Érika Canova que sem dúvida não hesitou em me ajudar, em me ouvir, me aconselhar e estar sempre ao meu lado para tudo;

Aos meus irmãos Rodrigo e Silmari, os quais eu não escolhi mais se pudesse com certeza não teria feito escolha melhor;

Aos meus cunhados Vilmar e Jeane que ingressaram na família durante esse período e que trouxeram suas energias positivas a toda a família;

Aos meus sobrinhos Arthur e Luiza que me proporcionaram momentos inesquecíveis de descontração durante essa caminhada; 
Aos amigos doutores e futuros doutores em Ciências Biológicas pela Faculdade de Medicina de Ribeirão Preto - USP (Departamento de Genética) Marco Aurélio, Murilo Soares, Igor Mattos e as amigas Manuela Gama e Gisele Fernandes, enfim a todos que estiveram comigo. 
"'.. Pegue a viola, e a sanfona que eu tocava Deixe um bule de café em cima do fogão Fogão de lenha, e uma rede na varanda Arrume tudo mãe querida, que seu filho vai voltar ..."

(Carlos Colla, Maurício Duboc, Xororó). 


\section{RESUMO}

Moreira, H. L. Objetivo de Seleção e Valores Econômicos para Bovinos Nelore em Sistema de Ciclo Completo. 100f. Tese (Doutorado) - Faculdade de Medicina de Ribeirão Preto da Universidade de São Paulo, Ribeirão Preto, SP. 2015.

O objetivo do presente trabalho foi definir os objetivos de seleção e estimar os valores econômicos para característica de importância econômica em um sistema de bovinos de corte criados em regime de ciclo completo, além de estimar os parâmetros genéticos para características produtivas, reprodutivas e de qualidade de carcaça avaliadas no programa de seleção Nelore Brasil. O desenvolvimento do modelo bioeconômico foi realizado considerando as informações do sistema de produção e dos parâmetros biológicos com objetivo de estabilizar o rebanho e calcular o número de animais em cada categoria, obter as informações de desempenho produtivo e econômico (receita e despesas) do sistema pecuário, e por fim a obtenção dos valores econômicos das características contidas no objetivo de seleção em sistema de ciclo completo, que para tal, foram utilizadas planilhas interligadas do programa Microsoft Excel ${ }^{\circledR}$. Os valores econômicos foram estimados simulando o aumento de $1 \%$ no valor da característica do objetivo de seleção, mantendo as demais constantes. A estimação dos parâmetros genéticos foi pelo método de Máxima Verossimilhança Restrita (REML) usando o modelo animal, utilizando o software WOMBAT e o ganho genético anual para as características de reprodução, carcaça e desenvolvimento ponderal foi estimado pela regressão linear do valor genético (VG) em função do ano de nascimento. O modelo bioeconômico foi eficaz na estimação das fontes de receitas e despesas do sistema de produção e os valores econômicos estimados seguindo a ordem de importância para o ciclo completo foram $\mathrm{R} \$ 3,69$ para peso ao abate de macho (PAM), R \$ 3,63 para peso a desmama de macho (PDM), R \$ 3,58 para taxa de desmama (TD), R\$ 3,40 para peso ao abate de fêmea (PAF), R \$ 2,30 para peso a desmama de fêmea (PDF) e R \$ 0,13 para peso ao adulto de vaca (PAV). Portanto, o PAM foi à característica de maior impacto no sistema de produção, porém, todas promoveram retorno econômico positivo com exceção do PAV que foi praticamente nulo. As estimativas de herdabilidade para as características de produção, reprodução e qualidade de carcaça foram favoráveis ao progresso genético por seleção direta. As correlações estimadas demonstram que machos com maior perímetro escrotal tendem a ser mais pesados e esses apresentarem maior rendimento e acabamento da carcaça. O processo de 
seleção empírica utilizado pelo programa Nelore Brasil está sendo eficiente, de acordo com os resultados positivos dos progressos genéticos nas estimativas de tendência. Portanto todas as características avaliadas no sistema de ciclo completo tiveram importância econômica positivas, indicando que o processo de seleção trariam aumentos de lucratividade e as avaliadas geneticamente poderiam ser incluídas como critério de seleção contribuindo com a maximização da resposta esperadas para as características do objetivo de seleção.

Palavras Chave: Característica de Produtivas; Modelo Bioeconômico; Parâmetros Genéticos; Ponderadores econômicos; Seleção Genética. 
A6stract 


\begin{abstract}
Moreira, H. L. Breeding Objectives and Economic Values for Nellore Cattle in a FullCycle System. 100f. Tese (Doutorado) - Faculdade de Medicina de Ribeirão Preto da Universidade de São Paulo, Ribeirão Preto, SP. 2015.
\end{abstract}

The objective of this study was to define the objectives of selecting and estimating economic values for characteristics of economic importance in a system of beef cattle raised in fullcycle scheme. We also aimed to estimate the parameters for genetic reproductive and productive characteristics of carcass quality evaluated in the breeding program Nellore Brazil. The bio-economic model was developed considering the information and production system of biological parameters to stabilize the herd and calculate the number of animals in each category, obtain information on economic performance (revenue and expenses) of the livestock system, and finally to obtain economic values of the characteristics contained in the objective of selection in full-cycle system. We used interlinked spreadsheets in the Microsoft Excel $^{\circledR}$. The economic values were estimated by simulating the increase of $1 \%$ for the value of the characteristic of objective selection, keeping the others constant. The estimation of genetic parameters was obtained by the method of Restricted Maximum Likelihood (REML) using the animal model in the WOMBAT software and genetic gain for annual breeding characteristics; weighted carcass and development were estimated by linear regression of genetic value $(\mathrm{GV})$ depending on the year of birth. The bio-economic model was effective in estimating revenue and expenditure sources of the production system and the estimated economic values, following the order of importance for the complete cycle, were $\mathrm{R} \$ 3.69$ for slaughter weight of male (SWM), R\$ 3.63 for weaning weight of male (WWM), R\$ 3.58 for weaning rate (WR), R\$ 3.40 for the slaughter weight of female (SWF), R\$ 2.30 for weaning weight of female (WWF) and R $\$ 0.13$ for adult cow weight (ACW). Therefore, SWM had the greatest impact on the production system, however, all aspects promoted positive economic return with the exception of $\mathrm{ACW}$, which was practically null. Heritability estimates for production, reproduction and carcass characteristics and quality were favorable to genetic progress for direct selection. The estimated correlations demonstrate that males with larger scrotal perimeter tend to be heavier and have higher carcass yield and finishing. The empirical selection process used by the program Brazil Nellore is efficient, according to the positive results of the genetic progress in trend estimates. Therefore, all features evaluated in the full- 
cycle system had positive economic importance, indicating that the selection process could bring gains in profitability and the genetically evaluated characteristics could be included as a breeding criterion, contributing to the maximization of the expected response for the traits of interest in breeding programs.

Keywords: Productive feature; Bio-economic Model; Genetic Parameters; Economic weights; Genetic Breeding. 
Lista de figuras 


\section{LISTA DE FIGURAS}

Figura 01 - Fluxograma do rebanho estabilizado no sistema de ciclo completo ..... 
Lista de tabelas 


\section{LISTA DE TABELAS}

Tabela 1 - Parâmetros biológicos utilizados na composição final do rebanho para obtenção dos valores econômicos

Tabela 2 - Fonte de receitas e despesas no sistema de produção

Tabela 3 - Valores de bonificações para bovinos da raça Nelore

Tabela 4 - Características de formação dos grupos de contemporâneos das características em estudo

Tabela 5 - Número de animais, pais, mães, grupos de contemporâneos (GC), médias, desvio-padrão (DP), valor mínimo (Min) e máximo (max) consideradas na analise das características em estudo

Tabela 6 - Composição do rebanho estabilizado

Tabela 7 - Indicadores econômicos de custos e receitas em sistemas de ciclo completo de Bovinos de corte

Tabela 8 - Indicadores econômicos de lucratividade do sistema de ciclo completo de bovinos de corte

Tabela 9 - Desempenho lucrativo em situação básico e simulada e estimação dos valores econômicos nas características em estudo

Tabela 10 - Desempenho econômico em situação básica e simulada e simulada e estimação dos valores econômicos sob o sistema de pagamento do programa Nelore natural

Tabela 11 - Análise de sensibilidade para avaliar mudanças nos valores econômicos quanto as alterações dos preços das pastagens, minerais e proteínado e valores de receitas

Tabela 12 - Estimativas de componentes de (co) variâncias e parâmetros genéticos e fenotípicos para as características consideradas no estudo

Tabela 13 - Estimativas de herdabilidade (diagonal principal), correlações genética (acima da diagonal) e fenotípica (abaixo da diagonal) para as características consideradas no estudo

Tabela 14 - Estimativas de tendência genéticas para as características consideradas no estudo 
Sumário 


\section{SUMÁRIO}

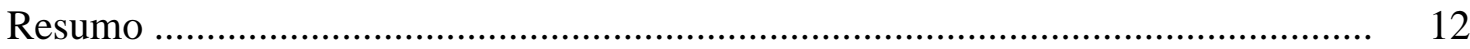

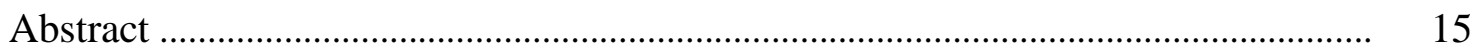

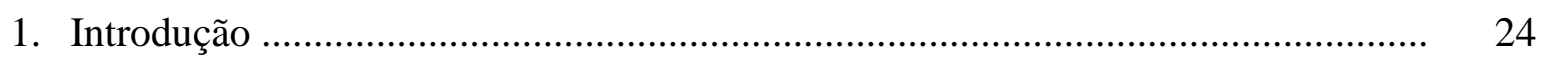

1.1 Considerações Gerais .............................................................................. 24

1.2 Objetivo e Critério de seleção ..................................................................... 25

1.3 Modelagem Bioeconômica …....................................................................... 26

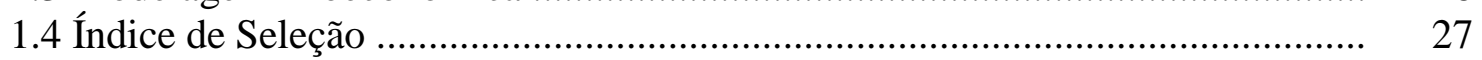

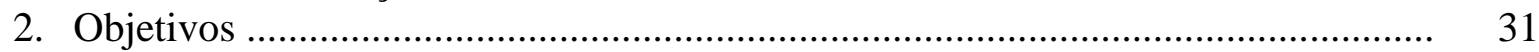

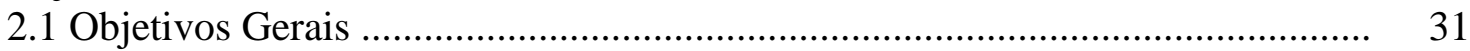

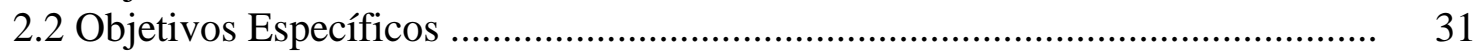

3. Material e Métodos ............................................................................................... 33

3.1 Descrição do sistema de produção, reprodução e comercialização ................... 33

3.2 Modelo Bioeconômico ................................................................................. $\quad 35$

3.3 Determinação das fontes de receita e despesas ............................................... 36

3.4 Estimação dos valores econômicos ............................................................. 38

3.5 Análise de sensibilidade ........................................................................... $\quad 38$

3.6 Estimação dos parâmetros genéticos ............................................................. 39

4. Resultado e Discussão ............................................................................................ 45

4.1 Estrutura do rebanho e análise econômica do sistema ...................................... 45

4.2 Valores econômicos em bovinos de corte em sistema de ciclo completo ......... 47

4.3 Valores econômicos em sistema de pagamento por qualidade ......................... $\quad 50$

4.4 Análise de sensibilidade ................................................................................ 51

4.5 Parâmetros Genéticos .......................................................................... 54

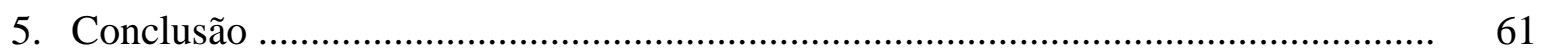

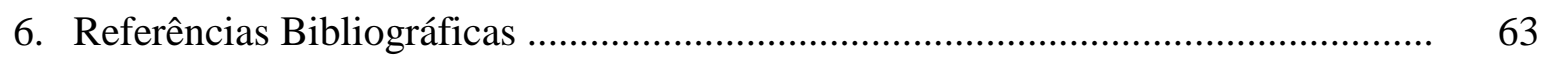

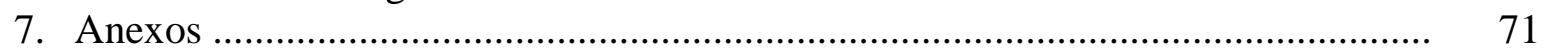

7.1 Planilha: Modelo Bioeconômico ..................................................................... 71

7.2 Planilha: Parâmetros Zootécnicos ................................................................... $\quad 72$

7.3 Planilha: Evolução do Rebanho ...................................................................... 73

7.4 Planilha: Planejamento Nutricional _.......................................................... 74

7.5 Planilha: Fontes de Receitas ............................................................................ $\quad 75$

7.6 Planilha: Fontes de Custos ........................................................................... 76

7.8 Planilha: Fontes de Lucros .......................................................................... 77

7.9 Planilha: Valores Econômicos ......................................................................... $\quad 78$

7.10 Planilha: Análise de Sensibilidade ............................................................ $\quad 79$

7.11 Planilha: Indicadores Econômicos de Custos e Receitas .................................. 80

7.12 Planilha: Indicadores Econômicos do Sistema ............................................. 81

7.13 Publicação ...................................................................................... 82 


\section{INTRODUÇÃO}

\subsection{Considerações Gerais}

A bovinocultura de corte tem destaque especial no mercado nacional e internacional de produção de carne, pois o Brasil está atualmente entre os maiores produtores e exportadores mundiais de carne bovina, fazendo desta atividade agropecuária uma das mais relevantes em termos econômicos para o país. Para manter tais aspectos conquistados e conseguir abrir novos mercados internacionais a pecuária brasileira terá que melhorar em termos de eficiência produtiva, genética, nutricional, sanitário, ambiental e marketing para que os produtos dessa cadeia sejam competitivos em termos de qualidade e produtividade, trazendo maiores avanços nas questões de eficiência econômica ao setor.

Dentre as estratégias de elevação de produtividade e qualidade de produtos ligados ao setor pecuário, a seleção de animais geneticamente superiores para características de valor econômico deve ser umas das prioridades. No Brasil os programas de melhoramento genético animal têm papel fundamental para a bovinocultura de corte, elevando os índices de produtividade, fertilidade e de qualidade de carcaça dos animais selecionados. Nestes programas várias características de importância econômica são consideradas no objetivo de seleção, tais como características produtivas, reprodutivas e as relacionadas à qualidade de carcaça, porém essas são ponderadas de forma empírica e o mais indicado é que estas ponderações fossem feitas com base econômica que maximize o retorno lucrativo para o sistema de produção.

Para Ponzoni e Newman (1989) o início de uma atividade ligada ao setor pecuário deveria se dar pela definição dos reais objetivos de seleção ligados a lucratividade do sistema. Pois tendo esses objetivos consolidados nessa base econômica, a alternativa seria a de se propor um índice de seleção que pudesse ponderar todas as características economicamente relevantes ao sistema e que promovesse a maximização da resposta à seleção. Essa metodologia foi proposta por Hazel (1943), visando à seleção de múltiplas características com base genético-econômica, onde a resposta à seleção seja baseada no lucro esperado para cada unidade de melhoramento ganho nas características do objetivo proposto.

Poucos estudos realizados no Brasil avaliaram as questões genéticas econômicas de sistema de bovinos de corte, pois a pecuária brasileira apresenta diversos sistemas de produções, onde uma característica economicamente relevante para um sistema, talvez não 
seja importante em outro. Diante disso, o objetivo do presente trabalho foi definir os objetivos de seleção e estimar os valores econômicos para característica de importância econômica em um sistema de bovinos de corte criados em regime de ciclo completo.

\subsection{Objetivo e critério de seleção}

Os conjuntos de características economicamente importantes que tendem a maximizar o lucro, maximizar o retorno econômico ou reduzir os custos por unidade dentro do sistema de produção devem ser o ponto mais importante a ser compreendido pelo empreendedor rural, a qual se denomina de objetivo de seleção (HARRIS,1970).

Para que se possa chegar a essa maximização do retorno econômico, os objetivos e critérios de seleção devem estar bem compreendidos dentro da proposta do sistema de produção que se deseja trabalhar. Diante dessa particularidade Ponzoni e Newman (1989) descreveram alguns passos importantes no intuito de facilitar essa compreensão como a especificação clara do sistema de produção, comercialização e reprodução que se deseja iniciar, identificar quais as reais características ligadas às fontes de receitas e despesas do sistema proposto e assim determinar as características biológicas capazes de influenciar essas fontes econômicas, e por fim que estas características permitam a estimação dos valores econômicos para esse sistema proposto.

Estabelecendo-se claramente os objetivos de seleção que maximizem os retornos econômicos da atividade faz-se necessário a definição das características tidas como critérios de seleção. Essas características serão criteriosamente utilizadas para predição dos valores genéticos dos animais a serem selecionados com o intuito de evidenciar os objetivos determinados para a seleção (PONZONI e NEWMAN, 1989). Para que essas características sejam consideradas como critérios, Queiroz et al. 2005 citam que as mesmas devem apresentar uma relevância para maximização do lucro, apresentar variabilidade genética para seleção, ter fácil mensuração e isso ser realizado a baixo custo.

No Brasil os primeiros trabalhos com estimação de valores econômicos para bovinos de corte foram de Formigoni et al. (2005), Bittencourt et al. (2006), Jorge Junior et al. (2007) e Brumatti et al. (2011) que avaliaram características ligadas aos objetivos de seleção para fertilidade, crescimento e qualidade de carcaça. Esses trabalhos demonstraram que estas características deveriam ser incluídas em um índice de seleção econômico para que houvesse a maximização da resposta à seleção. 
Portanto as definições de objetivos de seleção eficiente definirão claramente os critérios de seleção adequados aos sistemas de produção e às tendências de mercado global. Esses objetivos de seleção dentro da bovinocultura de corte estão se tornando alvo de preocupação em selecionar animais com potenciais genéticos para as características ligadas ao crescimento, reprodução e qualidade de carcaça, visando aumentar as produções e melhorar a qualidade dos produtos para que a pecuária brasileira se torne uma atividade competitiva frente às pressões de mercado.

\subsection{Modelagem bioeconômica}

Dentro de um sistema pecuário ou em qualquer outra atividade econômica as funções de rentabilidade são muito importantes no planejamento dos objetivos. Estas funções evidenciam os entraves principais do sistema que se deve dar maior atenção, para que sejam tomadas as decisões que beneficiem a maximização do lucro dentro do sistema pecuário, com a utilização de animais geneticamente superiores. O estudo detalhado dessas funções de rentabilidade (receita e despesa) permite a determinação dos valores econômicos das características importantes para o sistema estudado, quantificando economicamente os impactos que o melhoramento genético pode trazer ao utilizar animais avaliados.

Dickerson (1970) cita que o lucro e a eficiência são os parâmetros que avaliam a rentabilidade de uma atividade. Segundo esse autor o lucro é a diferença entre a receita e custo de produção, já a eficiência assume duas abordagens sendo uma a que se refere ao retorno do investimento que é a razão entre receita e custo, e a outra o custo por unidade de produção que é a razão entre custo e receita. Portanto as funções de rentabilidade propostas para os objetivos devem descrever detalhadamente as atividades produtivas incluindo as características biológicas que afetam as fontes de receitas e despesas do sistema de produção para que assim possam ser estimados os valores econômicos.

No processo de estimação dos valores econômicos o modelo bioeconômico seria uma das metodologias importantes, pois segundo Bourdon (1998) ele permite que se trabalhe diretamente com os dados biológicos o qual simula com precisão as particularidades reais de um sistema de produção. Gibson e Wilton, 1998 relatam que essa metodologia interliga planilhas com dados do cenário produtivo anual, fenômenos biológicos nas diversas categorias animais e aspectos econômicos atualizados, permitindo assim que quaisquer 
alterações nesses parâmetros possam refletir simultaneamente em mudanças atualizadas nos valores econômicos.

Porém Jorge Junior. et al. 2006 citam que a quantidade de informações necessárias para alimentar as fontes de dados desse modelo são umas das dificuldades encontradas, mas que podem ser amenizadas por informações contidas em relatórios técnicos e por consultas a profissionais competentes na área de trabalho.

\section{4 Índice de seleção}

Após a estimação dos valores econômicos para as características que compõem o objetivo de seleção, busca-se determinar a maior resposta a seleção $\left(\mathrm{S}_{\mathrm{H}}\right)$ por meio dos índices econômicos de seleção, que podem utilizar características que não estejam presentes no objetivo. Essa maximização da resposta promovida pelo índice teve como base a metodologia descrita por Hazel et al. (1943), em que, o objetivo de seleção ou agregado genotípico (H) é definido como uma função dos valores genéticos aditivos das características de interesse, ponderados pelos seus respectivos valores econômicos, dado pela seguinte expressão:

$$
H=v_{1} g_{1}+v_{2} g_{2}+\ldots+v_{m} g_{m}
$$

em que: $g_{i}$ é o valor genético aditivo da $i^{\text {ésima }}$ característica e $v_{i}$ é o valor econômico dessa mesma característica.

No entanto, os valores genéticos aditivos das várias características contidas no objetivo podem não ser conhecidos, por isso pode-se predizer o mérito genético global de um indivíduo pela combinação ponderada de características usando a fórmula:

$$
I=b_{1} x_{1}+b_{2} x_{2}+\ldots+b_{n} x_{n}
$$

em que $x_{i}$ é a observação da $i^{\text {ésima }}$ característica e $b_{i}$ é coeficiente do índice ou fator de ponderação para aquela mesma característica.

Assim, o agregado genotípico (H) combina as características que são economicamente importantes dentro do sistema (ligadas a receitas e despesas), já na 
metodologia do índice (I) podem ser combinadas características indicadoras que se correlacionem com as caracteristicas do objetivo de seleção (BOURDON, 1998).

Para essa metologia citada acima, busca-se estimar o coeficiente de seleção $b_{i}$, de forma que, a seleção dos indivíduos baseada nos seus valores de índice de seleção $I$, maximize a resposta no agregado genotípico $H$. De acordo com Brascamp (1985), a obtenção dos fatores de ponderação $(b)$, é representada da seguinte maneira:

$$
b=P^{-1} G v
$$

em que $b$ é o coeficente do índice ou o ponderador para uma determinada característica, $P$ é a matriz $n \times n$ de (co)variâncias fenotípicas das características em $I, G$ é a matriz $n \times n$ de (co)variância genética aditiva entre as características incluídas em $H$ e $I$, e $v$ é o vetor de valores econômicos das características componentes do objetivo de seleção.

Após a estimações dessas informações, outras podem ser avaliadas para que se possam fazer comparações entre diferentes índices, dentre elas a acurácia do índice de seleção $\left(r_{H I}\right)$, pode ser calculado como a correlação entre $H$ e $I$, sendo definida por:

$$
r_{H I}=\sqrt{\frac{b^{\top} G v}{v^{\prime} C v}}
$$

em que $C$ é a matriz $n \times n$ das (co)variâncias genéticas aditivas entre as características do genótipo agregado $(H)$.

O ganho genético por geração $\left(S_{G}\right)$ para cada característica é calculado da seguinte maneira:

$$
S_{G}=i \frac{b^{`} G}{\sqrt{b^{\prime} P b}}
$$

em que $i$ é a intensidade de seleção (assumida como um neste trabalho).

Já a resposta esperada $\left(S_{H}\right)(R \$)$ após uma geração de seleção é calculado utilizando a seguinte expressão:

$$
S_{H}=i \frac{b^{`} G v}{\sqrt{b^{`} P b}}
$$


A contribuição relativa de cada característica no objetivo de seleção pode ser calculada medindo-se a redução na eficiência do índice, se a característica estiver ou não incluída no índice de seleção. 


\section{OBJETIVOS}

\subsection{Objetivos Gerais}

O objetivo do presente trabalho foi definir os objetivos de seleção e estimar os valores econômicos para característica de importância econômica em um sistema de bovinos de corte criados em regime de ciclo completo.

\subsection{Objetivos Específicos}

Os objetivos específicos são:

- Definição dos objetivos de seleção para característica de importância econômica em um programa de melhoramento genético da raça Nelore em sistema de ciclo completo.

- Avaliar os valores econômicos com sistema de pagamento por bonificação de qualidade de carcaça.

- Estudar as mudanças nos valores econômicos pela análise de sensibilidade.

- Estimação dos parâmetros genéticos e as tendências genéticas das características a serem utilizadas como critérios de seleção na raça Nelore pertencentes ao programa Nelore Brasil. 


\section{Material e Métodos}

\subsection{Descrição do sistema de produção, reprodução e comercialização}

O sistema de produção proposto considerou um rebanho de bovinos Nelore comercial típico do Brasil central (MT, MS, GO, MG e SP), criados de forma semi-extensiva em pastagem de Brachiaria Brizantha cv Marandu e suplementados no período seco do ano com sal mineral proteínado. Esse sistema de produção é baseado nos sistema de ciclo completo com a absorção de novilhas de reposição, venda de novilhas vazias não reintegradas ao sistema (36 meses), venda de novilhos machos (36 meses de idade) e vacas e touros de descarte para o abate (Figura 1).

\begin{tabular}{|c|c|c|c|c|c|c|c|c|}
\hline VACAS PARIDAS & 1000 & & & & & & & \\
\hline VACAS PRENHES & 772 & 601 & 467 & 364 & 283 & 218 & & \\
\hline NOVILHAS PRENHES & 228 & & & & \multirow{5}{*}{$\begin{array}{c}\text { MESES } \\
0 / 7\end{array}$} & & & \\
\hline \multirow[t]{11}{*}{ NOVILHAS EXPOSTAS } & 268 & & & & & & & \\
\hline & & \multicolumn{3}{|c|}{790} & & & & \\
\hline & & $\mathrm{F}$ & & $M$ & & & & \\
\hline & & 497 & & 497 & & & & \\
\hline & & 473 & & 473 & \multirow[t]{2}{*}{$12 / 24$} & & ABATE & \\
\hline & & & & & & & 218 & VACAS \\
\hline & & 469 & & 469 & \multirow[t]{2}{*}{$24 / 36$} & & 10 & TOUROS \\
\hline & & $\downarrow$ & & & & & 464 & MACHOS \\
\hline & & 200 & & & & & 238 & FÊMEAS \\
\hline & & + & & & \multicolumn{4}{|c|}{9} \\
\hline & & 38 & & & & & & \\
\hline
\end{tabular}

Figura 1. Fluxograma do rebanho estabilizado no sistema de ciclo completo 
De acordo com as condições climáticas do Brasil central a estação seca compreendeuse de abril a setembro e a estação chuvosa de outubro a abril. Diante dessas informações a estação de monta natural foi realizada de novembro a janeiro, dividindo os lotes de acasalamentos com a relação de 30 fêmeas por touro. Seguindo o planejamento da estação de monta os nascimentos ocorriam nos meses de agosto a outubro com desmame dos animais ocorrendo aos sete meses de idade (março, abril e maio).

O manejo alimentar foi baseado em sistema de pastagem extensiva, distribuídas em uma área de 2000 hectares, sendo a maior taxa de lotação na época das águas de 2,5 UA/ha influência da grande oferta de forragem e na época da seca 1,4 UA/ha pela diminuição da qualidade do capim. Para não afetar o desempenho dos animais, devido ao efeito de estacionalidade, todos receberam na estação seca uma suplementação com sal mineral proteínado específico para cada categoria ( $1 \mathrm{~g} / \mathrm{kg}$ de PV em média), assim como nas águas com a oferta de sal mineralizado $(0,18 \mathrm{~g} / \mathrm{kg}$ de PV em média) auxiliando na ingestão de matéria seca potencializando o ganho de peso.

As informações usadas para calcular o desempenho dos animais e sua estabilização ao longo dos anos estão descritos na tabela 1. Tais informações foram utilizadas para avaliar as fontes de custos e receitas do sistema de ciclo completo e a estimação dos valores econômicos do objetivo proposto. 
Tabela 1. Parâmetros biológicos utilizados na composição final do rebanho para obtenção dos valores econômicos

\begin{tabular}{|c|c|}
\hline Parâmetros & Média \\
\hline Taxa anual de descarte de vacas $(\%)^{3}$ & 22 \\
\hline Taxa anual de descarte de touros $(\%)^{5}$ & 25 \\
\hline Taxa de concepção de vacas $(\%)^{1}$ & 78 \\
\hline Taxa de concepção de novilhas 24 meses (\%) & 85 \\
\hline Taxa de natalidade média \% & 79 \\
\hline Número de fêmeas/touro ${ }^{3}$ & 30 \\
\hline 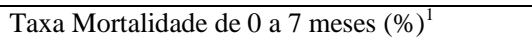 & 4 \\
\hline 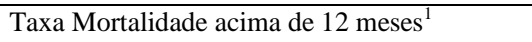 & 1 \\
\hline Vida útil da vaca $(\operatorname{anos})^{5}$ & 5 \\
\hline Peso Médio a Desmama Macho - PD $(\mathrm{kg})^{2}$ & 190 \\
\hline Peso Médio a Desmama Fêmea - PD $(\mathrm{kg})^{2}$ & 176 \\
\hline Peso Médio aos 365 dias Macho - P365 $(\mathrm{kg})^{2}$ & 252 \\
\hline Peso Médio aos 365 dias Fêmea - P365 (kg) & 228 \\
\hline Peso Médio aos 450 dias Macho - P450 (kg) ${ }^{2}$ & 297 \\
\hline Peso Médio aos 450 dias Fêmea - P450 (kg) ${ }^{2}$ & 263 \\
\hline Peso médio ao abate de fêmea $(36 \text { meses })^{2}$ & 450 \\
\hline Peso médio ao abate de macho $(36 \text { meses })^{2}$ & 510 \\
\hline Peso Médio da vaca Adulta - PAV $(\mathrm{kg})^{2}$ & 450 \\
\hline Peso Médio do touro reprodutor $-\mathrm{PR}(\mathrm{kg})^{5}$ & 700 \\
\hline Rendimento de carcaça de fêmea ${ }^{4}(\%)$ & 48 \\
\hline Rendimento de carcaça de macho ${ }^{4}(\%)$ & 55 \\
\hline
\end{tabular}

\subsection{Modelo Bioeconômico}

O desenvolvimento do modelo bioeconômico foi realizado considerando as informações do sistema de produção e dos parâmetros biológicos apresentados na Tabela 1, com objetivo de estabilizar o rebanho e calcular o número de animais em cada categoria, obter as informações de desempenho produtivo e econômico (receita e despesas) do sistema, e por fim a obtenção dos valores econômicos das características contidas no objetivo de seleção em sistema de ciclo completo.

Para tal foram utilizadas planilhas interligadas do programa Microsoft Excel ${ }^{\circledR}$, disponibilizadas como descritas as seguir: 
- Planilha de parâmetros biológicos: informações de padrões biológicos dos animais;

- Planilha de evolução mensal do rebanho: evolução do rebanho de acordo com o número de fêmeas em reprodução, taxa de reprodução, taxa mortalidade em diferentes idades, venda e descarte de animais até que o rebanho estabilizasse seu crescimento;

- Planilha de planejamento Nutricional: exigência de nutricionais (forragem, mineral e proteínado) dos animais em diferentes categorias;

- Planilha das fontes de receitas: descrição dos valores de receitas em cada categoria comercializada;

- Planilhas de custos: calculo dos custos mensais para cada categoria animal, compostos pelo custo com forragem, suplementação e veterinários;

- Planilha de lucro: calculo do lucro do sistema (lucro = receita - despesa);

- Planilha do lucro marginal: lucro marginal calculado pela mudança no desempenho de uma característica por vez que se tenha interesse econômico para o sistema, assim pode-se obter o lucro após o melhoramento na mesma;

- Planilha com estimação dos valores econômicos: calculo do valor econômico (VE) feito pela diferença entre o lucro ganho após a seleção e o lucro antes a seleção.

- Planilha de análise de sensibilidade: avaliação do impacto de possíveis mudanças nas variações de $\pm 5 \%, \pm 25 \%$ e $\pm 50 \%$.

\subsection{Determinação das fontes de receitas e despesas}

As fontes de despesas e receitas (Tabela 2) foram calculadas para as categorias de animais de interesse no estudo. As despesas são baseadas nos custos para alimentação dos animais, sendo para as pastagens os custos de formação, manutenção e depreciação anual, custo com o consumo anual de sal mineralizado e proteínado e custos veterinários.

As fontes de receitas do sistema foram baseadas na venda de vacas e touros de descartes, pesando respectivamente 450 e $700 \mathrm{~kg}$, bem como novilhos e novilhas de 36 meses de idade que não foram reintegradas ao rebanho, com um peso de 510 e $450 \mathrm{~kg}$ respectivamente. As receitas para animais destinados ao abate serão descritas para duas situações, sendo a primeira, onde o sistema de pagamento se baseia no valor pago por arroba de peso em cada categoria (sistema base) e na segunda baseado em um sistema de pagamento por qualidade (sistema por bonificação) onde as utilizações de touros melhoradores no 
acasalamento possam promover o crescimento de animais de melhores pesos e conformações de carcaça.

Tabela 2. Fonte de receitas e despesas no sistema de produção

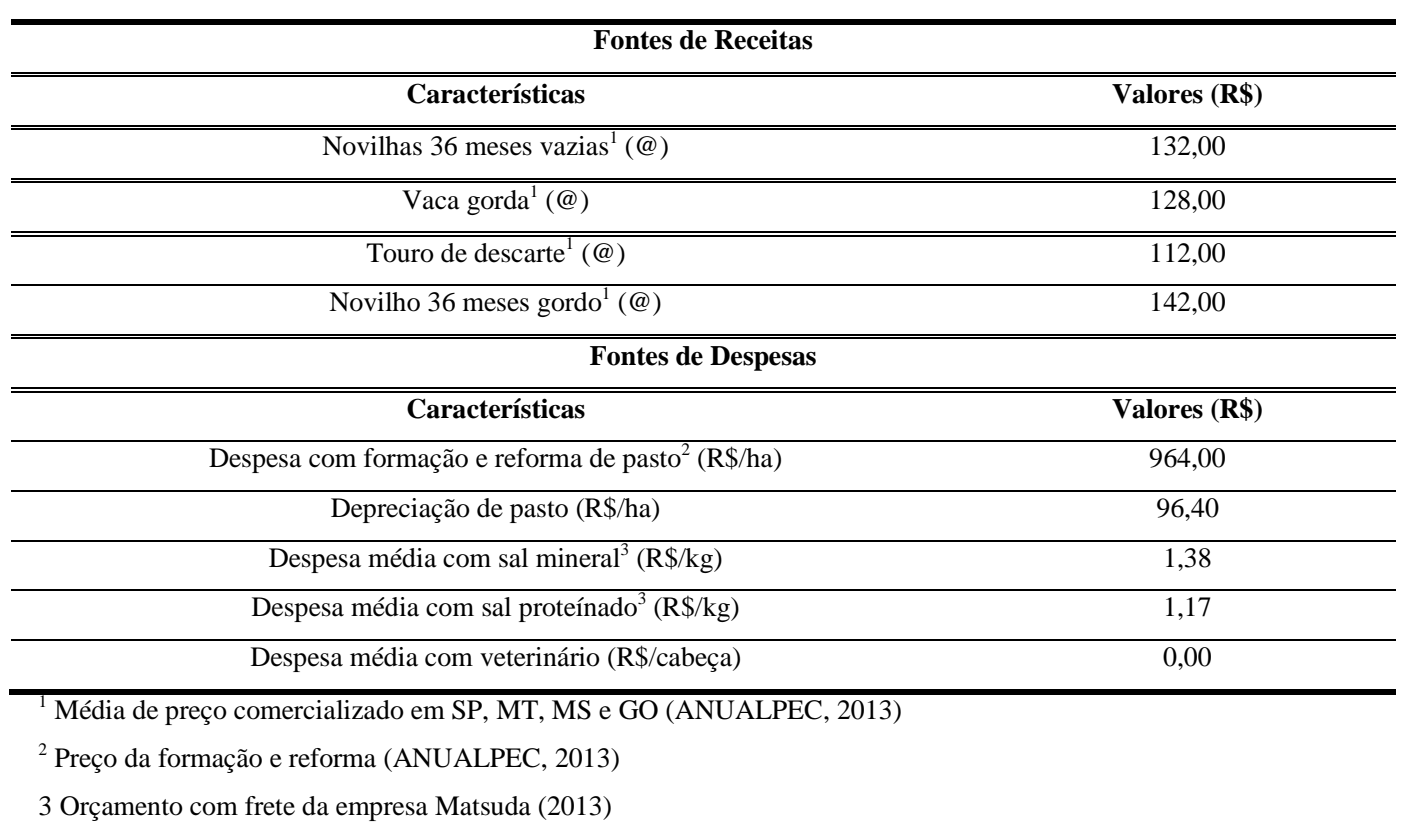

$\mathrm{Na}$ segunda situação pagamento diferencial (Tabela 3) é baseado no programa de qualidade Nelore natural, onde os pecuaristas têm a oportunidade de receber do frigorifico premiações que podem chegar a até $4 \%$ sobre o valor da arroba de seus animais. Porém os perfis dos animais para receber as bonificações são descritas abaixo:

Novilho Nelore: O novilho Nelore para ser classificado no lote de bonificação necessita ter peso médio da carcaça quente na variação de 17 a 21,9 arrobas (255 a 328,5 kg), com um padrão de gordura de acabamento entre 3 e $10 \mathrm{~mm}$ uniformemente distribuídos pela carcaça. Os machos castrados devem apresentar até 6 dentes incisivos permanente, porém aqueles não castrados devem apresentar toda dentição de leite. Esse padrão de carcaça descrito deve apresentar uma carcaça de conformação regular (retilínea, subconvexa, convexa).

Novilha Nelore: A novilha Nelore para ser classificado no lote de bonificação necessita ter peso médio de carcaça quente acima de 13 arrobas, com um padrão de gordura de acabamento entre 3 e $10 \mathrm{~mm}$ uniformemente distribuídos pela carcaça e uma dentição de 
até 4 dentes incisivos permanentes. Esse padrão exigido para as fêmeas devem ser de uma carcaça de conformação regular (retilínea, subconvexa, convexa).

Vacas Nelore: A vaca Nelore para ser classificado no lote de bonificação necessita ter um peso médio da carcaça quente acima de 15 arrobas (maior ou igual a $225 \mathrm{~kg}$ ), com um acabamento de gordura entre 3 e $10 \mathrm{~mm}$ uniformemente distribuídos pela carcaça, conferindo conformação regular à carcaça (retilínea, subconvexa, convexa).

Tabela 3 - Valores de bonificações para bovinos da raça Nelore

\begin{tabular}{cccc}
\hline $\begin{array}{c}\text { Índice de Classificação do } \\
\text { Lote }(\%)\end{array}$ & Novilho Nelore & Novilha Nelore & Vaca Nelore \\
\hline $0-49,9$ & 0,0 & 0,0 & 0,0 \\
$50-69,9$ & $+1 \%$ & $+2,0 \%$ & $+2,0 \%$ \\
$70-79,9$ & $+1,5 \%$ & $+3,0 \%$ & $+3,0 \%$ \\
Acima de 80 & $+2 \%$ & $+4,0 \%$ & $+4,0 \%$ \\
\hline
\end{tabular}

Fonte: http://www.nelore.org.br

\subsection{Estimação dos valores econômicos}

Para a estimação dos valores econômicos foi utilizado à metodologia de modelagem bioeconômica, que descreveu os parâmetros de receitas e despesas no sistema de produção de bovinos de corte criado a pasto em regime de ciclo completo. Essa modelagem ingressou todas as informações oriundas do sistema de produção (Tabela 1) alocadas em planilhas no programa Excel interligadas entre si e sendo uma dependente da outra, pois assim quaisquer alterações nos parâmetros refletiriam em alteração nos valores econômicos encontrados.

Os valores econômicos foram definidos pela metodologia proposta por Groen et al., 1997, decorrente de um aumento de 1\% para cada característica do objetivo, mantendo as demais constantes. Essa metodologia pode ser descrita pela equação:

$$
\mathrm{VE}=[(\delta(\text { Receita Anual }))-(\delta(\text { Custo Anual }))]
$$

Em que: VE é o valor econômico da característica, $\delta$ (Receita Anual) é a diferença marginal obtida no lucro depois e antes do melhoramento e $\delta$ (Custo Anual) é a diferença marginal obtida no custo depois e antes do melhoramento. 


\subsection{Análise de sensibilidade}

Para testar as mudanças nos valores econômicos referente às alterações em 5\%, $25 \%$ e $50 \%$ para mais ou para menos nos valores dos custos (forragem, suplementação e veterinários) e dos valores de receita (vendas dos animais), foi realizada a análise de sensibilidade que visa identificar se essas alterações promovem ou não mudanças significativas nos resultados simulados.

\subsection{Estimações de parâmetros genéticos}

Origem dos dados: Foram utilizados dados de animais (machos e fêmeas), nascidos entre os anos de 1998 a 2008, provenientes de 22 rebanhos localizados nos estados de Mato Grosso do Sul, Goiás, Rondônia, Minas Gerais e São Paulo, que participam do Programa de Melhoramento Genético da Raça Nelore (PMGRN) coordenado pela Associação Nacional dos Criadores e Pesquisadores (ANCP). Todos os animais do programa são submetidos a controles zootécnicos das características reprodutivas e produtivas, sendo esses mantidos em um regime alimentar de forma extensiva ou semi-extensiva. As fêmeas foram inseminadas no período de acasalamento e mantidas em lotes com touro de repasse.

Características Avaliadas: As características estudadas em princípio foram:

- Características de desenvolvimento ponderal corrigida para a idade: Peso ao Nascimento (PN), Peso aos 120 dias (P120), Peso aos 210 dias (P210), peso aos 365 dias (P365), peso aos 450 dias (P450) incluindo machos e fêmeas.

- Características reprodutivas: Perímetro Escrotal medido aos 365 e 450 dias de idade (PE365 e PE450) e Idade ao Primeiro Parto (IPP).

- Característica de Carcaça: Área de Olho de Lombo (AOL), Espessura de Gordura (EG) e Espessura de Gordura medido na garupa (EGP8).

Fatores ambientais: A definição dos grupos de contemporâneos (GC) foi feita com base na análise realizada pelo procedimento GLM (SAS Inst., Inc., Cary, NC). Os grupos de contemporâneo (GC) foram formados levando-se em conta as informações de fazenda (NFA $=22$ rebanhos), ano de nascimento do animal (AnoNasc $=11$ anos), estação de nascimento do animal $($ EstNasc $=2$ estações, sendo seca $=$ abril a setembro, chuva $=$ outubro a março $)$, lotes 
de manejos (Lote 120, 210, 365 e 450 dias) e sexo (Sx). As características que influenciaram as características em estudos e que foram utilizadas na formação dos grupos de contemporâneos estão descritos na Tabela 4.

Tabela 4. Características de formação dos grupos de contemporâneos das características em estudo.

\begin{tabular}{|c|c|c|}
\hline \multicolumn{3}{|c|}{ Produtivas } \\
\hline GC & Características & Valor de $\mathrm{P}$ \\
\hline PN & $\mathrm{Nfa}+\mathrm{Sx}+$ AnoNasc + EstNasc & $\mathrm{P}<0,001$ \\
\hline P120 & $\mathrm{Nfa}+\mathrm{Sx}+$ Lote $120+$ AnoNasc + EstNasc & $\mathrm{P}<0,001$ \\
\hline $\mathrm{P} 210$ & $\mathrm{Nfa}+\mathrm{Sx}+$ Lote $210+$ AnoNasc + EstNasc & $\mathrm{P}<0,001$ \\
\hline P365 & $\mathrm{Nfa}+\mathrm{Sx}+$ Lote120 + AnoNasc + EstNasc & $\mathrm{P}<0,001$ \\
\hline $\mathrm{P} 450$ & $\mathrm{Nfa}+\mathrm{Sx}+$ Lote $450+$ AnoNasc + EstNasc & $\mathrm{P}<0,001$ \\
\hline \multicolumn{3}{|c|}{ Reprodutivas } \\
\hline $\mathrm{GC}$ & Características & Valor de P \\
\hline PE365 & $\mathrm{Nfa}+$ Lote365 + AnoNasc + EstNasc & $\mathrm{P}<0,001$ \\
\hline PE450 & $\mathrm{Nfa}+$ Lote $450+$ AnoNasc + EstNasc & $\mathrm{P}<0,001$ \\
\hline IPP & $\mathrm{Nfa}+$ Lote $450+$ AnoNasc + EstNasc & $\mathrm{P}<0,001$ \\
\hline \multicolumn{3}{|c|}{ Qualidade de carcaça } \\
\hline $\mathrm{GC}$ & Características & Valor de $\mathrm{P}$ \\
\hline $\mathrm{AOL}$ & $\mathrm{Nfa}+\mathrm{Sx}+$ AnoNasc + EstNasc & $\mathrm{P}<0,001$ \\
\hline EG & $\mathrm{Nfa}+\mathrm{Sx}+$ AnoNasc + EstNasc & $\mathrm{P}<0,001$ \\
\hline EGP8 & $\mathrm{Nfa}+\mathrm{Sx}+$ AnoNasc + EstNasc & $\mathrm{P}<0,001$ \\
\hline
\end{tabular}

Consistências dos dados: Para todas as características analisadas, foram retirados do arquivo de análise registros de filhos de touros com menos de 4 filhos e GC com menos de 4 observações. Foi realizado o teste de normalidade dos resíduos para as variáveis e as observações com resíduos acima de 3,5 desvios-padrão e abaixo de -3,5 desvios-padrão foram excluídas do arquivo final de análise (Tabela 5). 
Tabela 5. Número de animais (N), pais, mães, grupos de contemporâneos (GC), médias, desvio-padrão (DP), valor mínimo (Min) e máximo (Max) consideradas na análise das características em estudo.

\begin{tabular}{|c|c|c|c|c|c|c|c|c|}
\hline \multicolumn{9}{|c|}{ REPRODUÇÃO } \\
\hline Características & $\mathrm{N}$ & Pai & Mãe & GC & Média & DP & Min & Max \\
\hline PE365 & 18.819 & 862 & 12.656 & 839 & 20,44 & 2,28 & 11,40 & 32,10 \\
\hline PE450 & 18.808 & 861 & 12.657 & 836 & 23,66 & 3,08 & 12,40 & 35,90 \\
\hline IPP & 13.335 & 823 & 9.842 & 875 & 35,16 & 4,98 & 21,00 & 49,00 \\
\hline \multicolumn{9}{|c|}{ CARCAÇA } \\
\hline Características & $\mathrm{N}$ & Pai & Mãe & $\mathrm{GC}$ & Média & DP & Min & Max \\
\hline AOL & 11.574 & 641 & 7.860 & 344 & 4,86 & 0,38 & 3,43 & 6,39 \\
\hline EGP8 & 11.561 & 641 & 7.863 & 344 & 0,47 & 0,19 & $-0,11$ & 1,27 \\
\hline EG & 11.541 & 641 & 7.839 & 343 & 0,37 & 0,17 & $-0,39$ & 1,16 \\
\hline \multicolumn{9}{|c|}{ PRODUTIVAS } \\
\hline Características & $\mathrm{N}$ & Pai & Mãe & $\mathrm{GC}$ & Média & DP & Min & Max \\
\hline PN & 25.176 & 685 & 13.371 & 42 & 32,67 & 3,91 & 20,00 & 49,00 \\
\hline P120 & 24.263 & 678 & 12.999 & 651 & 127,67 & 18,79 & 64,00 & 204,00 \\
\hline P210 & 23.599 & 666 & 12.686 & 541 & 184,75 & 29,07 & 87,00 & 300,00 \\
\hline P365 & 11.381 & 649 & 7.895 & 1433 & 241,75 & 42,20 & 107,00 & 478,00 \\
\hline P450 & 11.077 & 641 & 7.812 & 1543 & 280,53 & 51,55 & 119,00 & 524,00 \\
\hline
\end{tabular}

Análise dos dados: As análises para estimação dos componentes de variância foram realizadas pelo método de Máxima Verossimilhança Restrita (REML) usando o modelo animal, considerando para as características de PN, P120 e P210 o efeito fixo (GC), efeito aleatório (direto, materno e ambiente permanente) e efeito ambiental (residual). Para P365, P450, IPP, AOL, EG e EGP8 foram retirados o efeito materno e de ambiente permanente do modelo. Para todas as características de produção (PN, P120, P210, P365 e P450) e reprodução (PE365, PE450 e IPP) considerou-se a idade da vaca ao parto como covariável linear e quadrática $(\mathrm{P}<0,05)$, já para as características de carcaça (AOL, EG e EGP8) considerou-se a idade da medição como efeito linear $(\mathrm{P}<0,05)$. O programa computacional utilizado para estimação dos componentes de variância foi o WOMBAT, descrito por Meyer (2007) em análises uni e bicaracterístico.

Em termos matriciais, o modelo completo utilizado nas análises pode ser representado por:

$$
y=X \beta+Z_{1} a+Z_{2} m+W p+e
$$

em que: $\boldsymbol{y}$ é o vetor das observações; $\boldsymbol{X}$ é a matriz de incidência para efeitos fixos (GC), associando os elementos de $\boldsymbol{\beta}$ e $\boldsymbol{y} ; \boldsymbol{\beta}$ é o vetor de efeitos fixos (GC e IDV); $Z_{1}, Z_{2}$ e W são matrizes de incidência para os efeitos aleatórios genético aditivo direto, genético aditivo materno e ambiente permanente; $\boldsymbol{\alpha}$ é o vetor dos efeitos aleatórios genético aditivo direto; $\boldsymbol{m}$ é 
o vetor dos efeitos aleatórios genético aditivo materno; p é o vetor do efeito de ambiente permanente; e $\boldsymbol{e}$ é vetor dos efeitos residuais. As pressuposições assumidas para esse modelo são:

$$
\begin{gathered}
\mathbf{E}(\mathbf{y})=\mathbf{X} \boldsymbol{\beta} \\
E\left(\begin{array}{c}
a \\
m \\
p \\
e
\end{array}\right)=\left(\begin{array}{l}
0 \\
0 \\
0 \\
0
\end{array}\right) \quad \operatorname{Var}\left(\begin{array}{l}
a \\
m \\
p \\
e
\end{array}\right)=\left(\begin{array}{cccc}
A \sigma_{a}^{2} & A \sigma_{a m} & 0 & 0 \\
A \sigma_{a m} & A \sigma_{m}^{2} & 0 & 0 \\
0 & 0 & I \sigma_{p}^{2} & 0 \\
0 & 0 & 0 & I \sigma_{e}^{2}
\end{array}\right)
\end{gathered}
$$

em que: $\sigma_{a}^{2}$ é o componente de variância genética aditiva direta; $\sigma_{m}^{2}$ é o componente de variância genética aditiva materna; $\sigma_{a m}$ é o componente de covariância entre os efeitos genéticos aditivo direto e materno; $\sigma_{p}^{2}$ é o componente de variância de ambiente permanente; e $\sigma_{e}^{2}$ é o componente de variância residual; $A$ é a matriz de parentesco com 139210 animais; e $I$ é a matriz identidade.

Os valores iniciais para as variâncias foram obtidas a partir da literatura para cada característica, e as mesmas foram consideradas convergidas quando o critério de convergência fosse inferior a $10^{-9}$.

Para estimação das correlações genética e fenotípica entre as variáveis em estudo na qual se obedeceu ao seguinte modelo matricial bi-característica:

$$
\left(\begin{array}{l}
y_{1} \\
y_{2}
\end{array}\right)=\left(\begin{array}{cc}
X_{1} & 0 \\
0 & X_{2}
\end{array}\right)\left(\begin{array}{l}
\beta_{1} \\
\beta_{2}
\end{array}\right)+\left(\begin{array}{cc}
Z_{1} & 0 \\
0 & Z_{2}
\end{array}\right)\left(\begin{array}{l}
a_{1} \\
a_{2}
\end{array}\right)+\left(\begin{array}{l}
e_{1} \\
e_{2}
\end{array}\right)
$$

em que: $y_{1}$ e $y_{2}$ são os vetores das observações das variáveis 1 e 2 , respectivamente; $\beta_{1}$ e $\beta_{2}$ são os vetores das soluções dos efeitos fixos para as características 1 e 2, respectivamente; $a_{1}$ e $a_{2}$ são vetores das soluções dos efeitos aleatórios genético aditivos para as variáveis 1 e 2 , respectivamente; $X_{1}$ e $X_{2}$ são as matrizes de incidência associando os elementos de $\beta_{1}$ e $\beta_{2}$ com as observações em $y_{1}$ e $y_{2} ; Z_{1}$ e $Z_{2}$ são as matrizes de incidência associando os elementos de $a_{1}$ e $a_{2}$ com as observações de $y_{1}$ e $y_{2}$. A esperança de $y_{1}$ é $X_{1} \beta_{1}$ e de $y_{2}$ é $X_{2} \beta_{2}$; e a estrutura de variâncias e covariâncias dos efeitos aleatórios do modelo animal bicaracterística é: 


$$
\operatorname{Var}\left(\begin{array}{l}
a_{1} \\
a_{2} \\
e_{1} \\
e_{2}
\end{array}\right)=\left(\begin{array}{cccc}
A \sigma_{a_{1}}^{2} & A \sigma_{a_{1} a_{2}} & 0 & 0 \\
A \sigma_{a_{1} a_{2}} & A \sigma_{a_{2}}^{2} & 0 & 0 \\
0 & 0 & I \sigma_{e_{1}}^{2} & 0 \\
0 & 0 & 0 & I \sigma_{e_{2}}^{2}
\end{array}\right)
$$

em que: $\sigma_{a_{1}}^{2}$ e $\sigma_{a_{2}}^{2}$ são as variâncias do efeito genético aditivo direto e $\sigma_{e_{1}}^{2}$ e $\sigma_{e_{2}}^{2}$ são as variâncias residuais para as características 1 e 2, respectivamente; $\sigma_{a_{1} a_{2}}$ é a covariância genética aditiva entre as característica 1 e 2.

Tendência Genética: O ganho genético anual para as características de reprodução, carcaça e desenvolvimento ponderal foi estimado pela regressão linear do valor genético (VG) em função do ano de nascimento, descrita no modelo:

$$
\mathbf{y}=\mathbf{a}+\mathbf{b x}
$$

em que: $\mathrm{Y}=$ é o valor genético de cada característica, $\mathrm{a}=$ é o intercepto; $\mathrm{b}=$ coeficiente de regressão ou tendência; $\mathrm{x}$ = variável independente (ano).

A partir do valor do coeficiente de tendência $b$, foi calculada a Taxa Geométrica de Crescimento (TGC) por meio da seguinte expressão:

$$
\text { TGC }=(b-L) \times 100
$$

em que: $\mathrm{b}=$ é a tendência genética média anual; $\mathrm{L}=$ média do valor genético da característica no período avaliado.

A significância de TGC foi avaliada pelo teste "t". Os valores de TGC indicam, em porcentagem, a mudança linear média dos valores genéticos para cada variável. 
Resultados e Discussão 


\section{Resultados e Discussão}

\subsection{Estrutura do Rebanho e Análise econômica do sistema}

Após estruturação do sistema de produção e a avaliação dos parâmetros zootécnicos, o rebanho em estudo estabilizou-se após cinco anos corridos, sendo uma das premissas do modelo bioeconômico determinístico e estático que se demonstrou eficaz na avaliação do rebanho quanto aos seus centros de custo e de receitas para esse estudo (Tabela 6). Os parâmetros zootécnicos utilizados na composição do modelo foram baseados em sistema de produções do Brasil central e de algumas revisões de literatura, pois a modelagem bioeconômica requer certas informações que em muitos sistemas de produções não são avaliados. Segundo Jorge Junior et al., 2006 essa complexidade de cada modelo bioeconômico depende das informações disponibilizadas pelo sistema, e que a inexistência dessas podem serem supridas pela revisão de conhecimentos publicados em trabalhos ou por experiências de profissionais da área.

Tabela 6. Composição do rebanho estabilizado.

\begin{tabular}{cc}
\hline Categoria & Cabeças \\
\hline \hline Vacas & 990 \\
Touros & 42 \\
Bezerras 0 - 1 ano & 497 \\
Bezerras 1 - 2 anos & 473 \\
Novilhas 2 - 3 anos & 469 \\
Bezerros 0 - 1 ano & 497 \\
Bezerros 1 - 2 anos & 473 \\
Novilhos 2 - 3 anos & 469 \\
\hline
\end{tabular}

O número de vacas e novilhas com prenhes positiva estabilizado no sistema foram de 1000 fêmeas. Anualmente foram descartadas para venda $22 \%$ das vacas (218) e $25 \%$ dos touros (10) aliviando os custos das categorias com a suplementação proteica no período seco. Já no início da estação de reprodução novos reprodutores geneticamente superiores foram adquiridos para suprir a relação do número de touros por fêmeas necessários e houve a necessidade de exposição de 268 novilhas com idade de 24 meses. O excedente de novilhas 
que não emprenharam e as que não foram expostas somaram o total de 238 novilhas comercializadas juntamente com 464 machos aos 36 meses de idade, com pesos variando de 450 e $510 \mathrm{~kg}$, respectivamente para machos e fêmeas.

Com as informações da composição e evolução do rebanho por categoria animal, foi possível dimensionar os centros de custos alimentícios de acordo com as exigências dos animais quanto às quantidades de forrageiras, suplementação mineral e proteica, bem como as receitas provindas das vendas de machos e fêmeas de 36 meses, touros e vacas de descartes (Tabela 7).

Tabela 7. Indicadores econômicos de custos e receitas em sistema de ciclo completo de bovinos de corte.

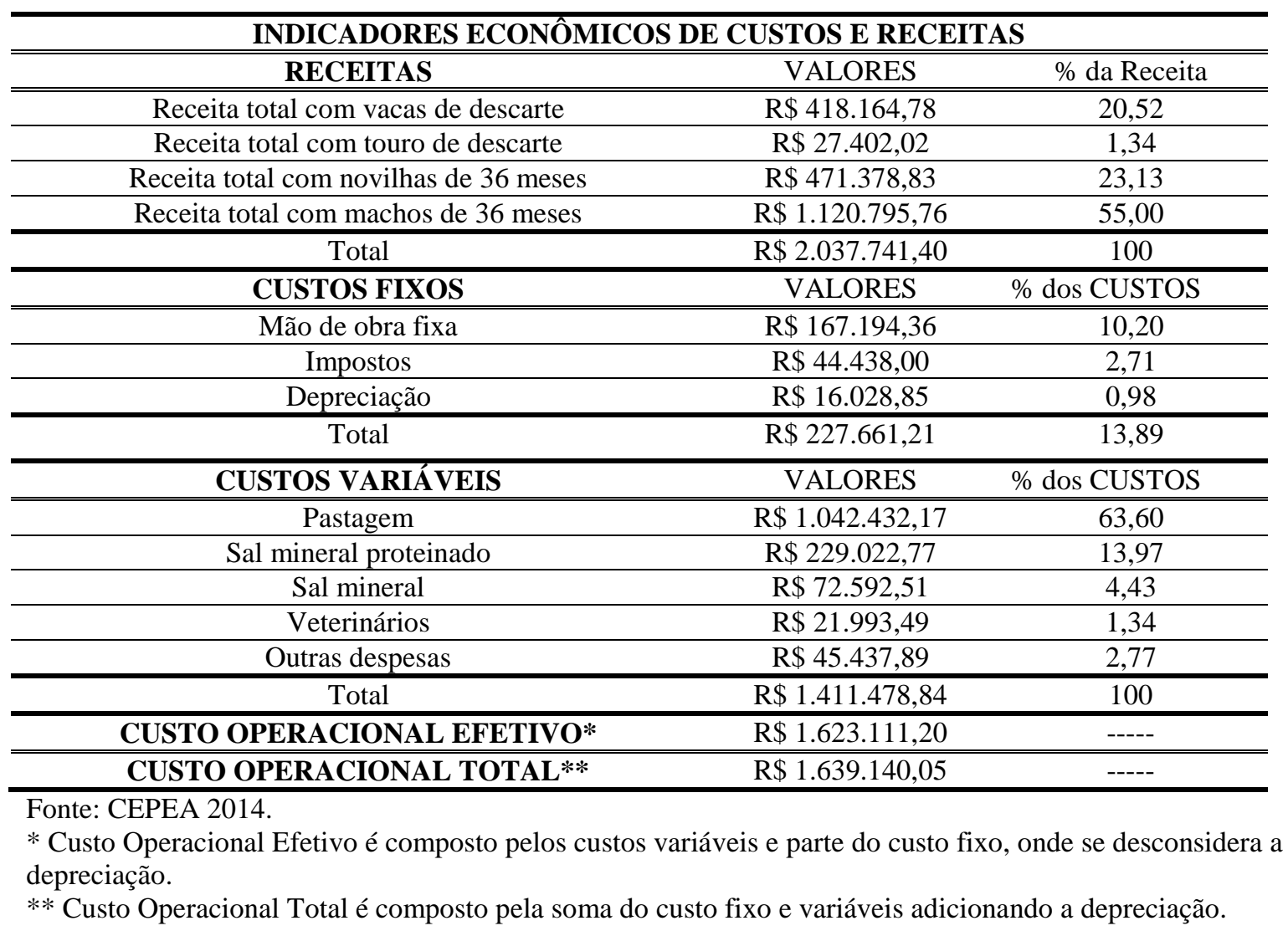

Analisando o centro de receitas a categoria com maior expressão total foi à venda de machos com 36 meses que representou 55\%, sendo seguido pela categoria de fêmeas de 36 meses que somaram $23,13 \%$ da receita total. Esses fatores se devem a quantidade de unidades animais presente nos lotes e pela maior disposição de $\mathrm{kg}$ de peso vivos a serem ofertados a vendas, concordando com os resultados relatados por Jorge Junior et al., 2006 e Campos et al., 2014 para sistemas de bovinos de corte em regime de ciclo completo. 
Os custos com a alimentação (pastagem, sal mineral e proteinado) dos animais somaram o total de $82 \%$ do custo total da propriedade, sendo esses custos os mais expressivos na determinação dos valores econômicos. Já os custos fixos segundo Ponzoni e Newman, 1989 não se alteraram com as mudanças simuladas nas características, assumindo valores nulos no processo de derivação parcial, porém foram avaliados neste estudo para demonstrar que a propriedade apresentou lucro anual total de $\mathrm{R} \$ 398.601,35$ ao ano, e lucratividade de 19,56\%. Esse é o indicador da proporção da receita bruta que se constitui em lucro após a diferença dos custos (Tabela 8), portanto, a propriedade avaliada apresenta eficiência produtiva e viável dentro do sistema de bovinos de corte.

Tabela 8. Indicadores econômicos de lucratividade do sistema de ciclo completo de bovinos de corte.

\begin{tabular}{lc}
\hline \multicolumn{2}{c}{ INDICADORES ECONÔMICOS DA PROPRIEDADE EM ESTUDO } \\
\hline \hline Margem Bruta & $\mathrm{R} \$ 414.630,20$ \\
\hline Margem Liquida & $\mathrm{R} \$ 398.601,35$ \\
\hline Lucro Total & $\mathrm{R} \$ 398.601,35$ \\
\hline Lucratividade & $19,56 \%$ \\
\hline Fonte: CEPEA 2014. \\
* Receita Total - Custo Operacional Efetivo \\
** Receita Total - Custo Operacional Total \\
$* * *$ Receita Total
\end{tabular}

\subsection{Valores econômicos em bovinos de corte em sistema de ciclo completo}

Os componentes de lucro (receita - despesa) apresentaram influências positivas quando submetidas à simulação do aumento de $1 \%$ no potencial genético dos animais para as características de peso adulto da vaca (PAV), peso ao abate de fêmeas (PAF), peso ao abate de machos (PAM), taxa de desmama (TD), peso a desmama de macho (PDM) e peso a desmama de fêmea (Tabela 9). 
Tabela 9. Desempenho lucrativo em situação básica e simulada e estimação dos valores econômicos nas características em estudo.

\begin{tabular}{cccccc}
\hline Características & $\begin{array}{c}\text { Lucro } \\
\text { Final (R\$) }\end{array}$ & $\begin{array}{c}\text { Lucro } \\
\text { Inicial (R\$) }\end{array}$ & $\begin{array}{c}\text { Lucro } \\
\text { Marginal (R\$) }\end{array}$ & $\begin{array}{c}\text { Ganho } \\
\text { Genético }\end{array}$ & $\begin{array}{c}\text { Valor } \\
\text { Econômico (R } \$)\end{array}$ \\
\hline \hline PAV & $8.127,32$ & $8.004,70$ & 122,62 & 980,07 & 0,13 \\
\hline PAF & $269.678,11$ & $266.033,48$ & $3.644,63$ & $1.071,74$ & 3,40 \\
\hline PAM & $891.659,62$ & $882.930,50$ & $8.729,11$ & $2.365,73$ & 3,69 \\
\hline TD & $1.166 .299,36$ & $1.148 .963,99$ & $17.335,37$ & $4.838,72$ & 3,58 \\
\hline PDM & $887.416,57$ & $882.930,50$ & $4.486,06$ & $1.235,08$ & 3,63 \\
\hline PDF & $266.831,15$ & $266.033,48$ & 797,67 & 346,15 & 2,30 \\
\hline
\end{tabular}

Peso Adulto da Vaca (PAV); Peso ao Abate de Fêmea (PAF); Peso ao Abate de Macho (PAM); Taxa de Desmama (TD); Peso a Desmama de Macho (PDM); Peso a Desmama de Fêmea.

A diferença apresentada pelo lucro antes e após a simulação do melhoramento é denominado de lucro marginal. Considerando os resultados encontrados a TD foi a que expressou maior impacto econômico seguido respectivamente por PAM, PDM, PAF, PDF e PAV (Tabela 9). Essa característica (TD) também foi de maior impacto e economicamente mais relevante, quanto ao lucro marginal nos estudos de Urioste et al., 1998 e Jorge Junior et al., 2007. A taxa de desmame está ligada ao número de unidades animais produzidos, onde qualquer incremento positivo nos valores dessas características causa maiores impactos econômicos favoráveis para o sistema de produção que trabalha a comercialização de animais.

O valor econômico obtido nesse estudo foi calculado pela divisão do lucro marginal pelo ganho genético (VE=LM/GG), proporcionado simulando-se o ganho de $1 \%$ na unidade de cada característica (GROEN et al., 1997), expressos por rebanho. No caso do valor econômico o maior impacto nesse estudo avaliando o ciclo completo foi o PAM (R\$3,69/kg), sendo este valor superior aos reportado por Jorge Junior et al., 2007 para a raça Nelore e Campos et al., 2014 para a raça Angus, onde os valores foram respectivamente R \$1,17 e R\$ 1,43. O PAF aos 36 meses de idade teve impacto positivo nesse sistema, sendo conjuntamente superior ao relatados pelos mesmos autores anteriormente citados, na ordem de $\mathrm{R} \$ 3,40$ para cada unidade kg ganho pelo rebanho em decorrência da seleção. Essa superioridade do valor econômico encontrado no presente estudo, tanto para machos quanto para fêmeas, pode ser devida a influência dos valores de comercialização dos animais, medidos em R \$/arroba de boi, terem se mantido altos ao longo do ano de 2014 quando comparados aos anos dos estudos mencionados e das diferenças de pesos de abate dos animais em cada estudo.

O estudo do PDM demonstrou que a cada $1 \%$ de ganho em unidades da característica houve o retorno econômico de $\mathrm{R}$ \$ 3,63 para os machos e $\mathrm{R}$ \$2,30 para as fêmeas em sistema de bovinos de corte em regime de ciclo completo. Essa característica é importante nesse tipo 
de sistema, pois a correlação genética entre as características varia de 0,50 a 0,65 (Boligon et al., 2008, Yokoo et al. 2007; Yokoo et al. 2010), ou seja entre 50 e 65\% dos genes responsáveis pelo maior peso dos animais ao desmame também são responsáveis pelo maior peso aos 36 meses de idade, facilitando assim a identificação de animais de maior desempenho ponderal e econômico e permitindo a formação de lotes de manejo para a escala de abate futura com lotes uniformes de padronização de carcaça.

Fernandez-Perea e Jiménez (2004) estimaram valores econômicos negativos para peso a desmama $-0,43 € /$ vaca/ano). Os autores justificaram que o sistema de produção adotado com suplementação dos animais do nascimento ao desmame elevou os custos de produção. No Brasil avaliando o sistema de ciclo completo com a raça Nelore Bittencourt et al., 2006; Jorge Junior et al., 2007 e Brumatti et al., 2011 relataram, os valores econômicos para peso ao desmame de U\$ 0,29, R\$ 0,34 e R\$ 0,57. Esses valores foram muito inferiores quando comparados com o valor encontrado no presente estudo de $\mathrm{R} \$ 3,63$ para machos e $\mathrm{R} \$ 2,30$ para fêmea. Laske et al., 2012, trabalhando com bovinos de corte em sistema de pecuária familiar obtiveram valor econômico superior para o peso a desmama na ordem de $\mathrm{R} \$ 17,07$ por unidade de melhoramento, no entanto, todos os valores reportados promoveram incrementos econômicos positivos para seus respectivos sistemas de produções.

Para Groen 1989 e Phocas et al., (1998) essa base de comparação dos valores econômicos entres sistemas deve ser feita com muita cautela, pois cada sistema de produção apresenta suas particularidades e que essas podem causar diferenças nos centros de custos e de receitas entre propriedades. Wolfavá e Wolf (2013) orientam não fazer as comparativas entre valores econômicos de uma mesma característica em sistemas de produções diferentes.

A taxa de desmama (TD), embora tenha sido a característica com maior impacto na lucratividade no sistema, quando avaliado o seu retorno econômico comparado ao ganho por seleção, mudou de classificação para a terceira colocação de importância com valor de $\mathrm{R} \$ 3,58$ por $1 \%$ de incremento na característica, valor próximo ao relatado por Jorge Junior et al., 2007 em seus estudos de $\mathrm{R} \$ 3,36$ por $1 \%$ de ganho.

Revisando outros estudos, a taxa de desmame foi à característica de maior importância relativa para os sistemas e com valores altamente expressivos aos citados anteriormente. Urioste et al., (1998) trabalhando com pecuária de corte em regime extensivo obtiveram um valor de U\$ 39,5 por 1\% de unidade ganho na característica. Em sistema familiar no sul do Brasil Laske et al., 2012 relataram valor econômico para taxa de desmame de $\mathrm{R} \$ 73,21$. O número de bezerros desmamados (NBD) por vaca por ano teve segundo Bittencourt et al., 
2006 um retorno econômico de $\mathrm{R}$ \$ 97. Para Campos et al. 2013 que avaliaram a mesma característica (NBD) na raça angus o valor econômico encontrado foi $\mathrm{R} \$ 6,67$ por $1 \%$ de ganho com a seleção genética.

O retorno econômico por $1 \%$ de unidade de melhoramento na característica PAV foi de $\mathrm{R} \$ 0,13$, valor próximo ao relatado por Jorge Junior et al., 2007 de R 0,09. Enquanto Laske et al., 2012 obteve o valor econômico de R \$ 4,75. Portanto as diferenças nesses valores se devem aos valores dos custos de matéria seca em cada sistema de produção ou até mesmo pela valorização da vaca ao abate nos períodos avaliados. Embora os valores econômicos demonstrassem promover lucro para os sistemas, Fernandez-Perea e Jiménez (2004) encontraram $-2,31 €$ por $\mathrm{kg}$, ou seja, o aumento do PAV reduziriam os lucros ao sistema de produção.

\subsection{Valores econômicos em sistema de pagamentos por qualidade}

Os valores econômicos das características estudadas quando avaliadas sob a ótica do sistema de pagamento do programa Nelore Natural, tiveram aspectos positivos em relação ao lucro do sistema (Tabela 10). Avaliando que padrões dos animais se encaixassem na maior cota de bonificação com formações padronizadas dos lotes acima de $80 \%$, a característica que maior se destacou foi o PAV que teve um incremento de $130 \%$ acima do valor econômico na situação de pagamento sem bonificação. Seguindo a ordem de importância no sistema com bonificação os valores econômicos foram superiores em $8 \%$ para PDF, 5\% para PAF, $4 \%$ para TD, 3\% PDM e 2\% para PAM. Esses valores econômicos superiores nas características ligadas às fêmeas são pelas maiores bonificações $(+4 \%$ sobre o valor da arroba) recebidos pelas mesmas em relação aos machos $(+2 \%)$, porém vale ressaltar, que os custos de produções mantiveram-se constantes, alterando-se somente os centros de receitas.

Embora os valores das bonificações por cotas de qualidade dos animais promoverem mudanças expressivas nos valores econômicos (VE) de algumas características quando comparada ao sistema de pagamento sem bonificação, afirma-se a importância de novas pesquisas avaliando outras formas de pagamentos por qualidade de carcaça no Brasil, bem como, a avaliação de custos de produção em animais de alto rendimento. Para isso, Mendes e Padilha (2007) relatam que a cadeia produtiva da carne no Brasil deve-se trabalhar de forma coordenada e se organizar de maneira eficiente buscando o mesmo ideal para o setor com um 
produto cárneo padronizado e de melhor qualidade satisfazendo a vontade de cada mercado consumidor.

Tabela 10. Desempenho econômico em situação básica e simulada e estimação dos valores econômicos sob o sistema de pagamento do programa Nelore natural.

\begin{tabular}{|c|c|c|c|c|c|}
\hline \multicolumn{6}{|c|}{ Valor Econômico para o Sistema Nelore Natural (50 - 59\% do lote) } \\
\hline Características & $\begin{array}{c}\text { Lucro } \\
\text { Final (R\$) }\end{array}$ & $\begin{array}{c}\text { Lucro } \\
\text { Inicial }(\mathrm{R} \$)\end{array}$ & $\begin{array}{c}\text { Lucro } \\
\text { Marginal (R\$) }\end{array}$ & $\begin{array}{c}\text { Ganho } \\
\text { Genético }\end{array}$ & $\begin{array}{c}\text { Valor } \\
\text { Econômico } \\
(\mathrm{R} \$) \\
\end{array}$ \\
\hline PAV & $16.574,25$ & $16.368,00$ & 206,25 & 980,07 & 0,21 \\
\hline PAF & $279.203,62$ & $275.461,06$ & $3.742,57$ & $1.071,74$ & 3,49 \\
\hline PAM & $902.967,22$ & $894.138,46$ & $8.828,76$ & $2.365,73$ & 3,73 \\
\hline TD & $1.187 .256,25$ & $1.169 .599,52$ & $17.656,73$ & $4.838,72$ & 3.65 \\
\hline PDM & $898.682,99$ & $894.138,46$ & $4.544,52$ & $1.235,08$ & 3,68 \\
\hline PDF & $276.289,19$ & $275.461,06$ & 828,13 & 346,15 & 2,39 \\
\hline \multicolumn{6}{|c|}{ Valor Econômico para o Sistema Nelore Natural $(60-79 \%$ do lote $)$} \\
\hline Características & $\begin{array}{c}\text { Lucro } \\
\text { Final (R\$) }\end{array}$ & $\begin{array}{c}\text { Lucro } \\
\text { Inicial }(\mathrm{R} \$)\end{array}$ & $\begin{array}{c}\text { Lucro } \\
\text { Marginal (R\$) }\end{array}$ & $\begin{array}{c}\text { Ganho } \\
\text { Genético }\end{array}$ & $\begin{array}{c}\text { Valor } \\
\text { Econômico } \\
(\mathrm{R} \$)\end{array}$ \\
\hline PAV & $20.797,71$ & $20.549,65$ & 248,07 & 980,07 & 0,25 \\
\hline PAF & $283.966,38$ & $280.174,85$ & $3.791,53$ & $1.071,74$ & 3,54 \\
\hline PAM & $908.621,03$ & $899.742,44$ & $8.878,59$ & $2.365,73$ & 3,75 \\
\hline TD & $1.197 .734,69$ & $1.179 .917,29$ & $17.817,41$ & $4.838,72$ & 3,68 \\
\hline PDM & $904.316,19$ & $889.742,44$ & $4.573,75$ & $1.235,08$ & 3,70 \\
\hline PDF & $281.018,21$ & $280.174,85$ & 843,36 & 346,15 & 2,44 \\
\hline \multicolumn{6}{|c|}{ Valor Econômico para o Sistema Nelore Natural (acima de $80 \%$ do lote) } \\
\hline Características & $\begin{array}{c}\text { Lucro } \\
\text { Final (R\$) }\end{array}$ & $\begin{array}{c}\text { Lucro } \\
\text { Inicial }(\mathrm{R} \$)\end{array}$ & $\begin{array}{c}\text { Lucro } \\
\text { Marginal (R\$) }\end{array}$ & $\begin{array}{c}\text { Ganho } \\
\text { Genético }\end{array}$ & $\begin{array}{c}\text { Valor } \\
\text { Econômico } \\
(\mathrm{R} \$)\end{array}$ \\
\hline PAV & $25.021,18$ & $24.731,29$ & 289,88 & 980,07 & 0,30 \\
\hline PAF & $288.729,14$ & $284.888,63$ & $3.840,50$ & $1.071,74$ & 3,58 \\
\hline PAM & $914.274,83$ & $905.346,42$ & $8.928,41$ & $2.365,73$ & 3,77 \\
\hline TD & $1.208 .213,14$ & $1.190 .235,05$ & $17.978,08$ & $4.838,72$ & 3,72 \\
\hline PDM & $909.949,40$ & $905.346,42$ & $4.602,98$ & $1.235,08$ & 3.73 \\
\hline PDF & $285.747,23$ & $284.888,63$ & 858,59 & 346,15 & 2,48 \\
\hline
\end{tabular}

Peso Adulto da Vaca (PAV); Peso ao Abate de Fêmea (PAF); Peso ao Abate de Macho (PAM); Taxa de Desmama (TD); Peso a Desmama de Macho (PDM); Peso a Desmama de Fêmea.

\subsection{Análise de sensibilidade}

A análise de sensibilidade explorou as variações ocorridas nos valores econômicos em diferentes situações mercadológicas, como aumentos ou reduções nos valores de custo das pastagens, minerais e suplementações proteicas e também nos centros de receitas do presente estudo (Tabela 11).

As variações no valor do custo de matéria seca das pastagens destinada à alimentação dos animais promoveram mudanças significativas nos valores econômicos do PAV da ordem de $\mathrm{R} \$ \pm 1,66$ com a variação $\pm 50 \%$ no custo da pastagem. $\mathrm{O}$ aumento de ganho genético de 
$1 \%$ característica PAV promoveriam redução no lucro do sistema se tiverem um aumento a partir de 5\% nos custos de matéria seca. Essa simulação provocou alterações nas ordens dos valores econômicos importantes para o sistema de ciclo completo, classificando as características nas seguintes ordens de importância quando reduzidos 50\% no custo: 1-PDM, 2-TD, 3-PAM, 4-PAF, 5-PDF e 6-PAV. Esses resultados eram esperados, pois o sistema foi baseado em criação de bovinos de forma extensiva, e o aumento ou a redução dos preços da matéria seca resultaria nas variações dos custos por categoria animal de acordo com exigência nutricional dos mesmos.

O custo com sal mineral utilizado no período das águas promoveu uma pequena

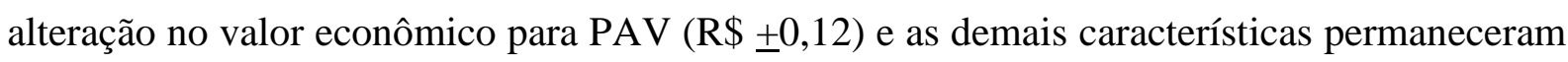
praticamente inalteradas. Na simulação de alterações no custo com proteínado ofertado no período seco a ordem de importância dos valores econômicos para o sistema não alteraram,

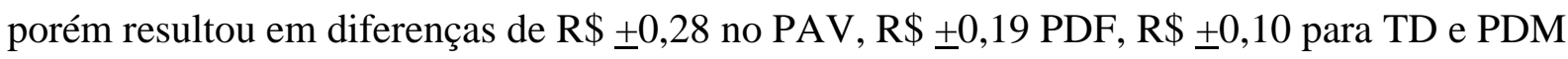
e R\$ $\pm 0,07$ para PAM e PAF. A característica PAV também apresentou sensibilidade ao aumento no custo de proteínado a partir de $25 \%$ o que promoveria reduções nos lucros de $\mathrm{R} \$$ 0,02 a $\mathrm{R} \$-0,16$ pelo aumento de $1 \%$ na unidade da característica.

A sensibilidade dos valores econômicos para variações nos centros de receitas não tiveram alterações em suas ordens de importância econômica entre as variações de 5 a $25 \%$. Porém quando reduzidos em 50\% os valores de receita a TD tornou-se a segunda característica mais importante, alternando-se a ordem com o PD. Se as receitas fossem aumentas em 50\% o PDM seria a característica mais importante no ciclo completo com aumento de $\mathrm{R}$ \$ 6,00 no lucro com ganho de $1 \%$ na unidade da característica, sendo seguidos pela TD e PAM.

$\mathrm{O}$ PAV foi à característica que expressou maior sensibilidade quanto às demais, na variação dos valores de receitas do sistema. A redução a partir de 5\% na receita reduziria o lucro do PAV no sistema, o que para as demais características, tantas as flutuações de preços para mais ou para menos, o lucro permaneceria positivo promovendo ganhos econômicos por seleção dentro do sistema. 
Tabela 11. Análise de sensibilidade para avaliar mudanças nos valores econômicos quanto às alterações dos preços das pastagens, minerais, proteínado e valores de receitas.

\begin{tabular}{|c|c|c|c|c|c|c|c|}
\hline \multicolumn{7}{|c|}{ ANÁLISE DE SENSIBILIDADE } & \\
\hline \multicolumn{8}{|c|}{ Sensibilidade ao Valor do Custo das Pastagens } \\
\hline Características & $-50 \%$ & $-25 \%$ & $-5 \%$ & $0 \%$ & $5 \%$ & $25 \%$ & $50 \%$ \\
\hline PAV & $\mathrm{R} \$ 1,79$ & $\mathrm{R} \$ 0,96$ & $\mathrm{R} \$ 0,29$ & $\mathrm{R} \$ 0,13$ & $\mathrm{R} \$-0,04$ & $\mathrm{R} \$-0,71$ & $\mathrm{R} \$-1,54$ \\
\hline PAF & $\mathrm{R} \$ 3,82$ & $\mathrm{R} \$ 3,61$ & $\mathrm{R} \$ 3,40$ & $\mathrm{R} \$ 3,40$ & $\mathrm{R} \$ 3,36$ & $\mathrm{R} \$ 3,19$ & $\mathrm{R} \$ 2,98$ \\
\hline PAM & $\mathrm{R} \$ 3,87$ & $\mathrm{R} \$ 3,78$ & $\mathrm{R} \$ 3,71$ & $\mathrm{R} \$ 3,69$ & $\mathrm{R} \$ 3,67$ & $\mathrm{R} \$ 3,60$ & $\mathrm{R} \$ 3,51$ \\
\hline TD & $\mathrm{R} \$ 3,95$ & $\mathrm{R} \$ 3,77$ & $\mathrm{R} \$ 3,62$ & $\mathrm{R} \$ 3,58$ & $\mathrm{R} \$ 3,55$ & $\mathrm{R} \$ 3,40$ & $\mathrm{R} \$ 3,21$ \\
\hline PDM & $\mathrm{R} \$ 4,05$ & $\mathrm{R} \$ 3,84$ & $\mathrm{R} \$ 3,67$ & $\mathrm{R} \$ 3,63$ & $\mathrm{R} \$ 3,59$ & $\mathrm{R} \$ 3,42$ & $\mathrm{R} \$ 3,22$ \\
\hline $\mathrm{PDF}$ & $\mathrm{R} \$ 3,11$ & $\mathrm{R} \$ 2,71$ & $\mathrm{R} \$ 2,39$ & $\mathrm{R} \$ 2,30$ & $\mathrm{R} \$ 2,22$ & $\mathrm{R} \$ 1,90$ & $\mathrm{R} \$ 1,50$ \\
\hline \multicolumn{8}{|c|}{ Sensibilidade ao Valor do Custo do Mineral } \\
\hline Características & $-50 \%$ & $-25 \%$ & $-5 \%$ & $0 \%$ & $5 \%$ & $25 \%$ & $50 \%$ \\
\hline PAV & $\mathrm{R} \$ 0,25$ & $\mathrm{R} \$ 0,19$ & $\mathrm{R} \$ 0,14$ & $\mathrm{R} \$ 0,13$ & $\mathrm{R} \$ 0,11$ & $\mathrm{R} \$ 0,06$ & $\mathrm{R} \$ 0,001$ \\
\hline PAF & $\mathrm{R} \$ 3,41$ & $\mathrm{R} \$ 3,41$ & $\mathrm{R} \$ 3,40$ & $\mathrm{R} \$ 3,49$ & $\mathrm{R} \$ 3,40$ & $\mathrm{R} \$ 3,39$ & $\mathrm{R} \$ 3,39$ \\
\hline PAM & $\mathrm{R} \$ 3,70$ & $\mathrm{R} \$ 3,69$ & $\mathrm{R} \$ 3,69$ & $\mathrm{R} \$ 3,69$ & $\mathrm{R} \$ 3,69$ & $\mathrm{R} \$ 3,69$ & $\mathrm{R} \$ 3,68$ \\
\hline TD & $\mathrm{R} \$ 3,61$ & $\mathrm{R} \$ 3,60$ & $\mathrm{R} \$ 3,59$ & $\mathrm{R} \$ 3,58$ & $\mathrm{R} \$ 3,58$ & $\mathrm{R} \$ 3,57$ & $\mathrm{R} \$ 3,56$ \\
\hline PDM & $\mathrm{R} \$ 3,67$ & $\mathrm{R} \$ 3,65$ & $\mathrm{R} \$ 3,64$ & $\mathrm{R} \$ 3,63$ & $\mathrm{R} \$ 3,63$ & $\mathrm{R} \$ 3,61$ & $\mathrm{R} \$ 3,60$ \\
\hline PDF & $\mathrm{R} \$ 2,36$ & $\mathrm{R} \$ 2,33$ & $\mathrm{R} \$ 2,31$ & $\mathrm{R} \$ 2,30$ & $\mathrm{R} \$ 2,30$ & $\mathrm{R} \$ 2,28$ & $\mathrm{R} \$ 2,25$ \\
\hline \multicolumn{8}{|c|}{ Sensibilidade ao Valor do Custo do Proteinado } \\
\hline Características & $-50 \%$ & $-25 \%$ & $-5 \%$ & $0 \%$ & $5 \%$ & $25 \%$ & $50 \%$ \\
\hline PAV & $\mathrm{R} \$ 0,41$ & $\mathrm{R} \$ 0,27$ & $\mathrm{R} \$ 0,15$ & $\mathrm{R} \$ 0,13$ & $\mathrm{R} \$ 0,10$ & $\mathrm{R} \$-0,02$ & $\mathrm{R} \$-0,16$ \\
\hline PAF & $\mathrm{R} \$ 3,55$ & $\mathrm{R} \$ 3,48$ & $\mathrm{R} \$ 3,40$ & $\mathrm{R} \$ 3,49$ & $\mathrm{R} \$ 3,39$ & $\mathrm{R} \$ 3,32$ & $\mathrm{R} \$ 3,25$ \\
\hline PAM & $\mathrm{R} \$ 3,76$ & $\mathrm{R} \$ 3,72$ & $\mathrm{R} \$ 3,70$ & $\mathrm{R} \$ 3,69$ & $\mathrm{R} \$ 3,68$ & $\mathrm{R} \$ 3,65$ & $\mathrm{R} \$ 3,62$ \\
\hline TD & $\mathrm{R} \$ 3,68$ & $\mathrm{R} \$ 3,63$ & $\mathrm{R} \$ 3,59$ & $\mathrm{R} \$ 3,58$ & $\mathrm{R} \$ 3,57$ & $\mathrm{R} \$ 3,53$ & $\mathrm{R} \$ 3,48$ \\
\hline PDM & $\mathrm{R} \$ 3,73$ & $\mathrm{R} \$ 3,68$ & $\mathrm{R} \$ 3,64$ & $\mathrm{R} \$ 3,63$ & $\mathrm{R} \$ 3,62$ & $\mathrm{R} \$ 3,58$ & $\mathrm{R} \$ 3,53$ \\
\hline PDF & $\mathrm{R} \$ 2,49$ & $\mathrm{R} \$ 2,40$ & $\mathrm{R} \$ 2,32$ & $\mathrm{R} \$ 2,30$ & $\mathrm{R} \$ 2,29$ & $\mathrm{R} \$ 2,21$ & $\mathrm{R} \$ 2,12$ \\
\hline \multicolumn{8}{|c|}{ Sensibilidade ao Valor da Receita dos Animais } \\
\hline Características & $-50 \%$ & $-25 \%$ & $-5 \%$ & $0 \%$ & $5 \%$ & $25 \%$ & $50 \%$ \\
\hline PAV & $\mathrm{R} \$-2,01$ & $\mathrm{R} \$-0,94$ & $\mathrm{R} \$-0,09$ & $\mathrm{R} \$ 0,13$ & $\mathrm{R} \$ 0,34$ & $\mathrm{R} \$ 1,19$ & $\mathrm{R} \$ 2,26$ \\
\hline PAF & $\mathrm{R} \$ 1,12$ & $\mathrm{R} \$ 2,26$ & $\mathrm{R} \$ 3,17$ & $\mathrm{R} \$ 3,49$ & $\mathrm{R} \$ 3,63$ & $\mathrm{R} \$ 4,54$ & $\mathrm{R} \$ 5,69$ \\
\hline PAM & $\mathrm{R} \$ 1,58$ & $\mathrm{R} \$ 2,64$ & $\mathrm{R} \$ 3,48$ & $\mathrm{R} \$ 3,69$ & $\mathrm{R} \$ 3,90$ & $\mathrm{R} \$ 4,74$ & $\mathrm{R} \$ 5,80$ \\
\hline TD & $\mathrm{R} \$ 1,29$ & $\mathrm{R} \$ 2,44$ & $\mathrm{R} \$ 3,35$ & $\mathrm{R} \$ 3,58$ & $\mathrm{R} \$ 3,81$ & $\mathrm{R} \$ 4,73$ & $\mathrm{R} \$ 5,87$ \\
\hline PDM & $\mathrm{R} \$ 1,27$ & $\mathrm{R} \$ 2,45$ & $\mathrm{R} \$ 3,40$ & $\mathrm{R} \$ 3,63$ & $\mathrm{R} \$ 3,87$ & $\mathrm{R} \$ 4,82$ & $\mathrm{R} \$ 6,00$ \\
\hline PDF & $\mathrm{R} \$ 0,10$ & $\mathrm{R} \$ 1,20$ & $\mathrm{R} \$ 2,08$ & $\mathrm{R} \$ 2,30$ & $\mathrm{R} \$ 2,52$ & $\mathrm{R} \$ 3,40$ & $\mathrm{R} \$ 4,50$ \\
\hline
\end{tabular}

Peso Adulto da Vaca (PAV); Peso ao Abate de Fêmea (PAF); Peso ao Abate de Macho (PAM);

Taxa de Desmama (TD); Peso a Desmama de Macho (PDM); Peso a Desmama de Fêmea.

Os resultados encontrados com a análise de sensibilidade indicaram que os valores econômicos estimados pelo modelo bioeconômico mostraram-se robustos frente às variações aplicadas nos custos das pastagens, minerais, proteínados e nas fontes de receita, conferindo uma maior confiabilidade na utilização desses como características de objetivo de seleção em sistema de ciclo completo. 


\subsection{Parâmetros Genéticos}

O Estudo de parâmetros genéticos (herdabilidades e correlações) dentro dos programas de avaliação genética é de grande importância, pois fornecem informações importantes que norteiam as estratégias a serem tomadas em prol do maior ganho genético por seleção direta ou indireta na população, avaliando assim, quais características poderiam compor um índice de seleção, além de fornecer outras informações importantes na tomada de decisões dos criadores (MARCONDES et al., 2011).

As estatísticas descritivas das características em estudos foram apresentadas na Tabela 5. As médias estimadas para as características de reprodução, carcaça e produção aproximaram-se aos valores citados pelo programa de melhoramento genético da raça Nelore (LÔBO et al., 2013) e de outros trabalhos avaliados na literatura como o relatado Yokoo et al. (2010) para características produtivas (P120, P210, P354 e P450), Forni e Albuquerque 2005 e Gressler et al., (2005) para as características reprodutivas e Alves et al. (2010) e Yokoo et al. (2010) para as características de carcaça.

As estimativas de herdabilidades para as características reprodutivas PE365, PE450 e IPP (Tabela 121) foram respectivamente $0,46,0,48$ e 0,19 , indicando que se for realizada a seleção direta para estas características ocorrerão ganhos genéticos expressivos. Os valores citados na literatura para perímetro escrotal tiveram uma variação de 0,42 a 0,53 (Pereira; Eler; Ferraz, 2002; Garnero et al., 2002; Dias; El Faro; Albuquerque, 2003; Gianlorenço et al., 2003; Yokoo et al., 2007) e para idade ao primeiro parto de 0,07 a 0,36 (Pereira, Eler and Ferraz (2002) e Dias, El Faro e Albuquerque (2004) o que reforça a ideia que a exploração da variabilidade genética dessas características podem antecipar os ganhos econômicos com animais sexualmente precoces.

Para as da carcaça como AOL, EGP8 e EG as estimativas de herdabilidade foram 0,28, 0,24 e 0,20 respectivamente. Se estas características forem exploradas como critérios de seleção nos programas de melhoramento da raça Nelore podem promover intensas melhorias nas qualidades das carcaças dos animais e consequentemente maiores retornos econômicos ao sistema de produção (Yokoo et al. 2008; Yokoo et al., 2010 e FARIA et al., 2015). 
Tabela 12. Estimativas de componentes de (co) variâncias e parâmetros genéticos e fenotípicos para as características consideradas no estudo.

\begin{tabular}{ccccccc}
\hline Característica & $\sigma_{a}^{2}$ & $\sigma_{m}^{2}$ & $\sigma_{e}^{2}$ & $\sigma_{p}^{2}$ & $h^{2}$ & $h_{m}^{2}$ \\
\hline \hline PE365 & 142,37 & --- & 167,22 & 309,59 & $0,46(0,02)$ & --- \\
PE450 & 268,65 & --- & 283,73 & 552,38 & $0,48(0,02)$ & --- \\
IPP & 2,82 & --- & 12,11 & 14,93 & $0,19(0,02)$ & --- \\
AOL & 0,15 & --- & 0,39 & 0,54 & $0,28(0,02)$ & --- \\
EGP8 & 0,03 & --- & 0,09 & 0,13 & $0,24(0,02)$ & --- \\
EG & 0,02 & --- & 0,08 & 0,10 & $0,20(0,02)$ & --- \\
PN & 5,24 & 0,86 & 5,92 & 12,03 & $0,43(0,02)$ & $0,07(0,01)$ \\
P120 & 88,26 & 38,51 & 128,65 & 255,43 & $0,35(0,02)$ & $0,15(0,01)$ \\
P210 & 294,34 & 82,43 & 240,15 & 449,04 & $0,47(0,02)$ & $0,13(0,01)$ \\
P365 & 237,65 & --- & 357,98 & 595,63 & $0,40(0,02)$ & --- \\
P450 & 212,04 & --- & 492,22 & 704,26 & $0,30(0,02)$ & --- \\
\hline
\end{tabular}

$\sigma_{a}^{2}$ : variância genética aditiva direta; $\sigma_{m}^{2}$ : variância genética aditiva materna; $\sigma_{e}^{2}$ : variância residual; $\sigma_{p}^{2}$ : variância fenotípica; $h^{2}:$ herdabilidade direta; $h_{m}^{2}:$ herdabilidade materna.

O coeficiente de herdabilidade direta para PN, P120, P210, P365 E P450 foram de magnitude moderada $(0,30$ a 0,47$)$. Quando comparado à variação das estimativas destes parâmetros que ocorreu do nascimento do animal até o peso aos 450 dias, os resultados foram similares com os obtidos por Mercadante et al., 1995, Albuquerque e Meyer, 2001, Santos et al., (2012) para a raça Nelore e Dias et al., 2005 na raça Tabapuã, onde as estimativas de herdabilidade diminuíram do nascimento até a idade de desmama e posteriormente aumentaram até aos 450 dias. Diante desses resultados avaliados pode se inferir que as características de peso pré desmame quanto as do pós desmame podem responder positivamente à seleção direta na raça Nelore, com expectativa de rápido ganho genético

As correlações genéticas entre as características de produtivas (PN, P120, P210, P365 E P450) apresentadas na Tabela 13, foram positivas e de altas magnitudes e estão acima dos $90 \%$ logo após os 120 dias de idade. 
Tabela 13. Estimativas de herdabilidade (diagonal principal), correlações genética (acima da diagonal) e fenotípica (abaixo da diagonal) para as características consideradas no estudo.

\begin{tabular}{cccccccccccc}
\hline Caract. & PE365 & PE450 & IPP & AOL & EGP8 & EG & PN & P120 & P210 & P365 & P450 \\
\hline PE365 & $\mathbf{0 , 4 6}$ & 0,96 & $-0,34$ & 0,18 & 0,06 & 0,06 & $-0,005$ & 0,41 & 0,44 & 0,35 & 0,33 \\
PE450 & 0,85 & $\mathbf{0 , 4 8}$ & $-0,35$ & 0,21 & 0,03 & 0,21 & $-0,04$ & 0,35 & 0,38 & 0,28 & 0,28 \\
IPP & $-0,10$ & $-0,10$ & $\mathbf{0 , 1 9}$ & $-0,02$ & $-0,13$ & $-0,35$ & 0,25 & $-0,11$ & $-0,17$ & 0,01 & $-0,04$ \\
AOL & 0,22 & 0,10 & 0,08 & $\mathbf{0 , 2 8}$ & 0,09 & 0,18 & $-0,03$ & 0,40 & 0,55 & 0,54 & 0,52 \\
EGP8 & 0,05 & 0,06 & $-0,13$ & 0,21 & $\mathbf{0 , 2 4}$ & 0,61 & $-0,13$ & $-0,13$ & $-0,07$ & 0,03 & 0,05 \\
EG & 0,05 & 0,10 & $-0,14$ & 0,22 & 0,53 & $\mathbf{0 , 2 0}$ & $-0,12$ & 0,11 & 0,20 & 0,18 & 0,18 \\
PN & 0,005 & $-0,02$ & 0,08 & 0,02 & $-0,03$ & $-0,02$ & $\mathbf{0 , 4 3}$ & 0,22 & 0,31 & 0,26 & 0,30 \\
P120 & 0,32 & 0,31 & 0,10 & 0,30 & 0,01 & 0,08 & 0,26 & $\mathbf{0 , 3 5}$ & 0,94 & 0,93 & 0,98 \\
P210 & 0,13 & 0,11 & $-0,03$ & 0,13 & $-0,01$ & 0,04 & 0,23 & 0,87 & $\mathbf{0 , 4 7}$ & 0,97 & 0,92 \\
P365 & 0,46 & 0,43 & $-0,12$ & 0,47 & 0,12 & 0,16 & 0,21 & 0,71 & 0,79 & $\mathbf{0 , 4 0}$ & 0,98 \\
P450 & 0,43 & 0,45 & $-0,16$ & 0,51 & 0,18 & 0,17 & 0,22 & 0,66 & 0,90 & 0,90 & $\mathbf{0 , 3 1}$ \\
\hline
\end{tabular}

Erro padrão variou de 0,01 a 0,02

Os valores altos obtidos para estimativas das correlações genéticas indicam que grande proporção de genes responsáveis pela expressão do peso aos 120 dias também são responsáveis pela expressão dos pesos aos 210, 365 e 450 dias de idade. Portanto os animais com maior potencial genético para peso corporal após os 120 dias também possuem maior potencial genético para peso nas idades mais avançadas, estabelecendo que possam ocorrer benefícios à cadeia produtiva quando for praticada a seleção de animais precoces, reduzindo número de pesagens e antecipando o descarte de animais indesejáveis para sistema de produção. Estimativas semelhantes de correlação genética entre P210 e P365 dias obtidas para bovinos da raça Nelore reforçam essa hipótese. Boligon et al. (2009) e Yokoo et al. (2007) obtiveram correlações favoráveis entre P210 e P365 de 80\% e 94\% respectivamente. As correlações genéticas estimadas por Yokoo et al. (2010) para P210 e P450 e P365 e P450 foram respectivamente $95 \%$ e 99\% na raça Nelore. LÔBO et al., 2002 estudaram os pesos aos doze (P12), dezoito (P18), vinte e quatro (P24) e trinta meses (P30) de idade e estimaram as correlações genéticas com o peso de abate, obtendo os valores de 0,77, 0,70, 0,60 e 0,53 respectivamente. Estimaram também as correlações genéticas dos (P12, P18, P24 e P30) com o peso da carcaça $(0,72,0,67,0,56$ e 0,47$)$.

Para as características reprodutivas as estimativas das correlações genéticas foram favoráveis (Tabela 13). A correlação genética entre PE365 e PE450 foi de 0,96, concordando com os valores obtidos por Gressler et al., (2000) indicando que a seleção para o tamanho da circunferência escrotal pode ser realizada aos 365 dias de idade. As correlações genéticas entre as medidas de perímetro escrotal (PE365 e PE450) em machos e as medidas de idade ao primeiro parto (IPP) em fêmeas, foram $-0,34$ e $-0,35$, respectivamente. Estes resultados estão dentro do intervalo encontrado na literatura (de 0,22 a -1,00) (Gressler et al., 2000, Pereira; 
Eler; Ferraz 2000 e Dias et al., 2003) demonstrando que pode-se ter ganhos genéticos indiretos na precocidade de fêmeas com a seleção para perímetro escrotal (PE) em machos, o que é economicamente viável ao sistema de produção, pela facilidade e economia nas medidas obtidas em machos.

Os resultados obtidos para correlações genéticas das características de carcaça foram 0,09 e 0,18 respectivamente entre AOL e EGP8 e entre AOL e EG. Valores considerados de baixa magnitude apesar de ser de sentido favorável para a seleção. A correlação genética entre EGP8 e EG foi de 0,61. Zuin et al., 2012 estimaram valores muito próximos entre AOL e EGP8 (0,09), AOL e EG (0,18). Esses resultados são biologicamente esperados já que o crescimento muscular na carcaça dos animais acontece primariamente à deposição de gordura, explicando assim as baixas associações entre AOL e EG.

As estimativas das correlações genéticas entre a idade ao primeiro parto e os pesos aos 120, 210, 365 e 450 dias foram de baixa magnitude favoráveis. Caetano et al., 2013 na raça Nelore e Talhari et al., (2003) na raça Canchim, também obtiveram estimativas favoráveis e baixas para estas características demonstrando que existem associações favoráveis, ainda que pequena, entre o desenvolvimento ponderal e a precocidade sexual das fêmeas. As correlações genéticas também contribuiriam para a precocidade sexual das fêmeas. As correlações genéticas das características reprodutivas avaliadas nos machos (PE365 e PE450) com PN foram praticamente nulas e com os pesos após os 120 dias de idade variaram de baixas a moderada $(0,28$ a 0,44$)$, indicando que a seleção de touros para maiores perímetros pode identificar também animais de maior potencial genético para crescimento ponderal (Castro Pereira et al., 2007; Regatieri et al., 2012).

Para a AOL as correlações genéticas com os pesos dos 120 até os 450 dias de idade foram positivas e favoráveis variando de 0,40 a 0,55 (Tabela 13). Esses valores positivos demonstram que animais com maior potencial de crescimento tendem a ter a carcaça com maior deposição muscular, promovendo um maior rendimento de carcaça e consequentemente maior valorização do produto (Yokoo et al., 2010). As associações genéticas da EGP8 com os pesos do nascimento até o desmame foram negativas e com P365 e P450 foram praticamente nulas. A correlação genética entre EG e PN foi negativa e entre EG e os pesos dos 120 ate 450 dias foram positivas e favoráveis $(0,11$ a 0,20$)$, indicando que a associação genética entre o peso e a deposição de gordura é positiva e de baixa magnitude.

As estimativas das correlações genéticas da AOL com PE365 e PE450, foram positivas e favoráveis $(0,18$ e 0,21 respectivamente). A seleção para perímetro escrotal, que 
vem sendo praticada nos animais avaliados neste trabalho, deve estar promovendo incrementos, ainda que pequenos, na AOL, enquanto a seleção para IPP deve estar afetando a AOL, pois a correlação genética entre IPP e AOL foi praticamente nula (Tabela 11).

Associações genéticas negativas e moderadas foram estimadas para IPP com as características EGP8 e EG. A seleção de fêmeas precoces sexualmente deve promover carcaça de animais com pouco acabamento de gordura. A seleção para perímetro escrotal aos 365 e aos 450 dias de idade deve afetar muito pouco o acabamento das carcaças quanto à deposição de gordura (EG). Estes resultados estão de acordo com os resultados obtidos por Barbosa et al., 2010, porém foram contrários aos resultados obtidos por Marques et al., 2013 também na raça Nelore que estimaram correlação genética negativa entre perímetro escrotal e EG (-0,04).

As estimativas de tendências genéticas apresentadas na Tabela 14 permitem avaliar como o processo de seleção está alterando os valores genéticos médios ao longo dos anos e assim testar a eficácia dos índices de seleção propostos para as características selecionadas.

Tabela 14. Estimativas de tendência genéticas para as características consideradas no estudo.

\begin{tabular}{cccc}
\hline Características & Coeficiente de Tendência & Erro Padrão & $\begin{array}{c}\text { Unidade da } \\
\text { variável }\end{array}$ \\
\hline \hline PE365 & 0,0360 & 0,01000 & $\mathrm{~cm} / \mathrm{ano}$ \\
\hline PE450 & 0,0500 & 0,02000 & $\mathrm{~cm} / \mathrm{ano}$ \\
\hline IPP & $-0,0100$ & 0,00200 & $\mathrm{mês} / \mathrm{ano}$ \\
\hline AOL & 0,0020 & 0,00010 & $\mathrm{~mm} / \mathrm{ano}$ \\
\hline EGP8 & 0,0001 & 0,00009 & $\mathrm{~mm} / \mathrm{ano}$ \\
\hline EG & 0,0003 & 0,00006 & $\mathrm{~mm} / \mathrm{ano}$ \\
\hline PN & 0,1950 & 0,00500 & $\mathrm{~kg} / \mathrm{ano}$ \\
\hline P120 & 0,5680 & 0,01000 & $\mathrm{~kg} / \mathrm{ano}$ \\
\hline P210 & 0,3830 & 0,00800 & $\mathrm{~kg} / \mathrm{ano}$ \\
\hline P450 & 0,5910 & 0,02000 & $\mathrm{~kg} / \mathrm{ano}$ \\
\hline
\end{tabular}

A seleção realizada nos machos para maior perímetro escrotal aos 365 e 450 dias de idade que vem sendo praticada nos rebanhos estudados proporcionou ganhos genéticos anuais na ordem de $0,036 \mathrm{~cm} /$ ano e $0,050 \mathrm{~cm} /$ ano $(\mathrm{P}<0,0001)$ respectivamente. Nas fêmeas foram obtidas tendências anuais de $-0,01$ mês/ano $(\mathrm{P}<0,0001)$, para idade ao primeiro parto, representando redução de $0,02 \%$ da média de IPP por ano, nos animais participantes do programa Nelore Brasil. Portanto, a seleção direta praticadas nos machos e fêmeas para precocidade sexual está promovendo mudanças lineares significativas nos valores genéticos dos animais avaliados.

As características de carcaça avaliadas nesse estudo apresentaram ganhos genéticos anuais positivos de 0,002 mm/ano para AOL, 0,0001 mm/ano para EGP8 e 0,0003 mm/ano 
para EG, evidenciando que nestas características houve progresso genético significativo ( $\mathrm{P}<0,0001)$ no período de avaliação dos animais que foi de 1998 a 2008. Zuin et al., (2012) trabalhando com o mesmo banco de dados, porém, com um período de avaliação maior (1978 até 2008), relataram que em relação a média geral do programa Nelore Brasil a tendência genética para AOL, EGP8 e EG diminuiu significativamente. No mesmo trabalho os autores reduziram o período e estudaram animais nascidos entre 1994 até 2008 e obtiveram tendência genética para AOL com aumento de $0,02 \%$ em relação a media geral.

As tendências genéticas para as características de crescimento foram: 0,195 kg/ano para PN; 0,568 kg/ano para P120, 0,383 kg/ano para P210, 0,591 kg/ano para P365 e 0,672 kg/ano para $\mathrm{P} 450(\mathrm{P}<0,0001)$ no período de 1998 a 2008. Estas estimativas foram superiores aos reportados por Sena et al., 2013 que também encontraram mudanças genéticas positivas nas características para a Raça Nelore avaliadas nas regiões da Amazônia Legal no período de 1995 a 2008.

Em síntese, as estimativas de parâmetros genéticos encontradas nesse estudo e as revisadas na literatura evidenciam que as características estudadas podem ser utilizadas como critérios de seleção nos programas de melhoramento animal. Segundo Queiroz et al. (2005), as características incluídas no índice, como critérios de seleção, devem apresentar facilidade de mensuração em idade precoce na vida do animal e ser de baixo custo de obtenção, além de que essas devem apresentar estimativas de herdabilidade de mediana a alta e estarem de certa forma contribuindo com os ganhos genéticos indiretos para com as características do objetivo de seleção.

Para Goddard e Thompson (1998), quanto maior for à correlação entre as características do objetivo e as definidas como critério maior seria a maximização das respostas quando a seleção for praticada empregando-se um índice de seleção. Portanto novas características devem ser avaliadas quanto ao seu potencial genético e econômico para que facilite as definições dos objetivos e critérios de seleção para a raça Nelore, permitido estudos de composições de índices de seleções econômicos que maximizem a resposta econômica para os sistemas de produção de bovinos de corte no Brasil.

Estudar quais as características importantes para melhorar a eficiência econômica dos sistemas de produção brasileiros é muito importante e difícil, no entanto precisa ser implementado para auxiliar na definição de objetivos e critérios de seleção. A importância que deve ser dada a cada característica e quando é conveniente que cada uma seja utilizada no processo de seleção, devem ser melhor estudadas. 
Com o aumento do número de programas de avaliação genética de bovinos de corte no Brasil, é necessário buscar-se continuamente novos critérios de seleção, para que a eficiência produtiva seja aumentada, no entanto, incluir novos critérios de seleção nos programas de avaliação genética, só dever ser feito após os estudos das suas relações com características ligadas à eficiência produtiva de todo o sistema. 


\section{Conclusão}

O modelo bioeconômico foi eficaz na estimação das fontes de receitas e despesas do sistema de produção e os valores econômicos promoveram retorno econômico positivo no sistema de bovinos de corte em ciclo completo com exceção do PAV que foi praticamente nulo.

A análise de sensibilidade indicou que os valores econômicos estimados pelo modelo bioeconômico mostraram-se robustos frente às variações aplicadas nos custos das pastagens, minerais, proteínado e nas fontes de receita, conferindo uma maior confiabilidade na utilização desses como características de objetivo de seleção neste sistema de ciclo completo.

As estimativas de herdabilidade para as características de produção, reprodução e qualidade de carcaça foram favoráveis ao progresso genético por seleção direta. E o processo de seleção empírica utilizada pelo programa Nelore Brasil está sendo eficiente, de acordo com os resultados positivos dos progressos genéticos nas estimativas de tendência.

Todas as características avaliadas no sistema de ciclo completo tiveram importância econômica positivas, indicando que o processo de seleção trariam aumentos de lucratividade e as avaliadas geneticamente poderiam ser incluídas como critério de seleção contribuindo com a maximização da resposta esperadas para as características do objetivo de seleção. 
Referências Bibliográficas 


\section{Referências Bibliográficas}

ALBUQUERQUE, L. G.; MEYER, K. Estimates of direct and maternal genetic effects for weights from birth to 600 days of age in Nelore cattle. Journal of Animal Breeding and Genetics, v. 118, p.83-92, 2001.

ALVES, D. N.; FARIA, C. U.; LÔBO, R. B. Correlações fenotípicas entre crescimento e características de carcaça medidas por ultra-sonografia em bovinos Nelore mocho criados em bioma cerrado. In. SIMPÓSIO NACIONAL EM CIÊNCIA ANIMAL, 1., 2010, Uberlândia. Anais... Uberlândia: Universidade Federal de Uberlândia, 2010.

ANUALPEC (2013). Anuário da pecuária brasileira. FNP Consultoria e Comércio 378.

BARBOSA, V.; MAGNABOSCO, C. U.; TROVO, J. B. F.; FARIA, C. U.; LOPES, D. T.; VIU, M. A. O.; LÔBO, R. B.; MAMEDE, M. M. S. Estudo genético quantitativo de característica de carcaça e perímetro escrotal, utilizando inferência bayesiana em novilhos Nelore. Bioscience Journal, v. 26, p. 789 - 797, 2010.

BITTENCOURT, T. C. C; LÔBO, R. B; BEZERRA, L. A.F. Objetivos de seleção para sistemas de produção de gado de corte em pasto: ponderadores econômicos. Arquivos Brasileiros de Medicina Veterinária e Zootecnia, v.58, n.2, p.196 - 204, 2006.

BOligOn, A. A.; AlBUQUeRQUE, L. G.; RORATO, P. R. N (2008). Associações genéticas entre pesos e características reprodutivas em rebanhos da raça Nelore. Revista Brasileira de Zootecnia, v. 37; n. 4; p. 596 - 601, 2008.

BOligon, A. A.; AlbuQuerque, L. G.; MerCADANTE, M. E. Z.; LÔBO, R. B. Herdabilidades e correlações entre pesos do nascimento à idade adulta em rebanhos da raça Nelore. Revista Brasileira de Zootecnia, v. 38, p. 2320 - 2326, 2009.

BOURDON, R. M. Shortcomings of current genetic evaluation systems. Journal Animal Science, v.76, n.9, p.2308 - 2323, 1998. 
BRUMATTI, R. C.; FERRAZ, J. B. S.; ELER, J. P.; FORMIGONNI, I. B. Desenvolvimento de índice de seleção em gado de corte sob o enfoque de um modelo bioeconômico. Archivos de Zootecnia, v.60, p.205 - 213, 2011.

CAETANO, S. L.; SAVEGNAGO, R. P.; BOLIGON, A. A.; RAMOS, S. B.; CHUD, T. C. S.; LÔBO, R. B.; MUNARI, D. P. Estimates of genetic parameters for carcass, growth and reproductive traits in Nellore Cattle. Livestock Science, v. 155, p. 1 - 7, 2013.

CAMPOS, G. S.; BRACCINI NETO, J.; OIAGEN, R. P.; CARDOSO, F. F.; COBUCI, J. A.; KEM, E. L.; CAMPOS, L. T.; BERTOLI, C. D.; McManus, C. M. Bioeconomic model and selection índices in Aberdeen Angus cattle. Journal Animal Breeding Genetics, p. 1 - 8, 2014.

CASTRO-PEREIRA, V. M.; ALENCAR, M. M.; BARBOSA, R. T. Estimativas de parâmetros genéticos e de ganhos diretos e indiretos a seleção para características reprodutivas e de crescimento em um rebanho da raça Canchim. Revista Brasileira de Zootecnia, v. 36, p. 1029-1036, 2007.

DIAS, L.T.; EL FARO, L.; ALBUQUERQUE, L.G. Estimativas de herdabilidade para perímetro escrotal de animais da raça Nelore. Revista Brasileira de Zootecnia. V. 32, p.1878-1882, 2003 (Supl.2).

DIAS, L.T.; EL FARO, L.; ALBUQUERQUE, L.G. Efeito da idade de exposição d novilhas à reprodução sobre estimativas de herdabilidade da idade ao primeiro parto em bovinos Nelore. Arquivos Brasileiros de Medicina Veterinária e Zootecnia. V. 56, p. 370-373, 2004.

DIAS, L. T.; AlbuQUERQUE, L. G.; TONHATI, H.; TEIXEIRA, R. A. Estimação de parâmetros genéticos para peso em diferentes idades para animais da raça Tabapuã. Revista Brasileira de Zootecnia, v. 34, p. 1914 - 1919, 2005.

DICKERSON G. Efficiency of animal production - Molding the biological components. Journal Animal Science, v.30, p.849-859, 1970. 
EMBRAPA - Empresa Brasileira de Pesquisa Agropecuária - Gado de corte. Disponível em: http://www.embrapa.br/a_embrapa/unidades-de-pesquisa-e-de-servicos/unidades-de-pesquisa -de-produtos/cnpgc/ . Acesso em outubro de 2013.

Euclides Filho, k (2008). A pecuária de corte no cerrado brasileiro. In: Faleiro, F. G.; Neto A. L. F. Savanas: desafios e estratégias para o equilíbrio entre sociedade, agronegócio e recursos naturais. Planaltina, DF: Embrapa Cerrados; Brasília, DF: Embrapa Informação Tecnológica, 2008, 1198p.

FARIA, C. U.; ANDRADE, W. B. F.; PEREIRA, C. F.; SILVA, R. P.; LÔBO, R. B. Análise bayesiana para características de carcaça avaliadas por ultrassonografia de bovinos da raça Nelore Mocho, criados em bioma Cerrado. Ciência Rural, v. 45, p. 317 - 322, 2015.

FERNANDEZ-PEREA, M. T.; JIMÉNEZ A. R. Economic weights for a selections index in Avileña purebred beef cattle. Livestock Production Science, v. 89, p. 223 -233, 2004.

FORMIGONI, I. B.; FERRAZ, J. B. S.; SILVA, J. A. II. V.; ELER, J. P.; BRUMATTI, R. C. Valores econômicos para habilidade de permanência e probabilidade de prenhez aos 14 meses em bovinos de corte. Arquivos Brasileiros de Medicina Veterinária e Zootecnia, v.57, p.220 - 226, 2005. Supl.2.

FORNI, S.; ALBUQUERQUE, L. G. Estimates of genetic correlations between days to calving and reproductive and weight traits in Nellore cattle. Journal Animal Science, v. 83, p.1511-1515, 2005.

GARNERO, A. D. V.; FERNANDES, M. B.; FIGUEIREDO, L. F. C.; LÔBO, R. B. Influência da incorporação de dados de progênies na classificação de touros da raça Nelore. Revista Brasileira de Zootecnia. V. 31, p.918-923, 2002.

GIANLORENÇO, V. K P.; ALENCAR, M. M.; TORAL, F. L. B.; MELLO, S. P. M.; FREITAS, A. R.; BARBOSA, P. F. Herdabilidades e correlações genéticas de características de machos e fêmeas, em um rebanho bovino da raça Canchim. Revista Brasileira de Zootecnia. V. 32, P. 1587-1593, 2003. 
GIBSON, J. P.; WILTON, J. W. Defining multiple-trait objectives for sustainable genetic improvement. Journal Animal Science, v. 76, p. 2303 - 2307, 1998.

GRESSLER, S. L.; BERGMANN, J. A.; PEREIRA, C. S.; PENNA, V. M.; PEREIRA, J. C.; GRESSLER, M. G. M. Estudos das associações genéticas entre perímetro escrotal e características reprodutivas de fêmeas Nelore. Revista Brasileira de Zootecnia. V.29, p.427437, 2000.

GRESSleR, M. G. M., PEREIRA, J. C. C., BERGMANN, J. A. G., ANDRADE, V. J.; PAULINO, M. F.; GRESSLER, S. L. Aspectos genéticos do peso à desmama e de algumas características reprodutivas de fêmeas Nelore. Arquivos Brasileiros de Medicina Veterinária e Zootecnia, v. 57, p.533-538, 2005.

GROEN, A. B. Economic values in cattle breeding. II. Influences of production circumstances in situations with output limitations. Livestock Production Science, v. 22, p. 17- 30, 1989.

GROEN, A. F., STEINE, T., COLlEAU, J. J., PEDERSEN, J., PRIBYL, J., REINSCH, N. Economic values is dairy cattle breeding, with special reference to functional traits. Report of an EAAP - working group. Livestock Production Science, v. 49, 1- 21, 1997.

HARRIS, D. L. Breeding for efficiency in livestock production: defining the economic objectives. Journal Animal Science, v.30, p. 860 - 865, 1970.

HAZEL, L. N. The genetic basis of constructing selection index. Genetics, v.28, p.476-90, 1943.

JORGE JUNIOR, J.; CARDOSO, V. L.; ALBUQUERQUE, L. G. Modelo bioeconômico para cálculo de custo e receitas em sistemas de produção de gado de corte visando à obtenção de valores econômicos de características produtivas e reprodutivas. Revista Brasileira de Zootecnia, v. 35, p. $2187-2196,2006$.

JORGE JUNIOR, J.; CARDOSO, V. L.; ALBUQUERQUE, L. G. Objetivos de seleção e valores econômicos em sistemas de produção de gado de corte no Brasil. Revista Brasileira de Zootecnia, v.36, n.5, p.1549 - 1558, 2007. 
LASKE, C. H.; TEIXEIRA, B. B. M.; DIONELLO, N. J. L.; CARDOSO, F. F. Breeding objectives and economic values for traits of low input Family - based beef cattle production system in the State of Rio Grande do Sul. Revista Brasileira de Zootecnia, v. 41, p. 298 $305,2012$.

LÔBO, R. N. B.; MARTINS, J. A. M., MALHADO, C. H. M., FILHO R. M.; MOURA, A. A. A. Correlações entre características de crescimento, abate e medidas corporais em tourinhos da raça Nelore. Revista Ciência agronômica, v. 33, n. 2, p. 5 - 12, 2002.

LÔBO, R. B.; BEZERRA, L. A. F.; OLIVEIRA, H. N.; FREITAS, M. A. R.; PENNA, V. M.; VOZZI, P. A.; BERGMANN, J. A. G.; FARIA, C. U.; OLIVEIRA, H. N. Avaliação Genética de Touros da da Raça Nelore, Guzerá, Brahman e Tabapuã: Sumário 2013. Ribeirão Preto, ANCP. 172 p., 2013.

MARCONDES, C. R.; ARAÚJO, R. O.; VOZZI, P. A.; GUNSKI, R. J.; GARNERO, A. del V.; LÔBO, R. B. Análise bayesiana do índice perímetro escrotal/peso de animais Nelore do estado do Tocantins, Brasil. Archivos de Zootecnia, v. 60, n. 232, p. 871 - 882, 2011.

MARQUES, E. G.; MAGNABOSCO, C. U.; LOPES, F. B.; SILVA, M. C. Estimativa de parâmetros genéticos de características de crescimento, carcaça e perímetro escrotal de animais da raça Nelore avaliados em provas de ganho em peso em confinamento. Bioscence Journal, v. 29, p. $159-167,2013$.

MENDES, J. T. G.; PADILHA, JR., J. B. Agronegócio: uma abordagem econômica. São Paulo: Pearson Prentice Hall, 2007, 369p.

MERCADANTE, M. E. Z.; LÔBO, R. B.; REYES, A. de los. Parâmetros genéticos para características de crecimiento em cebuíno de carne. Archivos Latinoamericano Producción Animal, v.3, p.45 - 89, 1995.

MEYER, K. WOMBAT - A tool for mixed model analyses in quantitative genetics by restricted maximum likelihood (REML). Journal of Zhejiang University Science B. v. 8, p. 815 - 821, 2007. 
PEREIRA, E.; ELER, J. P.; FERRAZ, J. B. S. Correlação genética entre perímetro escrotal e algumas características reprodutivas na raça Nelore. Revista Brasileira de Zootecnia. V. 29, p. 1676-1683, 2000.

PEREIRA E.; ELER J.P.; FERRAZ J.B.S. Análise genética de características reprodutivas na raça Nelore. Pesquisa Agropecuária Brasileira, v.37, p.703-708, 2002.

PHOCAS, F.; BLOCH, C.; CHAPELLE, P. Developing a breeding objective for a French purebred beef cattle selection programme. Livestock Production Science, v. 57, p. 49 - 65, 1998.

PONZONI, R. W.; NEWMAN, S. Developing breeding objectives for Australian beef cattle production. Animal Production, v.49, p.35 - 47, 1989.

QUEIROZ, S. A.; PELICIONI, L. C.; SILVA, B. F.; SESANA, J. C.; MARTINS, M . I. E. G.; SANCHES, A (2005). Índices de seleção para um rebanho Caracu de duplo propósito. Revista Brasileira de Zootecnia, v. 34, n. 3, p. 827 - 837, 2005.

REGATIEIRI, I. C.; BOLIGON, A. A.; BALDI, F.; ALBUQUERQUE, L. G. Genetic correlation between mature cow weight and productive and reproductive traits in Nellore cattle. Genetics and Molecular Research, v. 11, p. 2979 - 2986, 2012.

SANTOS, N. P. S.; FILHO, L. A. S.; SARMENTO, J. L. R.; FILHO, R. M.; BIAGIOTTI, D.; NETO, A. A. R (2012). Estimação de parâmetros genéticos de pesos em diferentes idades de bovinos da raça Nelore criados no meio norte do Brasil usando amostragem de gibbs. Acta Tecnológica, v. 7, p. $1-7,2012$.

SENA, J. S. S.; MATOS, A. S.; MARCONDES, C. R.; BEZERRA, L. A. F.; LÔBO, R. B. Parâmetros genéticos, tendências e resposta a seleção de características produtivas da raça Nelore na Amazônia legal. Atas de Saúde Ambiental, v. 1, p. 2-12, 2013.

TALHARI, F. M.; ALENCAR, M. M.; MASCIOLI, A. S.; SILVA, A. M.; BARBOSA, P. F. Correlações genéticas entre características produtivas de fêmeas em um rebanho da Raça Canchim. Revista Brasileira de Zootecnia, v. 32, p. 880 - 886, 2003. 
URIOSTE, J. I.; PONZONI, R. W.; AGUIRREZABALA, M. ROVERE, G. SAAVEDRA, D. Breeding objectives for pasture fed Uruguayan beef cattle. Journal Animal Breeding Genetics, v.115, p. $357-373,1998$.

WOLFAVÁ, M.; WOLF, J. Strategies for defining traits when calculating economic values for livestock breeding: a review. Animal, v.7, p. 1401 - 1413, 2013.

YOKOO, M. J. I.; ALBUQUERQUE, L. G.; LÔBO, R.B.; SAINZ, R. D.; JÚNIOR, J. M. C.; BEZERRA, L. A. F.; ARAUJO, F. R. C. Estimativas de parâmetros genéticos para altura do posterior, peso e circunferência escrotal em bovinos da raça Nelore. Revista Brasileira de Zootecnia, v. 36, n. 6, p. 1761 - 1768, 2007.

YOKOO, M. J. L.; ALBUQUERQUE, L. G.; LÔBO, R. B.; ARAUJO, F. R. C.; SILVA, J. A. V.; SAINZ, R. D. Genetic and environmental factors affecting ultrasound measures of longissimus muscle area and backfat thickness in Nelore cattle. Livestock Science, v. 117, p.147-154, 2008.

YOKOO, M. J.; LÔBO, R. B.; ARAUJO, F. R. C.; BEZERRA, L. A. F.; SAINZ, R. D.; ALBUQUERQUE, L. G. Genetic associations between carcass traits measured by real-time ultrasound and scrotal circumference and growth traits in Nelore cattle. Journal Animal Science, v. 88, p. 52-58, 2010.

ZUIN, R. G.; BUZANSKAS, M. E.; CAETANO, S. L.; VENTURINI, G. C.; GUIDOLIN, D. G. F.; GROSSI, D. A.; CHUD, T. C. S.; PAZ, C. C. P.; LÔBO, R. B.; MUNARI, D. P (2012). Genetic analysis on growth and carcass traits in Nelore cattle. Meat Science, v. 91, p. 352 357, 2012. 
Anexos 


\section{AHIEXOST.}

7.1 Planilha: Modelo Bioeconômico

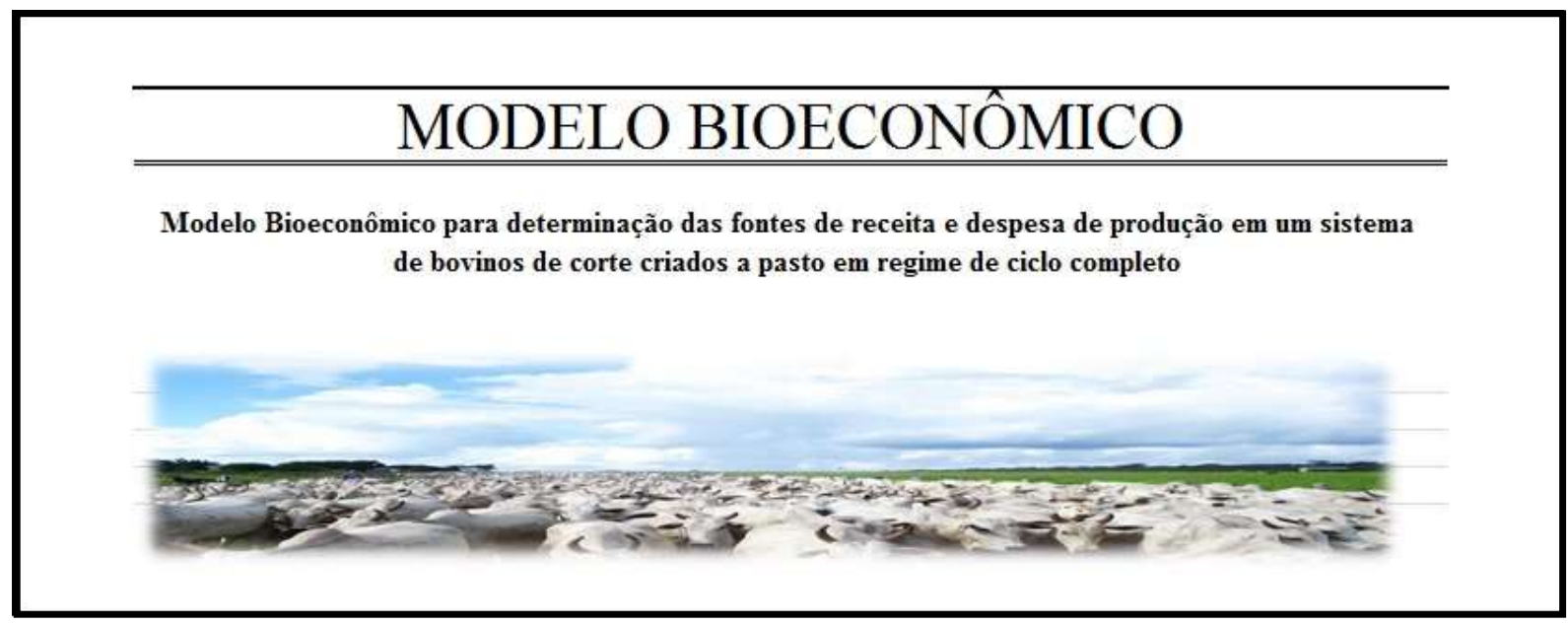


7.2 Planilha: Parâmetros Zootécnicos

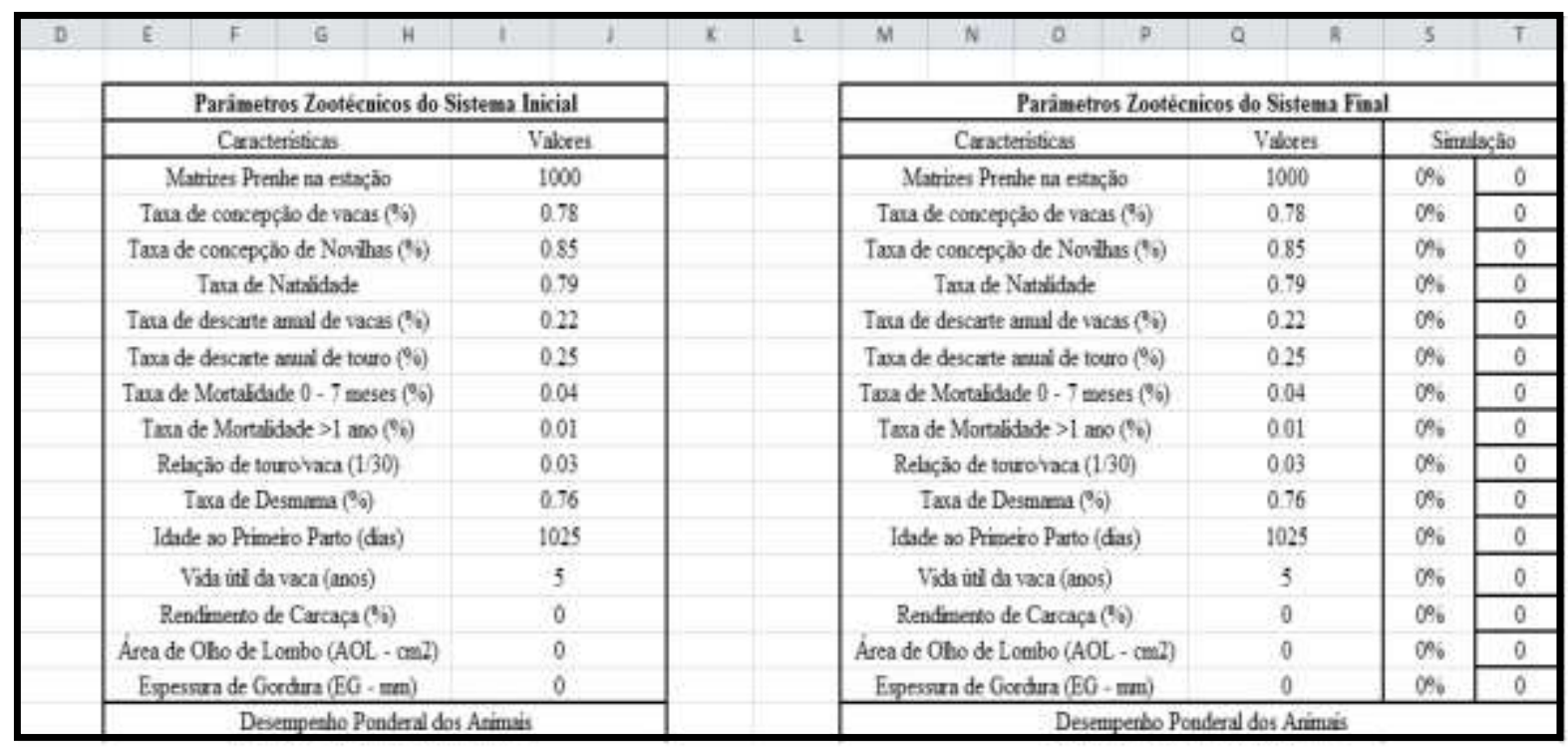


7.3 Planilha: Evolução do Rebanho

\begin{tabular}{|c|c|c|c|c|c|c|c|c|c|c|c|c|c|}
\hline \multirow[b]{3}{*}{ Catagoreas Animass } & Ano 10 & \multirow{2}{*}{\multicolumn{11}{|c|}{ 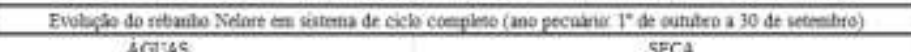 }} & \multirow{3}{*}{$\begin{array}{l}A=0 \text { II } \\
\text { Out }\end{array}$} \\
\hline & \multirow{2}{*}{ Out } & & & & & & & & & & & SECA & \\
\hline & & $\mathrm{Nor}$ & DeI & 120 & Fev & stex & $A B G$ & $30 x$ & fun & fue & $A \times 0$ & Set & \\
\hline Prenter Poemina & & & & & & & 1000 & 1000 & 1000 & 1000. & 1000 & 1000 & \\
\hline Maxizes em EM & & 1258 & 1258 & 1258 & & & & & & & & & \\
\hline Vacas & 990. & 990 & 990 & 990 & 950 & 990 & & & & & & & 950 \\
\hline Noullas Expostas & 267 & 267 & $26 ?$ & 267 & 367 & $26 ?$ & & & & & & & 263 \\
\hline Towos & 42 & 42 & +2 & 42 & 42 & 42 & 31 & 31 & 31 & 31 & 31 & 31 & 42 \\
\hline Bezerras $0-12$ moset & 497 & 497 & 497 & 407 & 497 & 497 & 478 & 478 & 471 & 478 & 478 & 475 & 497 \\
\hline Northu $12-24$ meess & 473 & 473 & 473 & 473 & 473 & 473 & 473 & 473 & 473 & 473 & 473 & 473 & 473 \\
\hline Norzas 34 - 36 maver & & & & & & & & & & & & & \\
\hline Bexerros 6-12 mates & 497 & 497 & 407 & 497 & 497 & 497 & 475 & 478 & 478 & 478 & 478 & 478 & 497 \\
\hline Gueroese 12 - 24 meses & 473 & 473 & 473 & 473 & 473 & 473 & 473 & 473 & 473 & 473 & 473 & 473 & 473 \\
\hline Sordhos 24.36 mmes & 488 & & & & & & & & & & & & 400 \\
\hline Descarte de vacas (venter) & & & & & & & 218 & & & & & & \\
\hline Fenexs 24 . 36 meses Prenthez & & & & & & & & & & & & & \\
\hline Fenas 24 - 36 meses vacias & 288 & 201 & 201 & 201 & 201 & 201 & 241 & $24 t$ & $24 t$ & 241 & 241 & 241 & 219 \\
\hline Estoqun de machos $24-36 \mathrm{~mm}$ & 464 & 468 & 468 & 468 & 468 & 468 & 465 & 463 & 468 & 468 & 468 & 468 & 464 \\
\hline Descrase de Touros & & & & & & & 10 & & & & & & \\
\hline Todx de anminti & 3709 & & & & & & $36+4$ & & & & & & 3709 \\
\hline Tolal do Lnidades Atmuis (LA) & 2724 & & & & & & 2650 & & & & & & 2724 \\
\hline
\end{tabular}




\subsection{Planilha 3: Planejamento Nutricional}

\begin{tabular}{|c|c|c|c|c|c|c|c|c|c|c|c|c|}
\hline \multicolumn{13}{|l|}{ ANTES MELLHORAMENTO } \\
\hline CATECORIA AVALIADA & & & $\mathrm{CAT}$ & EOORLA & VACAS & -NOVIIH & $\overline{A S-B E Z}$ & ERROS L & ACTANTH & & & \\
\hline MESESS & OUT & NOV & DEZZ & IAN & FEV & MAR & ABR & MA1 & $\pi N$ & $\pi \mathrm{r}$ & $A G O$ & SET \\
\hline $\mathrm{N}^{2}$ de Vacas (ab) & 990 & 990 & 90 & 950 & 90 & 900 & $m$ & 772 & $\pi 2$ & $7 \pi$ & $\pi 7$ & $m$ \\
\hline$N^{0}$ de Novithas $(\mathrm{cath})$ & 268 & 263 & 268 & 263 & 268 & 263 & 228 & 228 & 228 & 228 & 228 & 228 \\
\hline No de bezerras het (cab) & 497 & 497 & 497 & 497. & 497 & 497 & & & \multirow{2}{*}{\multicolumn{2}{|c|}{ DESMAMADOS }} & & \\
\hline$W^{2}$ de tezeroús lact (cab) & 497 & 497 & 497 & 497 & 497 & 497 & & & & & & \\
\hline PESO VTVO Vaces (kg) & 450 & 450 & 450 & 450 & 450 & 450 & 450 & 450 & 450 & 450 & 450 & 450 \\
\hline PESO VIVO NOVTL.HAS (fop) & 358 & 367 & 375 & 383 & 392 & 400 & 408 & 417 & 425 & 493 & 441 & 450 \\
\hline PESO VTVO BEZERRAS TOIAL (kg) & 52 & 73 & 93 & 114 & 135 & 156 & & & \multirow{2}{*}{\multicolumn{2}{|c|}{ DESMAAMADOS }} & & \\
\hline PESO VTVO BEZZERROS TOTAL (kE) & $\$ 5$. & 28 & 500 & 122 & 145 & 107 & & & & & & \\
\hline UNIDADE ANBAAL VACA (UA) & 1 & 1 & $t$ & 1 & $t$ & 1 & 1 & 1 & 1 & 1 & 1 & t \\
\hline UNIDADE ANTMAL NOVIIHA (LA) & $6.80:$ & 0.81 & e.33. & 0.85 & 0.37 & 0.89 & 091 & 0.93 & 0.94 & 0.96 & 0.98 & 100 \\
\hline UNDADE ANLMAL BE ZERRAS (UA) & 0.12 & 0.16 & ent & 0.25 & 0.30 & 035 & & & \multirow{2}{*}{\multicolumn{2}{|c|}{ DESMAMADOS }} & & \\
\hline UNDADE ANDMAL, BEZERKOS (UA) & 0.12 & 0.17 & 022 & 0.27 & 0.32 & 0.3) & & & & & & \\
\hline PESO TOTAL (kD) & 394,521 & 618,490 & 042,100 & $\cos , 329$ & 089,498 & 713,108 & 400,501 & 442,460 & 44,300 & 46.259 & 449,158 & 450.058 \\
\hline TA TOTAL. & 1,322 & 1,324 & 1,427 & 1,430 & 1,532 & $t, 535$ & 979 & 983 & 937 & 992 & $\$ 96$ & 1,000 \\
\hline Convame toeal de M/S (bests) & 411,805 & 413,303 & 415,002 & $4 ! 0,700$ & 418,399 & 420,097 & 334,826 & $336,2 \pi 0$ & 33,713 & 339,157 & 340,000 & 34204 \\
\hline Qud de MAS pasto fopMS ha) & 206 & 760 & 700 & 706 & 766 & 760 & 408 & 463 & 408 & uss & 408 & 4ss \\
\hline Area necessaria (ha) & 531 & 540 & 542 & 544 & 946 & 543 & 75 & 73 & 721 & 724 & $72 \mathrm{~s}$ & 731 \\
\hline Taxa de bactacto & 2.46 & 2.51 & 2.63 & 2.72 & 281 & 2.89 & 1.37 & 13) & 137 & 13 ? & 1.37 & 137 \\
\hline N de piquetes & 7 & 7 & 7 & 3 & 7 & 7 & ? & 7 & 7 & 1 & 7 & 7 \\
\hline Tamanho do piquete (ba) & 76,76 & $n 07$ & 7239 & $\pi .7$ & 78.02 & 78.4 & 102.17 & 10261 & 109.05 & 603.49 & 103.93 & 10437 \\
\hline
\end{tabular}


7.5 Planilha: Fontes de Receitas

\begin{tabular}{|c|c|c|c|c|c|c|}
\hline \multicolumn{7}{|c|}{ Receites em Sistema de Ciclo Completo em Módulo Inicial } \\
\hline Categuna & $\mathrm{N}$ de animais & Peso abate & RSigg & Roceta animal & Recetia Rebanbo & 1\% da racetata tocal \\
\hline Vacas de Descarte & 218 & 450 & 427 & RS 1,920000 & $R \$ 418,164,78$ & 0.21 \\
\hline Touro de Descante & 10 & 700 & 3.73 & RS 2,61333 & RS $27,402,02$ & 0.01 \\
\hline Fêmeas 36 meses & 238 & 450 & 4.49 & RS 1,979:21 & $\operatorname{RS} 471,378.83$ & 0.23 \\
\hline Machus 36 meses & 464 & 510 & 473 & RS 2,416.19 & RS $1,1200,795.76$ & 0.55 \\
\hline Total & 930 & & & RS $39,928.73$ & RS $2,037,741.40$ & 1.00 \\
\hline \multicolumn{7}{|c|}{ Receitas em Sistema de Ciclo Completo em Módulo Pós Melhoramento } \\
\hline Cartegunia & No de arimais & Peso abate & RShg & Recetia animal & Recetta Rebanbo & $\% 0$ da receta tocal \\
\hline Vacas de Descarte & 218 & 450 & 427 & RS $1,920,00$ & $\mathrm{RS} 418,164.78$ & 0.21 \\
\hline Touro de Descarte & 10 & 700 & 3.73 & RS $2,613.33$ & RS 27,002:02 & 0.01 \\
\hline Fèmeas 36 meses & 239 & 450 & 4.40 & RS 1979,21 & RS $471,378.83$ & 0.23 \\
\hline Machos 36 meses & 464 & 510 & 473 & RS $2,416.19$ & RS $\perp 1100,795.76$ & 0.55 \\
\hline Total & 930 & & & RS $8,928.73$ & RS 2037,741.40 & 1.00 \\
\hline
\end{tabular}


7.6 Planilha 5: Fontes de Custos

\begin{tabular}{|c|c|c|c|c|c|c|c|c|}
\hline c & $\mathrm{E}$ & $\sigma$ & 1 & $\mathrm{k}$ & M & $\mathrm{N}$ & 0 & Q \\
\hline & & & & & & & & \\
\hline & & & & & & & & \\
\hline \multicolumn{9}{|c|}{ Custos Totais ante Methoramento } \\
\hline \multicolumn{2}{|r|}{ Coxegocia } & Fonagum & Mineral & Proteinado & Veterininios. & & Total & 46 \\
\hline \multicolumn{2}{|r|}{ Vacas } & RS $325,434,36$ & RS $24,377.11$ & RS $36,091.72$ & RS 4,25689 & & RS $410,160: 07$ & 0,30 \\
\hline \multicolumn{2}{|r|}{ Touros } & RS $16,868.69$ & RS 1,62796 & RS 3.554.47 & RS 180.35 & & RS $22,231.47$ & 0.02 \\
\hline \multicolumn{2}{|c|}{ Bezerra 0.7 meses } & RS $21,140.96$ & RS 0.00 & RS 0.00 & RS 2,68320 & & RS $23,824.16$ & 0.02 \\
\hline \multicolumn{2}{|c|}{ Berema 7 - 12 meses } & RS $39,619.26$ & RS 0.00 & RS $15,621,66$ & RS 2.581 .31 & & RS $57,822.22$ & 0.04 \\
\hline \multicolumn{2}{|c|}{ Bezerra $12-24$} & RS $113,784,60$ & RS $10,345.78$ & RS $24,974.27$ & RS 2.034 .54 & & RS $151,139.19$ & 0.11 \\
\hline Nonil & ba 24 - 36 meses & RS $155,415,66$ & RS9,78499 & RS 38,12941 & RS 2,01528 & & RS 205,345.35 & 0.13 \\
\hline & aro 0-7 meses & RS $22,698.77$ & R5 0.00 & R5 0.00 & RS $2,136,62$ & & R5 $24,835.39$ & 0.02 \\
\hline Bere & tro 7 - 12 meses & RS $43,297,70$ & RS 0,00 & RS $18,583,44$ & RS 2055.48 & & RS $63,936,62$ & 0.05 \\
\hline Bezer & ao $12-24$ meses: & RS $127,872.76$ & RS $12,677.22$ & RS $26,296,70$ & RS $2,034.54$ & & RS $168,881.22$ & 0.12 \\
\hline Nowi & ho 24 - 36 meses & RS $176,299,42$ & RS $13,779,45$ & RS 45,77110 & RS 201528 & & RS 237,865.26 & 0.17 \\
\hline & Toed & RS 1.042 .432 .17 & RS 7259251 & RS $229,022.77$ & RS 21.993 .49 & & RS $1,366,04095$ & 1.00 \\
\hline
\end{tabular}


7.8 Planilha: Fontes de Lucros

\begin{tabular}{|c|c|c|c|c|c|}
\hline A & C & D & G & $\mathrm{H}$ & 1 \\
\hline \multicolumn{6}{|c|}{ Lucro antes Melhoramento } \\
\hline \multicolumn{2}{|r|}{ Categoria } & Receita & Custo & \multicolumn{2}{|c|}{ Lucro } \\
\hline \multicolumn{2}{|r|}{ Vacas } & RS $418,164.78$ & RS $410,160.07$ & \multicolumn{2}{|c|}{ RS $8,004.70$} \\
\hline \multicolumn{2}{|r|}{ Touros } & $\operatorname{RS} 27,402.02$ & $\mathrm{RS} 22,231.47$ & \multicolumn{2}{|c|}{$\mathrm{R} S 5,170.55$} \\
\hline \multicolumn{2}{|c|}{ Novilha 24 - 36 meses } & RS $471,378.83$ & RS $205,345.35$ & \multicolumn{2}{|c|}{ RS $266,033.48$} \\
\hline \multicolumn{2}{|c|}{ Novilho $24-36$ meses } & RS $1,120,795.76$ & RS $237,865.26$ & \multicolumn{2}{|c|}{ RS $882,930.50$} \\
\hline \multicolumn{2}{|c|}{ Total } & RS 2,037,741.40 & RS $875,602.16$ & \multicolumn{2}{|c|}{ RS $1,162,139.24$} \\
\hline \multicolumn{6}{|c|}{ 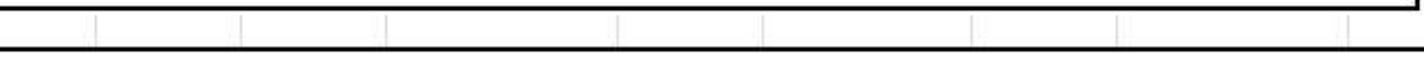 } \\
\hline \multicolumn{6}{|c|}{ Lucro Após Melhoramento } \\
\hline \multicolumn{2}{|r|}{ Categoria } & Receita & Custo & \multicolumn{2}{|c|}{ Lucro } \\
\hline \multicolumn{2}{|r|}{ Vacas } & RS $418,164.78$ & RS $410,160.07$ & \multicolumn{2}{|c|}{ RS $8,004.70$} \\
\hline \multicolumn{2}{|r|}{ Touros } & $\operatorname{RS~} 27,402.02$ & RS $22,231.47$ & & $5,170.55$ \\
\hline No & $24-36$ meses & RS $471,378.83$ & RS $205,345.35$ & & $66,033.48$ \\
\hline Nor & $24-36$ meses & RS $1,120,795.76$ & RS $237,865.26$ & & $82,930.50$ \\
\hline & Total & RS $2,037,741.40$ & RS $875,602.16$ & $\mathrm{RS}$ & $162,139.24$ \\
\hline
\end{tabular}


7.9 Planilha: Valores Econômicos

\begin{tabular}{|c|c|c|c|c|c|}
\hline Caracterisica & Iucro Final & Lucro lisidil & Lucro marginal & Ganbo Genético (kg) & Valor Econômico (kgrebarho) \\
\hline Peso Aduito Vaca & RS 0.00 & RS 0.00 & RS 000 & 0.00 & =DNo! \\
\hline Peso Abste Fêmea & RS 0.00 & RS 0.00 & RS 0.00 & 0.00 & $=\mathrm{DW} 0$ ! \\
\hline Peso Abate Macho & RS 0.00 & RS 0.00 & RSO000 & 0.00 & $=\mathrm{DN} / 0$ ! \\
\hline Taxa de Desmama & RS 0.00 & RS 0.00 & RS 0.00 & 0.00 & $=D N O !$ \\
\hline Peso a Desmama M & RS 0.00 & RS 0.00 & RS 0.00 & 0.00 & =DNO! \\
\hline Peso a Desmama F & RS 0.00 & RS 0.00 & $\mathrm{RS} 0.00$ & 0.00 & \#DNo! \\
\hline
\end{tabular}


7.10 Planilha: Análise de sensibilidade

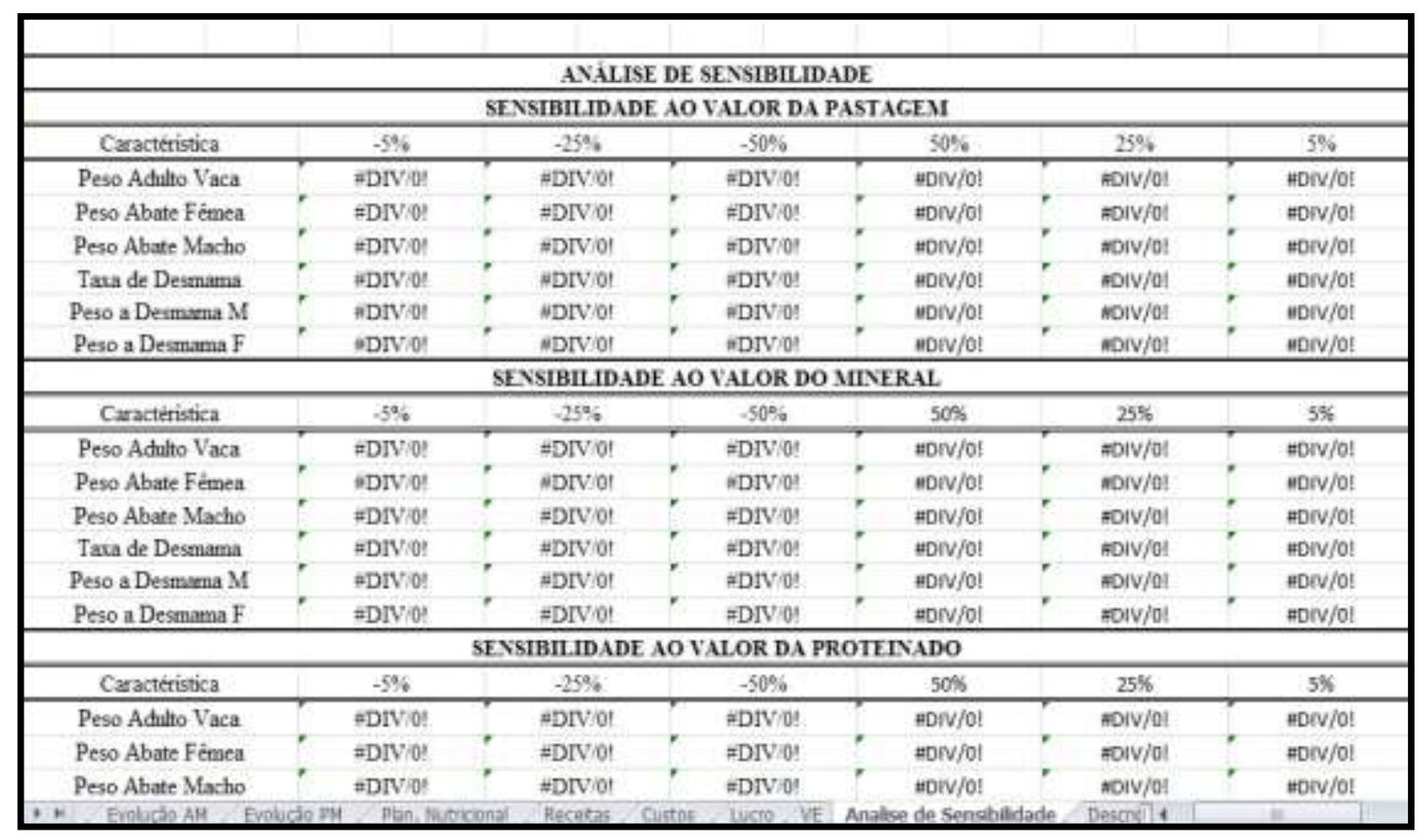


7.11 Planilha: Indicadores econômicos de custos de receitas

\begin{tabular}{|c|c|c|}
\hline \multicolumn{3}{|c|}{ Indicadores Econômicos de Custos e Receitas } \\
\hline Receitas & Valores & $\%$ Custos \\
\hline Receita Total Vaca Descarte & RS $418,164.78$ & 20.52 \\
\hline Receita Total Touro Descarte & $\mathrm{R} \$ 27,402.02$ & 1.34 \\
\hline Receita Total Fêmeas 36 meses & RS $471,378.83$ & 23.13 \\
\hline Receita Total Machos 36 meses & $\mathrm{RS} 1,120,795.76$ & 55.00 \\
\hline Total & RS $2,037,741.40$ & 100.00 \\
\hline Custos Fixos & Valores & $\%$ Custos \\
\hline Mão de Obra Fixa & RS $167,194.36$ & 10.20 \\
\hline Impostos & RS $44,438.00$ & 2.71 \\
\hline Depreciação & RS $16,028.85$ & 0.98 \\
\hline Total & RS $227,661.21$ & 13.89 \\
\hline Custos Variáveis & Valores & $\%$ Custos \\
\hline Pastagem & $\mathrm{RS} 1,042,432.17$ & 63.60 \\
\hline Sal Mineral Proteinado & RS $229,022.77$ & 13.97 \\
\hline Sal Mineral & RS $72,592.51$ & 4.43 \\
\hline Veterinários & RS $21,993.49$ & 1.34 \\
\hline Outras Despesas & RS $45,437.89$ & 2.77 \\
\hline Total & $\mathrm{RS} 1,411,478.84$ & 86.11 \\
\hline Custo Operacional Efetivo & $\mathrm{RS} 1,623,111.20$ & \\
\hline Custo Operacional Total & RS $1,639,140.05$ & \\
\hline Fonte: CEPEA 2014 & & \\
\hline
\end{tabular}


7.12 Planilha: Indicadores econômicos do sistema

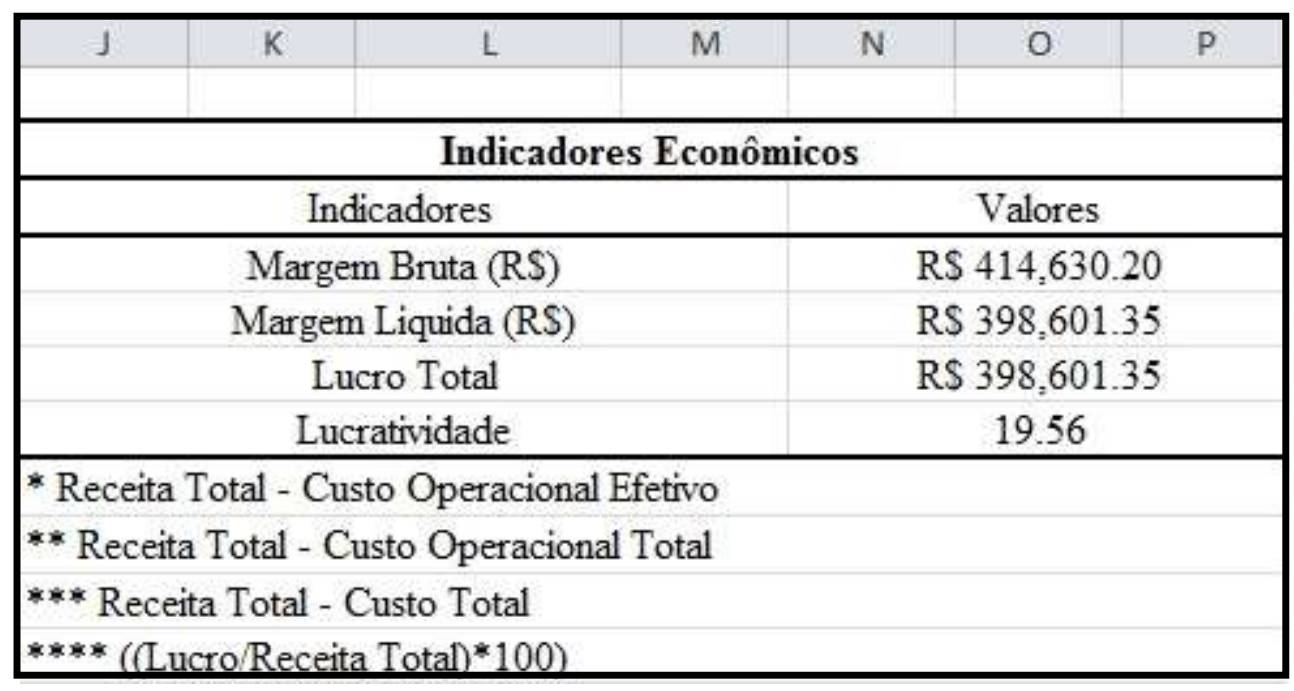




\subsection{Publicação}

O manuscrito abaixo no qual o aluno Heverton Luis Moreira consta na lista de autores estão sendo redigidos para publicação em revista indexada QUALIS A1.

\section{Objetivo de Seleção e Valores Econômicos para Bovinos Nelore em Sistema de Ciclo Completo}

Heverton Luis Moreira ${ }^{1}$, Raysildo Barbosa Lôbo ${ }^{1}$, Claudia Cristina Paro de Paz ${ }^{1,2}$

${ }^{1}$ Universidade de São Paulo - Faculdade de Medicina de Ribeirão Preto (USP-FMRP), Departamento de Genética, Av. Bandeirantes, 3900, CEP 14.049-900, Ribeirão Preto, São Paulo, Brasil. E-mail: hlmoreira@usp.br.

${ }^{2}$ Instituto de Zootecnia / Centro APTA de Bovinos de Corte, Rod. Carlos Tonani, Km94 - CP 63 CEP: 14.160-900, Sertãozinho - SP, Brasil.

RESUMO: O objetivo do trabalho foi o desenvolvimento de um modelo bioeconômico para a estimação dos valores econômicos de características de importância econômica em um sistema de bovinos de corte criados em regime de ciclo completo. O sistema de produção proposto considerou um rebanho de bovinos Nelore comercial típico do Brasil central, onde o modelo bioeconômico calculou os valores econômicos simulando os impactos das mudanças no lucro do sistema com o um aumento de $1 \%$ para cada característica do objetivo, mantendo as demais constantes. O modelo bioeconômico mostrou-se eficaz na estimação das fontes de receitas e despesas do sistema de produção e os valores econômicos estimados seguindo a ordem de importância para o ciclo completo foram $\mathrm{R} \$ 3,69$ para peso ao abate de macho (PAM), $\mathrm{R} \$ 3,63$ para peso a desmama de macho (PDM), $\mathrm{R} \$ 3,58$ para taxa de desmama (TD), $\mathrm{R} \$ 3,40$ para peso ao abate de fêmea (PAF), $R$ \$ 2,30 para peso a desmama de fêmea (PDF) e $R$ \$ 0,13 para peso ao adulto de vaca (PAV). Portanto, o PAM foi à característica de maior impacto no sistema de produção, porém todas promoveram retorno econômico positivo com exceção do PAV que foi praticamente nulo, sendo assim, a seleção das mesmas contribuem para o aumento de rentabilidade da propriedade em estudo. No entanto, o PAM foi à característica de maior impacto no sistema de produção, porém, todas promoveram retorno econômico positivo com exceção do PAV que foi praticamente nulo. Portanto todas as características avaliadas no sistema de ciclo completo tiveram importância econômica positivas, indicando que o processo de seleção trariam aumentos de lucratividade e as avaliadas geneticamente poderiam ser incluídas como critério de 
seleção contribuindo com a maximização da resposta esperadas para as características do objetivo de seleção.

PALAVRAS-CHAVE: Característica de Produtivas; Modelo Bioeconômico; Parâmetros Genéticos; Ponderadores econômicos; Seleção Genética.

\section{INTRODUÇÃO}

A bovinocultura de corte tem destaque especial no mercado nacional e internacional de produção de carne, pois o Brasil está atualmente entre os maiores produtores e exportadores mundiais de carne bovina, fazendo desta atividade agropecuária uma das mais relevantes em termos econômicos para o país. Para manter tais aspectos conquistados e conseguir abrir novos mercados internacionais a pecuária brasileira terá que melhorar em termos de eficiência produtiva, genética, nutricional, sanitário, ambiental e marketing para que os produtos dessa cadeia sejam competitivos em termos de qualidade e produtividade, trazendo maiores avanços nas questões de eficiência econômica ao setor.

Dentre as estratégias de elevação de produtividade e qualidade de produtos ligados ao setor pecuário, a seleção de animais geneticamente superiores para características de valor econômico deve ser umas das prioridades. No Brasil os programas de melhoramento genético animal têm papel fundamental para a bovinocultura de corte, elevando os índices de produtividade, fertilidade e de qualidade de carcaça dos animais selecionados. Nestes programas várias características de importância econômica são consideradas no objetivo de seleção, tais como características produtivas, reprodutivas e as relacionadas à qualidade de carcaça, porém essas são ponderadas de forma empírica e o mais indicado é que estas ponderações fossem feitas com base econômica que maximize o retorno lucrativo para o sistema de produção.

Para Ponzoni e Newman (1989) o início de uma atividade ligada ao setor pecuário deveria se dar pela definição dos reais objetivos de seleção ligados a lucratividade do sistema. Pois tendo esses objetivos consolidados nessa base econômica, a alternativa seria a de se propor um índice de seleção que pudesse ponderar todas as características economicamente relevantes ao sistema e que promovesse a maximização da resposta à seleção. Essa metodologia foi proposta por Hazel (1943), visando à seleção de múltiplas características com base genético-econômica, onde a resposta à 
seleção seja baseada no lucro esperado para cada unidade de melhoramento ganho nas características do objetivo proposto.

Poucos estudos realizados no Brasil avaliaram as questões genéticas econômicas de sistema de bovinos de corte, pois a pecuária brasileira apresenta diversos sistemas de produções, onde uma característica economicamente relevante para um sistema, talvez não seja importante em outro. Diante disso, o objetivo desse trabalho foram avaliar as características de importância econômica em sistema de ciclo completo para a raça Nelore viabilização de um estudo índice de seleção que maximizasse a resposta a seleção.

\section{MATERIAL e MÉTODOS}

O sistema de produção proposto considerou um rebanho de bovinos Nelore comercial típico do Brasil central (MT, MS, GO, MG e SP), criados de forma semiextensiva em pastagem de Brachiaria Brizantha cv Marandu e suplementados no período seco do ano com sal mineral proteínado. Esse sistema de produção (Figura 1) é baseado nos sistema de ciclo completo com a absorção de novilhas de reposição, venda de novilhas vazias não reintegradas ao sistema (36 meses), venda de novilhos machos (36 meses de idade) e vacas e touros de descarte para o abate.

De acordo com as condições climáticas do Brasil central a estação seca compreendeu-se de abril a setembro e a estação chuvosa de outubro a abril. Diante dessas informações a estação de monta natural foi realizada de novembro a janeiro, dividindo os lotes de acasalamentos com a relação de 30 fêmeas por touro. Seguindo o planejamento da estação de monta os nascimentos ocorriam nos meses de agosto a outubro com desmame dos animais ocorrendo aos sete meses de idade (março, abril e maio).

O manejo alimentar foi baseado em sistema de pastagem extensiva, distribuídas em uma área de 2000 hectares, sendo a maior taxa de lotação na época das águas de 2,5 UA/ha influência da grande oferta de forragem e na época da seca 1,4 UA/ha pela diminuição da qualidade do capim. Para não afetar o desempenho dos animais, devido ao efeito de estacionalidade, todos receberam na estação seca uma suplementação com sal mineral proteínado específico para cada categoria (1g/kg de PV em média), assim como nas águas com a oferta de sal mineralizado $(0,18 \mathrm{~g} / \mathrm{kg}$ de PV em média) auxiliando na ingestão de matéria seca potencializando o ganho de peso. 
O desenvolvimento do modelo bioeconômico (BEM) foi realizado considerando as informações do sistema de produção e dos parâmetros biológicos apresentados na Tabela 1 com o objetivo de estabilizar o rebanho de estabilizar o rebanho e calcular o número de animais em cada categoria, obter informações de desempenho produtivo e econômico (receita e despesas) do sistema, e por fim a obtenção dos valores econômicos das características contidas no objetivo de seleção em sistema de ciclo completo.

Para tal foram utilizadas planilhas interligadas do programa Microsoft Excel ${ }^{\circledR}$, disponibilizadas como descritas as seguir:

Planilha de parâmetros biológicos: informações de padrões biológicos dos animais;

Planilha de evolução mensal do rebanho: evolução do rebanho de acordo com o número de fêmeas em reprodução, taxa de reprodução, taxa mortalidade em diferentes idades, venda e descarte de animais até que o rebanho estabilizasse seu crescimento;

Planilha de planejamento Nutricional: exigência de nutricionais (forragem, mineral e proteínado) dos animais em diferentes categorias;

Planilha das fontes de receitas: descrição dos valores de receitas em cada categoria comercializada;

Planilhas de custos: calculo dos custos mensais para cada categoria animal, compostos pelo custo com forragem, suplementação e veterinários;

Planilha de lucro: calculo do lucro do sistema (lucro = receita - despesa);

Planilha do lucro marginal: lucro marginal calculado pela mudança no desempenho de uma característica por vez que se tenha interesse econômico para o sistema, assim pode-se obter o lucro após o melhoramento na mesma;

Planilha com estimação dos valores econômicos: calculo do valor econômico (VE) feito pela diferença entre o lucro ganho após a seleção e o lucro antes a seleção.

Planilha de análise de sensibilidade: avaliação do impacto de possíveis mudanças nas variações de $\pm 10 \%$ a $\pm 25 \%$.

As fontes de despesas e receitas (Tabela 2) foram calculadas para as categorias de animais de interesse no estudo. As despesas são baseadas nos custos para alimentação dos animais, sendo para as pastagens os custos de formação, manutenção e depreciação anual, custo com o consumo anual de sal mineralizado e proteínado e custos veterinários. 
As fontes de receitas do sistema foram baseadas na venda vacas e touros de descartes, pesando respectivamente 450 e $700 \mathrm{~kg}$, bem como novilhos e novilhas de 36 meses de idade que não foram reintegradas ao rebanho, com um peso de 510 e $450 \mathrm{~kg}$ respectivamente. As receitas para animais destinados ao abate serão descritas para duas situações, sendo a primeira, onde o sistema de pagamento se baseia no valor pago por arroba de peso em cada categoria e na segunda baseado em um sistema de pagamento por qualidade onde as utilizações de touros melhoradores no acasalamento possam promover o crescimento de animais de melhores pesos e conformações de carcaça.

Na segunda situação pagamento diferencial (Tabela 3) é baseado no programa de qualidade Nelore natural, onde os pecuaristas têm a oportunidade de receber do frigorífico premiações que podem chegar a até $4 \%$ sobre o valor da arroba de seus animais. Porém os perfis dos animais para receber as bonificações são descritas abaixo:

Novilho Nelore: O novilho Nelore para ser classificado no lote de bonificação necessita ter peso médio da carcaça quente na variação de 17 a 21,9 arrobas (255 a $328,5 \mathrm{~kg}$ ), com um padrão de gordura de acabamento entre 3 e $10 \mathrm{~mm}$ uniformemente distribuídos pela carcaça. Os machos castrados devem apresentar até 6 dentes incisivos permanente, porém aqueles não castrados devem apresentar toda dentição de leite. Esse padrão de carcaça descrito deve apresentar uma carcaça de conformação regular (retilínea, subconvexa, convexa).

Novilha Nelore: A novilha Nelore para ser classificado no lote de bonificação necessita ter um peso médio de carcaça quente acima de 13 arrobas, com um padrão de gordura de acabamento entre 3 e $10 \mathrm{~mm}$ uniformemente distribuídos pela carcaça e uma dentição de até 4 dentes incisivos permanentes. Esse padrão exigido para as fêmeas devem ser de uma carcaça de conformação regular (retilínea, subconvexa, convexa).

Vacas Nelore: A vaca Nelore para ser classificado no lote de bonificação necessita ter peso médio da carcaça quente acima de 15 arrobas (maior ou igual a 225 $\mathrm{kg}$ ), com acabamento de gordura entre 3 e $10 \mathrm{~mm}$ uniformemente distribuídos pela carcaça, conferindo conformação regular para à carcaça (retilínea, subconvexa, convexa).

Para a estimação dos valores econômicos foi utilizado à metodologia de modelagem bioeconômica, o qual descreveu os parâmetros de receitas e despesas no sistema de produção de bovinos de corte criado a pasto em regime de ciclo completo. Essa modelagem ingressou todas as informações oriundas do sistema de produção (Tabela 1) alocadas em planilhas no programa Excel interligadas entre si e sendo uma 
dependente da outra, pois assim quaisquer alterações nos parâmetros refletiriam em alteração nos valores econômicos encontrados.

Os valores econômicos foram definidos pela metodologia proposta por Groen et al., 1997, decorrente de um aumento de 1\% para cada característica do objetivo, mantendo as demais constantes. Essa metodologia pode ser descrita pela equação:

$$
\mathrm{VE}=[(\delta(\text { Receita Anual }))-(\delta(\text { Custo Anual }))]
$$

em que: VE é o valor econômico da característica, $\delta$ (Receita Anual) é a diferença marginal obtida no lucro depois e antes do melhoramento e $\delta$ (Custo Anual) é a diferença marginal obtida no custo depois e antes do melhoramento.

Para testar as mudanças nos valores econômicos referente às alterações em 5\%, $25 \%$ e $50 \%$ para mais ou para menos nos valores dos custos (forragem, suplementação e veterinários) e dos valores de receita (vendas dos animais), foi realizada a análise de sensibilidade que visa identificar se essas alterações promovem ou não mudanças significativas nos resultados simulados.

\section{RESULTADO}

Após estruturação do sistema de produção e a avaliação dos parâmetros zootécnicos, o rebanho em estudo estabilizou-se após cinco anos corridos, sendo uma das premissas do modelo bioeconômico determinístico e estático que se demonstrou eficaz na avaliação do rebanho quanto aos seus centros de custo e de receitas para esse estudo (Tabela 5). Os parâmetros zootécnicos utilizados na composição do modelo foram baseados em sistema de produções do Brasil central e de algumas revisões de literatura, pois a modelagem bioeconômica requer certas informações que em muitos sistemas de produções não são avaliados.

O número de vacas e novilhas com prenhes positiva estabilizado no sistema foram de 1000 fêmeas. Anualmente foram descartadas para venda 22\% das vacas (218) e $25 \%$ dos touros (10) aliviando os custos das categorias com a suplementação proteica no período seco. Já no início da estação de reprodução novos reprodutores geneticamente superiores foram adquiridos para suprir a relação do número de touros por fêmeas necessários e houve a necessidade de exposição de 268 novilhas com idade 
de 24 meses. O excedente de novilhas que não emprenharam e as que não foram expostas somaram o total de 238 novilhas comercializadas juntamente com 464 machos aos 36 meses de idade, com pesos variando de 450 e $510 \mathrm{~kg}$, respectivamente para machos e fêmeas.

Com as informações da composição e evolução do rebanho por categoria animal, foi possível dimensionar os centros de custos alimentícios de acordo com as exigências dos animais quanto às quantidades de forrageiras, suplementação mineral e proteica, bem como as receitas provindas das vendas de machos e fêmeas de 36 meses, touros e vacas de descartes (Tabela 5).

Analisando o centro de receitas a categoria com maior expressão total foi à venda de machos com 36 meses que representou 55\%, sendo seguido pela categoria de fêmeas de 36 meses que somaram 23,13\% da receita total. Os custos com a alimentação (pastagem, sal mineral e proteínado) dos animais somaram o total de $82 \%$ do custo total da propriedade, sendo esses custos os mais expressivos na determinação dos valores econômicos. Já os custos fixos segundo Ponzoni e Newman, 1989 não se alteraram com as mudanças simuladas nas características, assumindo valores nulos no processo de derivação parcial, porém foram avaliados neste estudo para demonstrar que a propriedade apresentou lucro anual total de $\mathrm{R} \$ 398.601,35$ ao ano, e lucratividade de $19,56 \%$. Esse é o indicador da proporção da receita bruta que se constitui em lucro após a diferença dos custos (Tabela 6), portanto, a propriedade avaliada apresenta eficiência produtiva e viável dentro do sistema de bovinos de corte.

Os componentes de lucro (receita - despesa) apresentaram influências positivas quando submetidas à simulação do aumento de $1 \%$ no potencial genético dos animais para as características de peso adulto da vaca (PAV), peso ao abate de fêmeas (PAF), peso ao abate de machos (PAM), taxa de desmama (TD), peso a desmama de macho (PDM) e peso a desmama de fêmea (Tabela 8).

A diferença apresentada pelo lucro antes e após à simulação do melhoramento é denominado de lucro marginal. Considerando os resultados encontrados a TD foi a que expressou maior impacto econômico seguido respectivamente por PAM, PDM, PAF, PDF e PAV (Tabela 7).

O valor econômico obtido nesse estudo foi calculado pela divisão do lucro marginal pelo ganho genético (VE=LM/GG), proporcionado simulando-se o ganho de $1 \%$ na unidade de cada característica (GROEN et al., 1997), expressos por rebanho. 
O estudo do PDM demonstrou que a cada $1 \%$ de ganho em unidades da característica houve o retorno econômico de $\mathrm{R}$ \$ 3,63 para os machos e $\mathrm{R}$ \$2,30 para as fêmeas em sistema de bovinos de corte em regime de ciclo completo. Essa característica é importante nesse tipo de sistema, pois a correlação genética entre as características varia de 0,50 a 0,65 (Boligon et al., 2008, Yokoo et al. 2007; Yokoo et al. 2010), ou seja entre 50 e $65 \%$ dos genes responsáveis pelo maior peso dos animais ao desmame também são responsáveis pelo maior peso aos 36 meses de idade, facilitando assim a identificação de animais de maior desempenho ponderal e econômico e permitindo a formação de lotes de manejo para a escala de abate futura com lotes uniformes de padronização de carcaça.

A taxa de desmama (TD), embora tenha sido a característica com maior impacto na lucratividade no sistema, quando avaliado o seu retorno econômico comparado ao ganho por seleção, mudou de classificação para a terceira colocação de importância com valor de $\mathrm{R} \$ 3,58$ por $1 \%$ de incremento na característica, valor próximo ao relatado por Jorge Junior et al., 2007 em seus estudos de R \$3,36 por 1\% de ganho.

Os valores econômicos das características estudadas quando avaliadas sob a ótica do sistema de pagamento do programa Nelore Natural, tiveram aspectos positivos em relação ao lucro do sistema (Tabela 8). Avaliando que padrões dos animais se encaixassem na maior cota de bonificação com formações padronizadas dos lotes acima de $80 \%$, a característica que maior se destacou foi o PAV que teve um incremento de $130 \%$ acima do valor econômico na situação de pagamento sem bonificação. Seguindo a ordem de importância no sistema com bonificação os valores econômicos foram superiores em $8 \%$ para PDF, 5\% para PAF, 4\% para TD, 3\% PDM e 2\% para PAM. Esses valores econômicos superiores nas características ligadas às fêmeas são pelas maiores bonificações (+4\% sobre o valor da arroba) recebidos pelas mesmas em relação aos machos $(+2 \%)$, porém vale ressaltar, que os custos de produções mantiveram-se constantes, alterando-se somente os centros de receitas.

A análise de sensibilidade explorou as variações ocorridas nos valores econômicos em diferentes situações mercadológicas, como aumentos ou reduções nos valores de custo das pastagens, minerais e suplementações proteicas e também nos centros de receitas do presente estudo (Tabela 9).

As variações no valor do custo de matéria seca das pastagens destinada à alimentação dos animais promoveram mudanças significativas nos valores econômicos do PAV da ordem de $\mathrm{R} \$ \pm 1,66$ com a variação $\pm 50 \%$ no custo da pastagem. $\mathrm{O}$ aumento 
de ganho genético de $1 \%$ característica PAV promoveriam redução no lucro do sistema se tiverem um aumento a partir de $5 \%$ nos custos de matéria seca. Essa simulação provocou alterações nas ordens dos valores econômicos importantes para o sistema de ciclo completo, classificando as características nas seguintes ordens de importância quando reduzidos 50\% no custo: 1-PDM, 2-TD, 3-PAM, 4-PAF, 5-PDF e 6-PAV.

O custo com sal mineral utilizado no período das águas promoveu uma pequena alteração no valor econômico para PAV $(R \$ \pm 0,12)$ e as demais características permaneceram praticamente inalteradas. Na simulação de alterações no custo com proteínado ofertado no período seco a ordem de importância dos valores econômicos para o sistema não alteraram, porém resultou em diferenças de $\mathrm{R} \$ \pm 0,28$ no $\mathrm{PAV}, \mathrm{R} \$$ $\pm 0,19 \mathrm{PDF}, \mathrm{R} \$ \pm 0,10$ para TD e PDM e R\$ $\pm 0,07$ para PAM e PAF. A característica PAV também apresentou sensibilidade ao aumento no custo de proteínado a partir de $25 \%$ o que promoveria reduções nos lucros de $\mathrm{R} \$-0,02$ a $\mathrm{R} \$-0,16$ pelo aumento de $1 \%$ na unidade da característica.

A sensibilidade dos valores econômicos para variações nos centros de receitas não tiveram alterações em suas ordens de importância econômica entre as variações de 5 a $25 \%$. Porém quando reduzidos em $50 \%$ os valores de receita a TD tornou-se a segunda característica mais importante, alternando-se a ordem com o PD. Se as receitas fossem aumentas em 50\% o PDM seria a característica mais importante no ciclo completo com aumento de $\mathrm{R}$ \$ 6,00 no lucro com ganho de $1 \%$ na unidade da característica, sendo seguidos pela TD e PAM.

O PAV foi à característica que expressou maior sensibilidade quanto às demais, na variação dos valores de receitas do sistema. A redução a partir de 5\% na receita reduziria o lucro do PAV no sistema, o que para as demais características, tantas as flutuações de preços para mais ou para menos, o lucro permaneceria positivo promovendo ganhos econômicos por seleção dentro do sistema.

\section{DISCUSSÃO}

A complexidade das informações que compões o modelo bioeconômico segundo Jorge Junior et al., 2006 depende das informações disponibilizadas pelo sistema pecuário, e que a inexistência dessas podem serem supridas pela revisão de conhecimentos publicados em trabalhos ou por experiências de profissionais da área como as apresentadas nesse trabalho. As informações do rebanho foram muito eficientes, onde permitiu a estabilização do rebanho, identificações das características 
biológicas que mais impactaram nas fontes de receitas e despesas do sistema de bovinos de corte em regime de ciclo completo.

Os fatores que fizeram do PAM e PAF serem os mais impactantes nas fontes de receita para o sistema se deve pela quantidade de unidades animais presente nos lotes e pela maior disposição de $\mathrm{kg}$ de peso vivos a serem ofertados a vendas, concordando com os resultados relatados por Jorge Junior et al., 2006 e Campos et al., 2014 para sistemas de bovinos de corte em regime de ciclo completo.

Quando se avaliou o lucro marginal a taxa de desmame (TD) foi a que promoveu maior impacto econômico. Nos estudos de Urioste et al., 1998 e Jorge Junior et al., 2007. A taxa de desmame está ligada ao número de unidades animais produzidos, onde qualquer incremento positivo nos valores dessa característica causa maiores impactos econômicos favoráveis para o sistema de produção que trabalha a comercialização de animais.

No caso do valor econômico o maior impacto nesse estudo avaliando o ciclo completo foi o PAM (R\$3,69/kg), sendo este valor superior aos reportado por Jorge Junior et al., 2007 para a raça Nelore e Campos et al., 2014 para a raça Angus, onde os valores foram respectivamente $\mathrm{R} \$ 1,17$ e $\mathrm{R} \$ 1,43$. O PAF aos 36 meses de idade teve impacto positivo nesse sistema, sendo conjuntamente superior ao relatados pelos mesmos autores anteriormente citados, na ordem de $\mathrm{R} \$ 3,40$ para cada unidade $\mathrm{kg}$ ganho pelo rebanho em decorrência da seleção. Essa superioridade do valor econômico encontrado no presente estudo, tanto para machos quanto para fêmeas, pode ser devida a influência dos valores de comercialização dos animais, medidos em R $\$$ /arroba de boi, terem se mantido altos ao longo do ano de 2014 quando comparados aos anos dos estudos mencionados e das diferenças de pesos de abate dos animais em cada estudo.

Fernandez-Perea e Jiménez (2004) estimaram valores econômicos negativos para peso a desmama $-0,43 € /$ vaca/ano). Os autores justificaram que o sistema de produção adotado com suplementação dos animais do nascimento ao desmame elevou os custos de produção. No Brasil avaliando o sistema de ciclo completo com a raça Nelore Bittencourt et al., 2006; Jorge Junior et al., 2007 e Brumatti et al., 2011 relataram, os valores econômicos para peso ao desmame de U\$ 0,29, R \$ 0,34 e R\$ 0,57. Esses valores foram muito inferiores quando comparados com o valor encontrado no presente estudo de $\mathrm{R}$ \$ 3,63 para machos e R $\$$ 2,30 para fêmea. Laske et al., 2012, trabalhando com bovinos de corte em sistema de pecuária familiar obtiveram valor econômico superior para o peso a desmama na ordem de $\mathrm{R} \$ 17,07$ por unidade de 
melhoramento, no entanto, todos os valores reportados promoveram incrementos econômicos positivos para seus respectivos sistemas de produções.

Para Groen 1989 e Phocas et al., (1998) essa base de comparação dos valores econômicos entres sistemas deve ser feita com muita cautela, pois cada sistema de produção apresenta suas particularidades e que essas podem causar diferenças nos centros de custos e de receitas entre propriedades. Wolfavá e Wolf (2013) orientam não fazer as comparativas entre valores econômicos de uma mesma característica em sistemas de produções diferentes.

Revisando outros estudos, a taxa de desmame foi à característica de maior importância relativa para os sistemas e com valores altamente expressivos aos citados anteriormente. Urioste et al., (1998) trabalhando com pecuária de corte em regime extensivo obtiveram um valor de U\$ 39,5 por $1 \%$ de unidade ganho na característica. Em sistema familiar no sul do Brasil Laske et al., 2012 relataram valor econômico para taxa de desmame de $\mathrm{R} \$ 73,21$. O número de bezerros desmamados (NBD) por vaca por ano teve segundo Bittencourt et al., 2006 um retorno econômico de R \$ 97. Para Campos et al. 2013 que avaliaram a mesma característica (NBD) na raça angus o valor econômico encontrado foi $\mathrm{R} \$ 6,67$ por $1 \%$ de ganho com a seleção genética.

O retorno econômico por $1 \%$ de unidade de melhoramento na característica PAV foi de $\mathrm{R} \$ 0,13$, valor próximo ao relatado por Jorge Junior et al., 2007 de $\mathrm{R} \$ 0,09$. Enquanto Laske et al., 2012 obteve o valor econômico de R\$ 4,75. Portanto as diferenças nesses valores se devem aos valores dos custos de matéria seca em cada sistema de produção ou até mesmo pela valorização da vaca ao abate nos períodos avaliados. Embora os valores econômicos demonstrassem promover lucro para os sistemas, Fernandez-Perea e Jiménez (2004) encontraram -2,31€ por kg, ou seja, o aumento do PAV reduziriam os lucros ao sistema de produção.

O estudo de pagamento por bonificações por cotas de qualidade dos animais promoveram mudanças expressivas nos valores econômicos (VE) de algumas características quando comparada ao sistema de pagamento sem bonificação. Diante dessa avaliadas neste estudo afirma-se a importância de novas pesquisas avaliando outras formas de pagamentos por qualidade de carcaça no Brasil, bem como, a avaliação de custos de produção em animais de alto rendimento. Para isso, Mendes e Padilha (2007) relatam que a cadeia produtiva da carne no Brasil deve-se trabalhar de forma coordenada e se organizar de maneira eficiente buscando o mesmo ideal para o setor 
com um produto cárneo padronizado e de melhor qualidade satisfazendo a vontade de cada mercado consumidor.

Os resultados obtidos na análise de sensibilidade quanto as modificações nos valores dos custos de pastagem eram esperados, pois o sistema foi baseado em criação de bovinos de forma extensiva, e o aumento ou a redução dos preços da matéria seca resultaria nas variações dos custos por categoria animal de acordo com exigência nutricional dos mesmos. Esses resultados encontrados com a análise de sensibilidade indicaram que os valores econômicos estimados pelo modelo bioeconômico mostraramse robustos frente às variações aplicadas nos custos das pastagens, minerais, proteínados e nas fontes de receita, conferindo uma maior confiabilidade na utilização desses das características do objetivo de seleção em sistema de ciclo completo.

\section{AGRADECIMENTOS}

Agradecimentos a Pós Graduação da Faculdade de Medicina de Ribeirão Preto USP (Departamento de Genética) e ao Conselho Nacional de Desenvolvimento de Pesquisa - CNPq pelo financiamento do projeto (472753/2010-0) e auxilio a bolsa de estudos (140517/2011-1).

\section{REFERÊNCIAS BIBLIOGRÁFICAS}

ANUALPEC (2013). Anuário da pecuária brasileira. FNP Consultoria e Comércio 378.

BITTENCOURT, T. C. C; LÔBO, R. B; BEZERRA, L. A.F. Objetivos de seleção para sistemas de produção de bovinos de corte em pasto: ponderadores econômicos. Arquivos Brasileiros de Medicina Veterinária e Zootecnia, v.58, n.2, p.196 - 204, 2006.

BOLIGON, A. A.; ALBUQUERQUE, L. G.; RORATO, P. R. N (2008). Associações genéticas entre pesos e características reprodutivas em rebanhos da raça Nelore. Revista Brasileira de Zootecnia, v. 37; n. 4; p. 596 - 601, 2008.

BRUMATTI, R. C.; FERRAZ, J. B. S.; ELER, J. P.; FORMIGONNI, I. B. Desenvolvimento de índice de seleção em gado de corte sob o enfoque de um modelo bioeconômico. Archivos de Zootecnia, v.60, p.205 - 213, 2011.

CAMPOS, G. S.; BRACCINI NETO, J.; OIAGEN, R. P.; CARDOSO, F. F.; COBUCI, J. A.; KEM, E. L.; CAMPOS, L. T.; BERTOLI, C. D.; McManus, C. M. Bioeconomic model and selection índices in Aberdeen Angus cattle. Journal Animal Breeding Genetics, p. 1 - 8, 2014. 
EMBRAPA - Empresa Brasileira de Pesquisa Agropecuária - Gado de corte. Disponível em:_http://www.embrapa.br/a_embrapa/unidades-de-pesquisa-e-deservicos/unidades-de-pesquisa-de-produtos/cnpgc/. Acesso em outubro de 2013.

EUCLIDES FILHO, K (2008). A pecuária de corte no cerrado brasileiro. In: Faleiro, F. G.; Neto A. L. F. Savanas: desafios e estratégias para o equilíbrio entre sociedade, agronegócio e recursos naturais. Planaltina, DF: Embrapa Cerrados; Brasília, DF: Embrapa Informação Tecnológica, 2008, 1198p.

FERNANDEZ-PEREA, M. T.; JIMÉNEZ A. R. Economic weights for a selections index in Avileña purebred beef cattle. Livestock Production Science, v. 89, p. 223 233, 2004.

GODDARD, M. E. THOMPSON, R. Use of prior information in forming selection indices. Journal Animal Breeding Genetics (in press).

GROEN, A. B. Economic values in cattle breeding. II. Influences of production circumstances in situations with output limitations. Livestock Production Science, v. 22, p. 17- 30, 1989.

GROEN, A. F., STEINE, T., COLLEAU, J. J., PEDERSEN, J., PRIBYL, J., REINSCH, $\mathrm{N}$. Economic values is dairy cattle breeding, with special reference to functional traits. Report of an EAAP - working group. Livestock Production Science, v. 49, 1- 21, 1997.

HAZEL, L. N. The genetic basis of constructing selection index. Genetics, v.28, p.476-90, 1943.

JORGE JUNIOR, J.; CARDOSO, V. L.; ALBUQUERQUE, L. G. Modelo bioeconômico para cálculo de custo e receitas em sistemas de produção de gado de corte visando à obtenção de valores econômicos de características produtivas e reprodutivas. Revista Brasileira de Zootecnia, v. 35, p. 2187 - 2196, 2006.

JORGE JUNIOR, J.; CARDOSO, V. L.; ALBUQUERQUE, L. G. Objetivos de seleção e valores econômicos em sistemas de produção de gado de corte no Brasil. Revista Brasileira de Zootecnia, v.36, n.5, p.1549 - 1558, 2007.

LASKE, C. H.; TEIXEIRA, B. B. M.; DIONELlO, N. J. L.; CARDOSO, F. F. Breeding objectives and economic values for traits of low input Family - based beef cattle production system in the State of Rio Grande do Sul. Revista Brazileira de Zootecnia, v. 41, p. 298 - 305, 2012.

LÔBO, R. B.; BEZERRA, L. A. F.; OLIVEIRA, H. N.; FREITAS, M. A. R.; PENNA, V. M.; VOZZI, P. A.; BERGMANN, J. A. G.; FARIA, C. U.; OLIVEIRA, H. N. Avaliação Genética de Touros da Raça Nelore, Guzerá, Brahman e Tabapuã: Sumário 2013. Ribeirão Preto, ANCP. 172 p., 2013.

MENDES, J. T. G.; PADILHA, JR., J. B. Agronegócio: uma abordagem econômica. São Paulo: Pearson Prentice Hall, 2007, 369p. 
PHOCAS, F.; BLOCH, C.; CHAPELLE, P. Developing a breeding objective for a French purebred beef cattle selection programme. Livestock Production Science, v. 57, p. $49-65,1998$.

PONZONI, R. W.; NEWMAN, S. Developing breeding objectives for Australian beef cattle production. Animal Production, v.49, p.35 - 47, 1989.

URIOSTE, J. I.; PONZONI, R. W.; AGUIRREZABALA, M. ROVERE, G. SAAVEDRA, D. Breeding objectives for pasture fed Uruguayan beef cattle. Journal Animal Breeding Genetics, v.115, p. 357 -373, 1998.

WOLFAVÁ, M.; WOLF, J. Strategies for defining traits when calculating economic values for livestock breeding: a review. Animal, v.7, p. 1401 - 1413, 2013.

YOKOO, M. J. I.; ALBUQUERQUE, L. G.; LÔBO, R.B.; SAINZ, R. D.; JÚNIOR, J. M. C.; BEZERRA, L. A. F.; ARAUJO, F. R. C. Estimativas de parâmetros genéticos para altura do posterior, peso e circunferência escrotal em bovinos da raça Nelore. Revista Brasileira de Zootecnia, v. 36, n. 6, p. 1761 - 1768, 2007.

YOKOO, M. J.; LÔBO, R. B.; ARAUJO, F. R. C.; BEZERRA, L. A. F.; SAINZ, R. D.; ALBUQUERQUE, L. G (2010). Genetic associations between carcass traits measured by real-time ultrasound and scrotal circumference and growth traits in Nelore cattle.

Journal Animal Science, v. 88, p. 52-58, 2010.

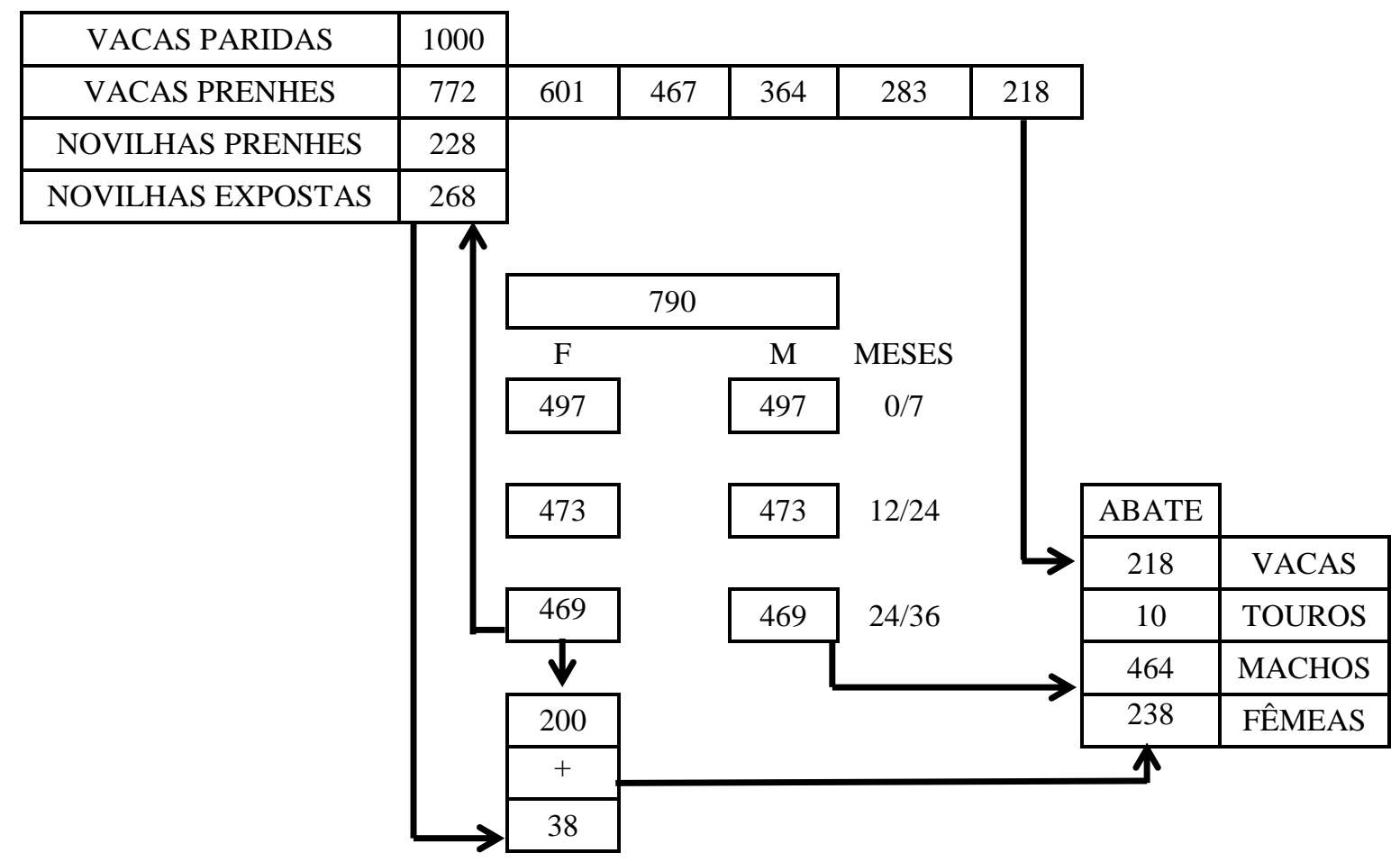

Figura 1. Fluxograma do rebanho estabilizado no sistema de ciclo completo 
Tabela 1. Parâmetros biológicos utilizados na composição final do rebanho para obtenção dos valores econômicos

\begin{tabular}{|c|c|}
\hline Parâmetros & Média \\
\hline Taxa anual de descarte de vacas $(\%)^{3}$ & 22 \\
\hline Taxa anual de descarte de touros $(\%)^{5}$ & 25 \\
\hline Taxa de concepção de vacas $(\%)^{1}$ & 78 \\
\hline Taxa de concepção de novilhas 24 meses $(\%)^{4}$ & 85 \\
\hline Taxa de natalidade média $\%$ & 79 \\
\hline Número de fêmeas/touro ${ }^{3}$ & 30 \\
\hline Taxa Mortalidade de 0 a 7 meses $(\%)^{1}$ & 4 \\
\hline 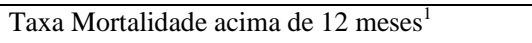 & 1 \\
\hline Vida útil da vaca (anos) ${ }^{5}$ & 5 \\
\hline Peso Médio a Desmama Macho - PD $(\mathrm{kg})^{2}$ & 190 \\
\hline Peso Médio a Desmama Fêmea - PD $(\mathrm{kg})^{2}$ & 176 \\
\hline Peso Médio aos 365 dias Macho - P365 $(\mathrm{kg})^{2}$ & 252 \\
\hline Peso Médio aos 365 dias Fêmea - P365 $(\mathrm{kg})^{2}$ & 228 \\
\hline Peso Médio aos 450 dias Macho - P450 (kg) ${ }^{2}$ & 297 \\
\hline Peso Médio aos 450 dias Fêmea - P450 (kg) ${ }^{2}$ & 263 \\
\hline Peso médio ao abate de fêmea $(36 \text { meses })^{2}$ & 450 \\
\hline Peso médio ao abate de macho $(36 \text { meses })^{2}$ & 510 \\
\hline Peso Médio da vaca Adulta $-\mathrm{PAV}(\mathrm{kg})^{2}$ & 450 \\
\hline Peso Médio do touro reprodutor $-\mathrm{PR}(\mathrm{kg})^{5}$ & 700 \\
\hline Rendimento de carcaça de fêmea ${ }^{4}(\%)$ & 48 \\
\hline Rendimento de carcaça de macho ${ }^{4}(\%)$ & 55 \\
\hline
\end{tabular}

adaptado de Euclides Filho, 2008; ${ }^{2}$ Lôbo et al., 2013; ${ }^{3}$ Anualpec, 2013; ${ }^{4}$ Jorge Junior et al., 2007; $\quad{ }^{5}$ Embrapa (CNPGC), 2013.

Tabela 2. Fonte de receitas e despesas no sistema de produção

\begin{tabular}{|c|c|}
\hline \multicolumn{2}{|c|}{ Fontes de Receitas } \\
\hline Características & Valores (R\$) \\
\hline Novilhas 36 meses vazias ${ }^{1}$ (@) & 132,00 \\
\hline Vaca gorda ${ }^{1}(@)$ & 128,00 \\
\hline "Touro de descarte ${ }^{1}$ (@) & 1112,00 \\
\hline Novilho 36 meses gordo ${ }^{1}$ (@) & 142,00 \\
\hline \multicolumn{2}{|c|}{ Fontes de Despesas } \\
\hline Características & Valores (R\$) \\
\hline Despesa com formação e reforma de pasto ${ }^{2}(\mathrm{R} \$ / \mathrm{ha})$ & 964,00 \\
\hline Depreciação de pasto $(\mathrm{R} \$ / \mathrm{ha})$ & 96,40 \\
\hline 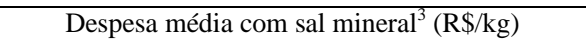 & 1,38 \\
\hline Despesa média com sal proteínado ${ }^{3}(\mathrm{R} \$ / \mathrm{kg})$ & 1,17 \\
\hline Despesa média com veterinário (R \$/cabeça) & 0,00 \\
\hline
\end{tabular}

${ }^{1}$ Média de preço comercializado em SP, MT, MS e GO (ANUALPEC, 2013)

${ }^{2}$ Preço da formação e reforma (ANUALPEC, 2013)

3 Orçamento com frete da empresa Matsuda (2013) 
Tabela 3 - Valores de bonificações para bovinos da raça Nelore

\begin{tabular}{cccc}
\hline $\begin{array}{c}\text { Índice de Classificação do } \\
\text { Lote }(\%)\end{array}$ & Novilho Nelore & Novilha Nelore & Vaca Nelore \\
\hline \hline $0-49,9$ & 0,0 & 0,0 & 0,0 \\
$50-69,9$ & $+1 \%$ & $+2,0 \%$ & $+2,0 \%$ \\
$70-79,9$ & $+1,5 \%$ & $+3,0 \%$ & $+3,0 \%$ \\
Acima de 80 & $+2 \%$ & $+4,0 \%$ & $+4,0 \%$ \\
\hline
\end{tabular}

Fonte: http://www.nelore.org.br

Tabela 5. Composição do rebanho estabilizado em sistema de bovinos de corte em regime de ciclo completo.

\begin{tabular}{cc}
\hline Categoria & Cabeças \\
\hline \hline Vacas & 990 \\
Touros & 42 \\
Bezerras 0 - 1 ano & 497 \\
Bezerras 1 - 2 anos & 473 \\
Novilhas 2 - 3 anos & 469 \\
Bezerros 0 - 1 ano & 497 \\
Bezerros 1 - 2 anos & 473 \\
Novilhos 2 - 3 anos & 469 \\
\hline
\end{tabular}

Tabela 5. Indicadores econômicos de custos e receitas em sistema de ciclo completo de bovinos de corte.

\begin{tabular}{|c|c|c|}
\hline \multicolumn{3}{|c|}{ INDICADORES ECONÔMICOS DE CUSTOS E RECEITAS } \\
\hline RECEITAS & VALORES & $\%$ da Receita \\
\hline Receita total com vacas de descarte & R\$ 418.164,78 & 20,52 \\
\hline Receita total com touro de descarte & $\mathrm{R} \$ 27.402,02$ & 1,34 \\
\hline Receita total com novilhas de 36 meses & $\mathrm{R} \$ 471.378,83$ & 23,13 \\
\hline Receita total com machos de 36 meses & $\mathrm{R} \$ 1.120 .795,76$ & 55,00 \\
\hline Total & $\mathrm{R} \$ 2.037 .741,40$ & 100 \\
\hline CUSTOS FIXOS & VALORES & $\%$ dos CUSTOS \\
\hline Mão de obra fixa & $\mathrm{R} \$ 167.194,36$ & 10,20 \\
\hline Impostos & $\mathrm{R} \$ 44.438,00$ & 2,71 \\
\hline Depreciação & $\mathrm{R} \$ 16.028,85$ & 0,98 \\
\hline Total & $\mathrm{R} \$ 227.661,21$ & 13,89 \\
\hline CUSTOS VARIÁVEIS & VALORES & $\%$ dos CUSTOS \\
\hline Pastagem & "R\$1.042.432,17 & 63,60 \\
\hline Sal mineral proteínado & $\mathrm{R} \$ 229.022,77$ & 13,97 \\
\hline Sal mineral & $\mathrm{R} \$ 72.592,51$ & 4,43 \\
\hline Veterinários & $\mathrm{R} \$ 21.993,49$ & 1,34 \\
\hline Outras despesas & $\mathrm{R} \$ 45.437,89$ & 2,77 \\
\hline Total & $\mathrm{R} \$ 1.411 .478,84$ & 100 \\
\hline CUSTO OPERACIONAL EFETIVO* & $\mathrm{R} \$ 1.623 .111,20$ & $-\overline{-----}$ \\
\hline "CUSTO OPERACIONAL TOTAL** & R\$ 1.639.140,05 & "----- \\
\hline
\end{tabular}

Fonte: CEPEA 2014.

* Custo Operacional Efetivo é composto pelos custos variáveis e parte do custo fixo, onde se desconsidera a depreciação.

** Custo Operacional Total é composto pela soma do custo fixo e variáveis adicionando a depreciação. 
Tabela 6. Indicadores econômicos de lucratividade do sistema de ciclo completo de bovinos de corte.

\begin{tabular}{cc}
\hline INDICADORES ECONÔMICOS DA PROPRIEDADE EM ESTUDO \\
\hline \hline Margem Bruta & $\mathrm{R} \$ 414.630,20$ \\
\hline Margem Liquida & $\mathrm{R} \$ 398.601,35$ \\
\hline Lucro Total & $\mathrm{R} \$ 398.601,35$ \\
\hline Lucratividade & $19,56 \%$ \\
\hline
\end{tabular}

Fonte: CEPEA 2014.

* Receita Total - Custo Operacional Efetivo

** Receita Total - Custo Operacional Total

*** Receita Total

Tabela 7. Desempenho lucrativo em situação básica e simulada e estimação dos valores econômicos nas características em estudo.

\begin{tabular}{cccccc}
\hline Características & $\begin{array}{c}\text { Lucro } \\
\text { Final (R\$) }\end{array}$ & $\begin{array}{c}\text { Lucro } \\
\text { Inicial (R } \$)\end{array}$ & $\begin{array}{c}\text { Lucro } \\
\text { Marginal (R } \$)\end{array}$ & $\begin{array}{c}\text { Ganho } \\
\text { Genético }\end{array}$ & $\begin{array}{c}\text { Valor } \\
\text { Econômico (R\$) }\end{array}$ \\
\hline \hline PAV & $8.127,32$ & $8.004,70$ & 122,62 & 980,07 & 0,13 \\
\hline PAF & $269.678,11$ & $266.033,48$ & $3.644,63$ & $1.071,74$ & 3,40 \\
\hline PAM & $891.659,62$ & $882.930,50$ & $8.729,11$ & $2.365,73$ & 3,69 \\
\hline TD & $1.166 .299,36$ & $1.148 .963,99$ & $17.335,37$ & $4.838,72$ & 3,58 \\
\hline PDM & $887.416,57$ & $882.930,50$ & $4.486,06$ & $1.235,08$ & 3,63 \\
\hline PDF & $266.831,15$ & $266.033,48$ & 797,67 & 346,15 & 2,30 \\
\hline
\end{tabular}

Peso Adulto da Vaca (PAV); Peso ao Abate de Fêmea (PAF); Peso ao Abate de Macho (PAM); Taxa de Desmama (TD); Peso a Desmama de Macho (PDM); Peso a Desmama de Fêmea. 
Tabela 8. Desempenho econômico em situação básica e simulada e estimação dos valores econômicos sob o sistema de pagamento do programa Nelore natural.

\begin{tabular}{|c|c|c|c|c|c|}
\hline \multicolumn{6}{|c|}{ Valor Econômico para o Sistema Nelore Natural (50 - 59\% do lote) } \\
\hline Características & $\begin{array}{c}\text { Lucro } \\
\text { Final (R\$) }\end{array}$ & $\begin{array}{c}\text { Lucro } \\
\text { Inicial }(\mathrm{R} \$)\end{array}$ & $\begin{array}{c}\text { Lucro } \\
\text { Marginal (R\$) }\end{array}$ & $\begin{array}{c}\text { Ganho } \\
\text { Genético }\end{array}$ & $\begin{array}{c}\text { Valor } \\
\text { Econômico } \\
(\mathrm{R} \$)\end{array}$ \\
\hline PAV & $16.574,25$ & $16.368,00$ & 206,25 & 980,07 & 0,21 \\
\hline PAF & $279.203,62$ & $275.461,06$ & $3.742,57$ & $1.071,74$ & 3,49 \\
\hline PAM & $902.967,22$ & $894.138,46$ & $8.828,76$ & $2.365,73$ & 3,73 \\
\hline TD & $1.187 .256,25$ & $1.169 .599,52$ & $17.656,73$ & $4.838,72$ & 3.65 \\
\hline PDM & $898.682,99$ & $894.138,46$ & $4.544,52$ & $1.235,08$ & 3,68 \\
\hline PDF & $276.289,19$ & $275.461,06$ & 828,13 & 346,15 & 2,39 \\
\hline \multicolumn{6}{|c|}{ Valor Econômico para o Sistema Nelore Natural $(60-79 \%$ do lote $)$} \\
\hline Características & $\begin{array}{c}\text { Lucro } \\
\text { Final (R\$) }\end{array}$ & $\begin{array}{c}\text { Lucro } \\
\text { Inicial }(\mathrm{R} \$)\end{array}$ & $\begin{array}{c}\text { Lucro } \\
\text { Marginal (R\$) }\end{array}$ & $\begin{array}{c}\text { Ganho } \\
\text { Genético }\end{array}$ & $\begin{array}{c}\text { Valor } \\
\text { Econômico } \\
(\mathrm{R} \$)\end{array}$ \\
\hline PAV & $20.797,71$ & $20.549,65$ & 248,07 & 980,07 & 0,25 \\
\hline PAF & $283.966,38$ & $280.174,85$ & $3.791,53$ & $1.071,74$ & 3,54 \\
\hline PAM & $908.621,03$ & $899.742,44$ & $8.878,59$ & $2.365,73$ & 3,75 \\
\hline TD & $1.197 .734,69$ & $1.179 .917,29$ & $17.817,41$ & $4.838,72$ & 3,68 \\
\hline PDM & $904.316,19$ & $889.742,44$ & $4.573,75$ & $1.235,08$ & 3,70 \\
\hline PDF & $281.018,21$ & $280.174,85$ & 843,36 & 346,15 & 2,44 \\
\hline \multicolumn{6}{|c|}{ Valor Econômico para o Sistema Nelore Natural (acima de $80 \%$ do lote) } \\
\hline Características & $\begin{array}{c}\text { Lucro } \\
\text { Final (R\$) }\end{array}$ & $\begin{array}{c}\text { Lucro } \\
\text { Inicial }(\mathrm{R} \$)\end{array}$ & $\begin{array}{c}\text { Lucro } \\
\text { Marginal (R\$) }\end{array}$ & $\begin{array}{c}\text { Ganho } \\
\text { Genético }\end{array}$ & $\begin{array}{c}\text { Valor } \\
\text { Econômico } \\
(\mathrm{R} \$)\end{array}$ \\
\hline PAV & $25.021,18$ & $24.731,29$ & 289,88 & 980,07 & 0,30 \\
\hline PAF & $288.729,14$ & $284.888,63$ & $3.840,50$ & $1.071,74$ & 3,58 \\
\hline PAM & $914.274,83$ & $905.346,42$ & $8.928,41$ & $2.365,73$ & 3,77 \\
\hline TD & $1.208 .213,14$ & $1.190 .235,05$ & $17.978,08$ & $4.838,72$ & 3,72 \\
\hline PDM & $909.949,40$ & $905.346,42$ & $4.602,98$ & $1.235,08$ & 3.73 \\
\hline $\mathrm{PDF}$ & $285.747,23$ & $284.888,63$ & 858,59 & 346,15 & 2,48 \\
\hline
\end{tabular}

Peso Adulto da Vaca (PAV); Peso ao Abate de Fêmea (PAF); Peso ao Abate de Macho (PAM); Taxa de

Desmama (TD); Peso a Desmama de Macho (PDM); Peso a Desmama de Fêmea. 
Tabela 9. Análise de sensibilidade para avaliar mudanças nos valores econômicos quanto as alterações dos preços das pastagens, minerais, proteínado e valores de receitas.

\begin{tabular}{|c|c|c|c|c|c|c|c|}
\hline \multicolumn{7}{|c|}{ ANÁLISE DE SENSIBILIDADE } & \\
\hline \multicolumn{8}{|c|}{ Sensibilidade ao Valor do Custo das Pastagens } \\
\hline Características & $-50 \%$ & $-25 \%$ & $-5 \%$ & $0 \%$ & $5 \%$ & $25 \%$ & $50 \%$ \\
\hline PAV & $\mathrm{R} \$ 1,79$ & $\mathrm{R} \$ 0,96$ & $\mathrm{R} \$ 0,29$ & $\mathrm{R} \$ 0,13$ & $\mathrm{R} \$-0,04$ & $\mathrm{R} \$-0,71$ & $\mathrm{R} \$-1,54$ \\
\hline PAF & $\mathrm{R} \$ 3,82$ & $\mathrm{R} \$ 3,61$ & $\mathrm{R} \$ 3,40$ & $\mathrm{R} \$ 3,40$ & $\mathrm{R} \$ 3,36$ & $\mathrm{R} \$ 3,19$ & $\mathrm{R} \$ 2,98$ \\
\hline PAM & $\mathrm{R} \$ 3,87$ & $\mathrm{R} \$ 3,78$ & $\mathrm{R} \$ 3,71$ & $\mathrm{R} \$ 3,69$ & $\mathrm{R} \$ 3,67$ & $\mathrm{R} \$ 3,60$ & $\mathrm{R} \$ 3,51$ \\
\hline TD & $\mathrm{R} \$ 3,95$ & $\mathrm{R} \$ 3,77$ & $\mathrm{R} \$ 3,62$ & $\mathrm{R} \$ 3,58$ & $\mathrm{R} \$ 3,55$ & $\mathrm{R} \$ 3,40$ & $\mathrm{R} \$ 3,21$ \\
\hline PDM & $\mathrm{R} \$ 4,05$ & $\mathrm{R} \$ 3,84$ & $\mathrm{R} \$ 3,67$ & $\mathrm{R} \$ 3,63$ & $\mathrm{R} \$ 3,59$ & $\mathrm{R} \$ 3,42$ & $\mathrm{R} \$ 3,22$ \\
\hline PDF & $\mathrm{R} \$ 3,11$ & $\mathrm{R} \$ 2,71$ & $\mathrm{R} \$ 2,39$ & $\mathrm{R} \$ 2,30$ & $\mathrm{R} \$ 2,22$ & $\mathrm{R} \$ 1,90$ & $\mathrm{R} \$ 1,50$ \\
\hline \multicolumn{8}{|c|}{ Sensibilidade ao Valor do Custo do Mineral } \\
\hline Características & $-50 \%$ & $-25 \%$ & $-5 \%$ & $0 \%$ & $5 \%$ & $25 \%$ & $50 \%$ \\
\hline PAV & $\mathrm{R} \$ 0,25$ & $\mathrm{R} \$ 0,19$ & $\mathrm{R} \$ 0,14$ & $\mathrm{R} \$ 0,13$ & $\mathrm{R} \$ 0,11$ & $\mathrm{R} \$ 0,06$ & $\mathrm{R} \$ 0,001$ \\
\hline PAF & $\mathrm{R} \$ 3,41$ & $\mathrm{R} \$ 3,41$ & $\mathrm{R} \$ 3,40$ & $\mathrm{R} \$ 3,49$ & $\mathrm{R} \$ 3,40$ & $\mathrm{R} \$ 3,39$ & $\mathrm{R} \$ 3,39$ \\
\hline PAM & $\mathrm{R} \$ 3,70$ & $\mathrm{R} \$ 3,69$ & $\mathrm{R} \$ 3,69$ & $\mathrm{R} \$ 3,69$ & $\mathrm{R} \$ 3,69$ & $\mathrm{R} \$ 3,69$ & $\mathrm{R} \$ 3,68$ \\
\hline TD & $\mathrm{R} \$ 3,61$ & $\mathrm{R} \$ 3,60$ & $\mathrm{R} \$ 3,59$ & $\mathrm{R} \$ 3,58$ & $\mathrm{R} \$ 3,58$ & $\mathrm{R} \$ 3,57$ & $\mathrm{R} \$ 3,56$ \\
\hline PDM & $\mathrm{R} \$ 3,67$ & $\mathrm{R} \$ 3,65$ & $\mathrm{R} \$ 3,64$ & $\mathrm{R} \$ 3,63$ & $\mathrm{R} \$ 3,63$ & $\mathrm{R} \$ 3,61$ & $\mathrm{R} \$ 3,60$ \\
\hline PDF & $\mathrm{R} \$ 2,36$ & $\mathrm{R} \$ 2,33$ & $\mathrm{R} \$ 2,31$ & $\mathrm{R} \$ 2,30$ & $\mathrm{R} \$ 2,30$ & $\mathrm{R} \$ 2,28$ & $\mathrm{R} \$ 2,25$ \\
\hline \multicolumn{8}{|c|}{ Sensibilidade ao Valor do Custo do Proteínado } \\
\hline Características & $-50 \%$ & $-25 \%$ & $-5 \%$ & $0 \%$ & $5 \%$ & $25 \%$ & $50 \%$ \\
\hline PAV & $\mathrm{R} \$ 0,41$ & $\mathrm{R} \$ 0,27$ & $\mathrm{R} \$ 0,15$ & $\mathrm{R} \$ 0,13$ & $\mathrm{R} \$ 0,10$ & $\mathrm{R} \$-0,02$ & $\mathrm{R} \$-0,16$ \\
\hline PAF & $\mathrm{R} \$ 3,55$ & $\mathrm{R} \$ 3,48$ & $\mathrm{R} \$ 3,40$ & $\mathrm{R} \$ 3,49$ & $\mathrm{R} \$ 3,39$ & $\mathrm{R} \$ 3,32$ & $\mathrm{R} \$ 3,25$ \\
\hline PAM & $\mathrm{R} \$ 3,76$ & $\mathrm{R} \$ 3,72$ & $\mathrm{R} \$ 3,70$ & $\mathrm{R} \$ 3,69$ & $\mathrm{R} \$ 3,68$ & $\mathrm{R} \$ 3,65$ & $\mathrm{R} \$ 3,62$ \\
\hline TD & $\mathrm{R} \$ 3,68$ & $\mathrm{R} \$ 3,63$ & $\mathrm{R} \$ 3,59$ & $\mathrm{R} \$ 3,58$ & $\mathrm{R} \$ 3,57$ & $\mathrm{R} \$ 3,53$ & $\mathrm{R} \$ 3,48$ \\
\hline PDM & $\mathrm{R} \$ 3,73$ & $\mathrm{R} \$ 3,68$ & $\mathrm{R} \$ 3,64$ & $\mathrm{R} \$ 3,63$ & $\mathrm{R} \$ 3,62$ & $\mathrm{R} \$ 3,58$ & $\mathrm{R} \$ 3,53$ \\
\hline PDF & $\mathrm{R} \$ 2,49$ & $\mathrm{R} \$ 2,40$ & $\mathrm{R} \$ 2,32$ & $\mathrm{R} \$ 2,30$ & $\mathrm{R} \$ 2,29$ & $\mathrm{R} \$ 2,21$ & $\mathrm{R} \$ 2,12$ \\
\hline \multicolumn{8}{|c|}{ Sensibilidade ao Valor da Receita dos Animais } \\
\hline Características & $-50 \%$ & $-25 \%$ & $-5 \%$ & $0 \%$ & $5 \%$ & $25 \%$ & $50 \%$ \\
\hline PAV & $\mathrm{R} \$-2,01$ & $\mathrm{R} \$-0,94$ & $\mathrm{R} \$-0,09$ & $\mathrm{R} \$ 0,13$ & $\mathrm{R} \$ 0,34$ & $\mathrm{R} \$ 1,19$ & $\mathrm{R} \$ 2,26$ \\
\hline PAF & $\mathrm{R} \$ 1,12$ & $\mathrm{R} \$ 2,26$ & $\mathrm{R} \$ 3,17$ & $\mathrm{R} \$ 3,49$ & $\mathrm{R} \$ 3,63$ & $\mathrm{R} \$ 4,54$ & $\mathrm{R} \$ 5,69$ \\
\hline PAM & $\mathrm{R} \$ 1,58$ & $\mathrm{R} \$ 2,64$ & $\mathrm{R} \$ 3,48$ & $\mathrm{R} \$ 3,69$ & $\mathrm{R} \$ 3,90$ & $\mathrm{R} \$ 4,74$ & $\mathrm{R} \$ 5,80$ \\
\hline TD & $\mathrm{R} \$ 1,29$ & $\mathrm{R} \$ 2,44$ & $\mathrm{R} \$ 3,35$ & $\mathrm{R} \$ 3,58$ & $\mathrm{R} \$ 3,81$ & $\mathrm{R} \$ 4,73$ & $\mathrm{R} \$ 5,87$ \\
\hline PDM & $\mathrm{R} \$ 1,27$ & $\mathrm{R} \$ 2,45$ & $\mathrm{R} \$ 3,40$ & $\mathrm{R} \$ 3,63$ & $\mathrm{R} \$ 3,87$ & $\mathrm{R} \$ 4,82$ & $\mathrm{R} \$ 6,00$ \\
\hline PDF & $\mathrm{R} \$ 0,10$ & $\mathrm{R} \$ 1,20$ & $\mathrm{R} \$ 2,08$ & $\mathrm{R} \$ 2,30$ & $\mathrm{R} \$ 2,52$ & $\mathrm{R} \$ 3,40$ & $\mathrm{R} \$ 4,50$ \\
\hline
\end{tabular}

Peso Adulto da Vaca (PAV); Peso ao Abate de Fêmea (PAF); Peso ao Abate de Macho (PAM); Taxa de Desmama (TD); Peso a Desmama de Macho (PDM); Peso a Desmama de Fêmea. 